\title{
Refining indications for Mohs micrographic surgery in treatment of facial basal cell carcinoma
}

Citation for published version (APA):

Smeets, N. (2004). Refining indications for Mohs micrographic surgery in treatment of facial basal cell carcinoma. [Doctoral Thesis, Maastricht University]. Universiteit Maastricht. https://doi.org/10.26481/dis.20041126ns

Document status and date:

Published: 01/01/2004

DOI:

$10.26481 /$ dis.20041126ns

Document Version:

Publisher's PDF, also known as Version of record

\section{Please check the document version of this publication:}

- A submitted manuscript is the version of the article upon submission and before peer-review. There can be important differences between the submitted version and the official published version of record.

People interested in the research are advised to contact the author for the final version of the publication, or visit the DOI to the publisher's website.

- The final author version and the galley proof are versions of the publication after peer review.

- The final published version features the final layout of the paper including the volume, issue and page numbers.

Link to publication

\footnotetext{
General rights rights.

- You may freely distribute the URL identifying the publication in the public portal. please follow below link for the End User Agreement:

www.umlib.nl/taverne-license

Take down policy

If you believe that this document breaches copyright please contact us at:

repository@maastrichtuniversity.nl

providing details and we will investigate your claim.
}

Copyright and moral rights for the publications made accessible in the public portal are retained by the authors and/or other copyright owners and it is a condition of accessing publications that users recognise and abide by the legal requirements associated with these

- Users may download and print one copy of any publication from the public portal for the purpose of private study or research.

- You may not further distribute the material or use it for any profit-making activity or commercial gain

If the publication is distributed under the terms of Article $25 \mathrm{fa}$ of the Dutch Copyright Act, indicated by the "Taverne" license above, 


\section{Refining indications for Mohs micrographic surgery in treatment of facial basal cell carcinoma}


(C) N.W.J. Smeets, Maastricht 2004

ISBN 90-9018716-2

Grafische vormgeving:

Els Lücker

Druk:

Datawyse Maastricht 


\title{
Refining indications for Mohs micrographic surgery in treatment of facial basal cell carcinoma
}

\author{
Proefschrift \\ ter verkrijging van de graad van doctor \\ aan de universiteit Maastricht, \\ op gezag van de Rector Magnificus, \\ Prof mr. G.P.M.F.Mols \\ volgens het besluit van het College van Decanen, \\ in het openbaar te verdedigen op \\ vrijdag 26 november 2004 om 16.00 uur \\ door \\ Nicole Wilhelmina Johanna Smeets
}


Promotor:

Prof. dr. H.A.M. Neumann (Erasmus MC Rotterdam)

Copromotor:

Dr. G.A.M. Krekels (Catharina Ziekenhuis Eindhoven)

Beoordelingscommissie:

Prof. dr. P.M. Steylen (voorzitter)

Prof. dr. F. Camacho Martinez

Prof. dr. M.J.A.P. Daemen

Prof. dr. J.J. Manni

Dr. M.E.J.M. Verhaegh (Atrium MC Heerlen)

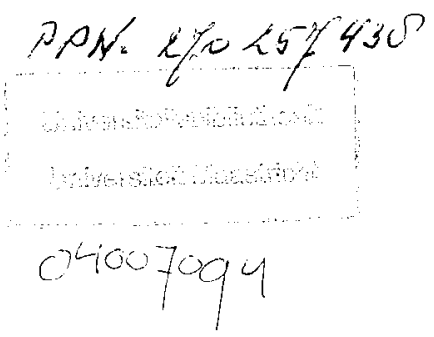

The prospective randomised study (chapter 4 en 5) was financed by the "College van Zorgverzekeraars".

Financial support for this thesis was supplied by: Vichy, Laservision Instruments BV, 3M Pharma, Fujisawa Holland BV, Waldmann Medische Techniek BV, Euro Tec BV, Glaxo Wellcome, Galderma, Serono Benelux BV, Bauerfeind Benelux BV, Leo Pharma BV, Fagron Farmaceuticals BV, Valeant, Bipharma BV, Smith \& Nephew, Hoofddorp, Coloplast. 


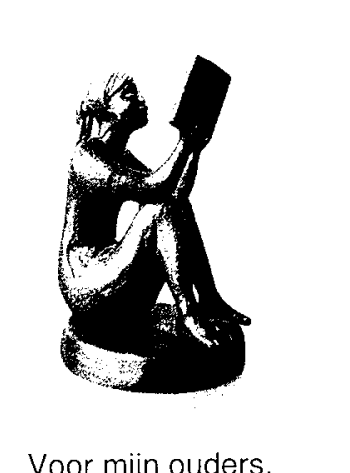




\section{Contents}

List of abbreviations $\quad 8$

General introduction 9

$\begin{array}{lll}\text { Chapter } 1 & \text { Basal cell carcinoma } & 13\end{array}$

Chapter 2 Mohs micrographic surgery $\quad 29$

Chapter 3 Mohs micrographic surgery for treatment of basal cell carcinoma of the face; results of a retrospective study and comparison with literature results $\quad \mathbf{4 5}$

Chapter 4 Surgical excision versus Mohs micrographic surgery: a prospective randomised trial $\quad 55$

Chapter 5 Cosmetic outcome of treatment of basal cell carcinoma of the face: a comparison between Mohs micrographic surgery and surgical excision $\quad 75$

Chapter $6 \quad$ Adjuvant cytokeratin staining in Mohs micrographic surgery for basal cell carcinoma $\quad 89$

Chapter 7 Photodynamic therapy as adjuvant treatment of extensive basal cell carcinoma treated with Mohs micrographic surgery

Chapter 8 Summary, general discussion and recommendations for treatment and research 103

$\begin{array}{lr}\text { Bibliography } & 109\end{array}$

$\begin{array}{lr}\text { Samenvatting } & 125\end{array}$

$\begin{array}{ll}\text { Dankwoord } & 131\end{array}$

$\begin{array}{ll}\text { Curriculum vitae/ list of publications } & 135\end{array}$ 


\section{List of abbreviations}

$\begin{array}{ll}\text { BCC } & \text { basal cell carcinoma } \\ \text { SCC } & \text { squamous cell carcinoma } \\ \text { NMSC } & \text { non-melanoma skin cancer } \\ \text { MMS } & \text { Mohs micrographic surgery } \\ \text { SE } & \text { surgical excision } \\ \text { PDT } & \text { photodynamic therapy } \\ \text { NBCCS } & \text { nevoid basal cell carcinoma syndrome, Gorlins syndrome } \\ \text { AK } & \text { actinic keratosis } \\ \text { H\&E } & \text { haematoxylin and eosin } \\ \text { RT } & \text { radiotherapy } \\ \text { CS } & \text { cryosurgery } \\ \text { CE } & \text { curettage and electrodessication }\end{array}$


General introduction 
Skin cancer is the most common form of cancer among caucasians and its incidence is still rising (Holme et al., 2000). Overall, the forms of skin cancer can be divided into melanoma and non-melanoma skin cancer (NMSC).

Melanoma is the form of skin cancer best known among the general population, although it accounts for less than 10\% of all cases (Ko et al., 1994; Neering and Cramer, 1988). The NMSCs are roughly divided into three groups: basal cell carcinoma (BCC), squamous cell carcinoma (SCC) and other, less common, NMSCs. Examples of other forms of NMSC include Bowen's disease, Merkel cell carcinoma, dermatofibrosarcoma protuberans, atypical fibroxanthoma, eccrine porocarcinoma and sebaceous carcinoma. These types of NMSC have a very low incidence but may have a high local recurrence rate, and some tumours are able to metastasise. BCC is the most common form, accounting for around $80 \%$ of all NMSC cases. SCC is the second most common form, accounting for approximately $20 \%$ of all NMSC cases (Karagas et al., 1999; Marks, 1995). The incidence of NMSC has risen significantly: rises in incidence of $66-235 \%$ for BCC and of $16-350 \%$ for SCC over a period of ten to fourteen years have been reported (Hannuksela-Svahn et al., 1999; Holme et al., 2000; Karagas et al., 1999; Ko et al., 1994). Because it occurs so frequently, management of NMSC is a significant and increasing problem from a socio-economic perspective (Housman et al., 2003).

$\mathrm{BCC}$ is the most common form of cancer in Caucasians affecting 1 in every 5-6 people in the USA (Rigel et al., 1996). Although it is not a life-threatening disease in most cases, the impact on today's health care is large because of its high incidence and the consequences for the patient. Since there is no registration of NMSCs, all incidence rates are estimations. From an enquiry among dermatologists in the Netherlands in 1998, we know that the incidence was then 28,000 BCCs a year (Thissen et al., 1998). Assuming a rise in incidence of approximately $7 \%$ per year, the incidence can be estimated at around 40,000 BCCs a year in 2004, but the true incidence is probably higher. Although metastasis is very rare, death caused by metastasised BCC does occur (Robinson and Dahiya, 2003; Snow et al., 1994; van Bockel et al., 2003). However, the most likely cause of death from BCC is because of local invasion and destruction of vital structures by primary and especially recurrent BCCs (Mikhail et al., 1986; Sahl et al., 1994).

Most BCCs, around 75-80\%, are located in sun-exposed areas of the body, such as the head and neck area (Motley et al., 1995). However, while the absolute number of BCCs located in the face is rising, the percentage of facially located BCCs is decreasing (Dahl et al., 1992; Holme et al., 2000). This is probably due to changing habits like more intensive sunbathing. The mean age of the patients is around 65-70 years with less than $10 \%$ younger than 40 years (Hannuksela-Svahn et al., 1999; Holme et al., 2000; Ko et al., 1994). Overall, it occurs slightly more in men than in women, but before the age of 45 years the incidence is equal for both sexes (Coebergh et al., 1991; Holme et al., 2000). 
A BCC can be treated by different treatment modalities (Chapter 2) (Kuijpers et al., 2002; Netscher and Spira, 2004). The most important goal in treatment of BCC is complete curation of tumour. The most commonly used treatment modality world-wide is surgical excision (SE) (Bower et al., 2001; Goldberg, 1996; 2003). Most BCCs can be easily treated by conventional treatment modalities like SE, cryosurgery (CS), curettage and electrodessication (CE), and radiotherapy (RT). However, a small percentage of $\mathrm{BCCs}$ behave more aggressively and need more aggressive treatment. Risk factors for this aggressive behaviour are tumours located in the face, especially in the $\mathrm{H}$-zone (Figure 1.5), tumours with an aggressive histopathologic subtype (morphea, micronodular and BCC with squamous differentiation), tumours with a size of $2 \mathrm{~cm}$ or more and recurrent BCCs (Batra and Kelley, 2002; Breuninger and Dietz, 1991; Bumpous et al., 2000; Randle, 1996).

Mohs micrographic surgery (MMS) is a specialised excision technique with peroperative frozen section margin examination (Chapter 3) (Shriner et al., 1998). This technique was developed by Dr. Frederic E. Mohs in the 1930 s and his first results were published in 1941 (Mohs, 1941a). His fixed tissue technique, also called chemosurgery, was based on the principle that the application of zinc chloride to tissue (tumour) fixes it and the tumour could then be horizontally shaved off, after which $100 \%$ of the resection borders could be examined microscopically. Areas of cancer identified by this microscopic examination were located on maps, drawn both on paper and on the tissue itself. Disadvantages of this technique were the pain it caused to the patient and the long wait in between the two stages ( 24 hours for fixation). In the 1950 s, Mohs tried to avoid the time problem and the irritation that zinc chloride caused to the eyes by introducing the 'fresh tissue technique'. This meant that the tumour was excised at a $45^{\circ}$ angle and horizontal frozen sections were made without fixation in zinc chloride. The graphic mapping of the tumour both on the patient and on paper remained. This fresh tissue technique gradually became more popular, especially among dermatologists. Nowadays the fixed tissue technique is used only in selected cases (Braun, 1981). Because the fresh tissue technique no longer involved fixation with zinc chloride, the name of the treatment was changed from 'Chemosurgery' to 'Mohs micrographic surgery'.

Nowadays in the USA, $30 \%$ of all NMSCs are treated by MMS, mostly using the fresh tissue technique (Gaston et al., 1999). In Europe, MMS is not so widely used, and only large and aggressive NMSCs are treated by it (Julian and Bowers, 1997; Neumann et al., 1996; Wennberg et al., 1999).

There has been some debate about the justification of large-scale application of MMS in the treatment of BCC (Lawrence, 1993; Shuster, 1999). Arguments against MMS are that it is a time and labour consuming (and thus expensive) treatment. Although results reported in the literature indicate much lower recurrence rates than with any other treatment modalities, these results have been obtained from, mostly retrospective, non-comparative trials (Rowe et al., 1989a; Rowe et al., 1989b). There 
has never been a prospective randomised controlled trial that compared MMS with another treatment modality (Lawrence, 1993; Shuster, 1999).

\section{The aims of this thesis are:}

\section{To evaluate which BCCs justify a more time-consuming treatment like MMS in terms of recurrence prevention, preservation of healthy tissue and patient perspective (avoiding multiple treatments), and finally at what extra costs.}

This thesis first presents an overview of BCC (Chapter 1) including its epidemiology, the various clinical / histopathologic subtypes and the different treatment modalities available. Chapter 2 describes the development of MMS, the technique itself and its indications.

To achieve the above aim, several studies were done:

- A literature review was done and a retrospective study was conducted of our own 5-year recurrence rates after treatment of facial BCC with MMS (Chapter 3).

- A prospective randomised trial was held comparing MMS and SE for aggressive primary BCC and a trial for first and second recurrent BCC of the face (Chapter 4). The primary outcome measure was the recurrence of BCC. Secondary outcome measures were incomplete excision, defect size and the costs of both treatments.

- A further study compared the cosmetic outcomes of MMS and SE in the treatment of BCC of the face (Chapter 5).

Another question we tried to answer was why recurrences still occur after treatment with MMS, in which theoretically $100 \%$ of the resection margins is examined. Because one explanation for these recurrences could be failure of the histopathologic examination, we analysed the sensitivity of haematoxylin and eosin (H\&E) stained slides by using an adjuvant cytokeratin staining that increases contrast between tumor cells and surrounding tissue (Chapter 6).

We noticed during treatment with MMS that in patients with multiple skin cancers, superficially growing $\mathrm{BCC}$ often remains after eradication of the primary tumour. This reflects the actinic damage of the skin in these patients. To prevent multiple Mohs stages and large defects we searched for a way to obtain complete curation of tumour without creating large defects.

A new promising technique for the treatment of superficially growing $B C C$ is photodynamic therapy (PDT), which may be beneficial especially in patients who develop multiple BCCs. We report early results of patients treated with PDT in combination with MMS for extensive facial BCC (Chapter 7).

Based on the results of our studies, we have formulated indications for the use of MMS, SE and PDT for different forms of BCC of the face (Chapter 8) to obtain optimal medical, socially justified and patient friendly treatment results. 


\section{Chapter 1}

\section{Basal cell carcinoma}




\section{Epidemiology}

A basal cell carcinoma ( $\mathrm{BCC}$ ) can be characterised as a slowly growing tumour with a potential to destroy or invade local tissue and a small potential to metastasise. It is the most common cancer in Caucasians, affecting approximately 1 in every 5-6 people on a life-time basis (Rigel et al., 1996). In the Netherlands, the incidence of BCC was 28,000 cases a year in 1998 (Thissen et al., 1998). The 2004 incidence has been estimated as 40,000 BCCs a year. That the incidence is still rising has been suggested by many authors, who have reported increases of $66-235 \%$ over a period of approximately 10 years (Gallagher et al., 1990; Holme et al., 2000; Karagas et al., 1999; Ko et al., 1994; Levi et al., 2001). Explanations for this rise in incidence include a greater exposure to sunlight, the general ageing of the population and the increasing depletion of the ozone layer (Karagas et al., 1999; Ko et al., 1994). The risk of developing BCC is much larger in a fair-skinned population. People with a history of extensive sun exposure as a result of their profession (like farmers and building workers), residents of tropical countries and sun-bathers are at higher risk of developing BCC (Ko et al., 1994).

Metastasis rates varying from 0.0028 to $0.55 \%$ have been reported (Lo et al., 1991; Robinson and Dahiya, 2003; Spates et al., 2003). These rates were found to depend on the type of specialist and centre (referral or not) involved, so the higher percentages may be caused by selection bias. The most common sites for metastasis are lymph nodes, lung, bone, skin and liver (Miller, 1991). Factors that increase the risk of metastasis are: large, ulcerated tumours, head location, male sex, multiple recurrences and morphea $\mathrm{BCC}$ or $\mathrm{BCC}$ with squamous differentiation (Robinson and Dahiya, 2003; Spates et al., 2003). Fewer than $20 \%$ of patients with a metastasis survive for 1 year and approximately $10 \%$ of patients survive for 5 years (Lo et al., 1991). Death from BCC occurs not only from metastasis but also from unlimited tumour growth (Sahl et al., 1994).

\section{Clinical and histologic characteristics}

In $75-80 \%$ of cases, BCCs are located in the head and neck area, (Holme et al., 2000; Motley et al., 1995) most frequently on the nose, peri-orbitally or on the ears (Coebergh et al., 1991; Dahl et al., 1992; Heckmann et al., 2002; Karagas et al., 1999). This is due to the most important causative factor for BCC, namely exposure to sunlight.

BCC can have several forms of clinical appearance, which are closely related to the histopathologic subtype. Numerous histopathologic subtypes have been described, with some authors reporting up to 26 different subtypes (Wade and Ackerman, 1978). However, these numbers have been reduced to five major histopathologic subtypes: solid or nodular, superficial, infiltrative, morphea and micronodular (Saldanha et al., 2003; Sexton et al., 1990). Like many classifications, this one is also debatable for two reasons. Because all skin malignancies are infiltrative, this term is a misnomer and the term morphea is preferably used to describe this aggressive histopathologic type. A 
special histopathologic subtype is that of BCC with squamous differentiation or basosquamous cell carcinoma. This type comprises both basal cell and squamous cell carcinoma parts and accounts for approximately $0.5 \%$ of all BCCs (Bowman et al., 2003). It has a higher incidence of recurrence and metastasis than BCC (and SCC) (Bowman et al., 2003; Maloney, 1995).

Reported frequencies of occurrence of histopathologic subtype have varied greatly, mostly because different authors use different subdivisions. However, they all agree that the nodular type is the most common, followed by the superficial type (Bastiaens et al., 1998; McCormack et al., 1997; Sexton et al., 1990).

Nodular BCC

A BCC is most typically described as a nodular tumour with a pearly or waxy border, prominent telangiectases and sometimes a central dell or ulceration with crust (fig 1.1a). This clinical type is the most common and comprises with the nodular histopathologic type (21-63.8\%)(Bastiaens et al., 1998; McCormack et al., 1997; Rippey, 1998; Sexton et al., 1990) (fig 1.1b) and the micronodular type (14.5\%)(Rippey, 1998; Sexton et al., 1990) (fig 1.1c). Nodular BCCs are characterised by rounded masses of neoplastic cells with well-defined peripheral contours.

Peripheral palisading and mucinous retraction clefts are usually prominent. The stroma tends to be slightly myxoid. The micronodular BCC suntype has been described in approximately $15 \%$ of cases (Rippey, 1998; Sexton et al., 1990). Since some other studies do not mention the micronodular type, it is difficult to report exact frequency numbers. As the name suggests, it involves miniature nodular tumour parts. Mucinous retraction spaces are less conspicuous. A nodular BCC can also be pigmented and may then resemble a benign pigmented nevus or a malignant melanoma (fig 1.2). The pigment is melanin, which is located both within the tumour and in the surrounding dermis (Maloney, 1995).

\section{Superficial BCC}

A BCC may present clinically as an erythematous crusted patch (fig 1.3a) and then correspondends to the histopathologic subtype of superficially growing $\mathrm{BCC}$ (fig $1.3 \mathrm{~b}$ ). This is found in 14.8-17\% of all BCCs (Bastiaens et al., 1998; McCormack et al., 1997; Rippey, 1998; Sexton et al., 1990) and is characterised by tumour foci extending from the epidermis and / or adnexae into the papillary dermis. The tumour islands are relatively small, with rounded contours, and show the typical peripheral palisading. Rarely, small foci of neoplasm may be detached from the epidermis and present in the underlying papillary dermis. Many of the tumours exhibit another predominant pattern in their central portions with features of a superficial growth pattern in the peripheral parts. There has been some debate whether a superficial BCC is a multifocal tumour. A three-dimensional study of 7 superficially growing BCCs has rejected this theory and showed that a superficial BCC is also a contiguous tumour (Lang et al., 1987). It is most often located on the trunk, but may also be found on the extremities or face. Its differential diagnosis includes Bowen's disease, actinic keratosis, nummular eczema and psoriasis. It is found in younger patients and more commonly in women than in 
man. Because of its distribution, it has been suggested that the aetiology of superficial $\mathrm{BCC}$ is different from that of nodular BCC. Whereas, intermittent sun exposure could be a cause of superficial BCC, more chronic exposure is supposed to be the cause of the nodular type of BCC (Bastiaens et al., 1998; McCormack et al., 1997).

Morphea BCC

The most difficult type to detect is the type that looks like a scar with a few telangiectases (fig 1.4a). It may have parts where it rises above the skin with shiny papules. This tumour is histologically characterised as the morphea type BCC (fig $1.4 \mathrm{~b})$. It is composed of irregular small, elongated tumour islands with sharp angulated ends infiltrating as narrow strands or cords of cells of varying sizes. Peripheral palisading is poorly developed and retraction spaces are uncommon. The tumour stroma is more likely to be slightly collagenous / sclerotic rather than myxoid. Although this is the least common type (0.5-20\%)(Bastiaens et al., 1998; McCormack et al., 1997; Rippey, 1998; Sexton et al., 1990), it is the most aggressive type and is most frequently located in the face.

Mixed type BCCs

Not all BCCs can be classified into one of these histopathologic subtypes. Some tumours are composed of more than one type of $\mathrm{BCC}$, with the more aggressive part most often at the base or periphery of the tumour (Maloney, 1995). Frequencies range from 6.7 to $38.5 \%$ of cases (Bastiaens et al., 1998; McCormack et al., 1997; Rippey, 1998; Sexton et al., 1990). The most common combinations are nodular / micronodular and nodular / morphea. These mixed tumours behave like their most aggressive type of BCC.

$\mathrm{BCCs}$ are frequently classified, on the basis of their histopathologic appearance and clinical behaviour, into non-aggressive (nodular and superficial) and aggressive type BCC (micronodular, morphea and BCC with squamous differentiation).

Immunohistochemical staining

Both clinical and histopathologically, the diagnosis of BCC is in most cases not problematic. The histologic differential diagnosis of nodular BCC includes trichoepithelioma, nodular hidradenoma and eccrine spiradenoma. The most important item in the differential diagnosis of superficial BCC is actinic keratosis. The diagnosis of morphea type BCC can cause the greatest problems; it has to be differentiated from adnexal carcinomas like microcystic adnexal carcinoma or desmoplastic trichoepithelioma. Obviously, BCC with squamous differentiation has to be distinguished from SCC. Although there is no specific immunohistochemical staining for BCC, several markers can support the diagnosis. BCCs express cytokeratins 5, 14, 15 and 17, which can be detected by various markers, such as MNF-116 (Kurzen et al., 2001; Ramnarain et al., 1995). The most frequently used markers to distinguish BCC from SCC cells are Bcl-2 and Ber-EP 4 (Beer et al., 2000; Verhaegh et al., 1995). 


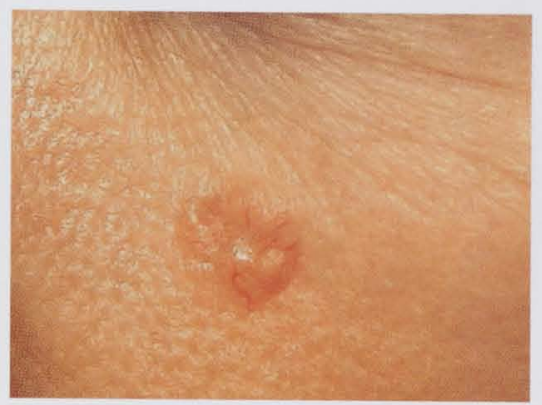

Figure 1.1a.

Nodular basal carcinoma.

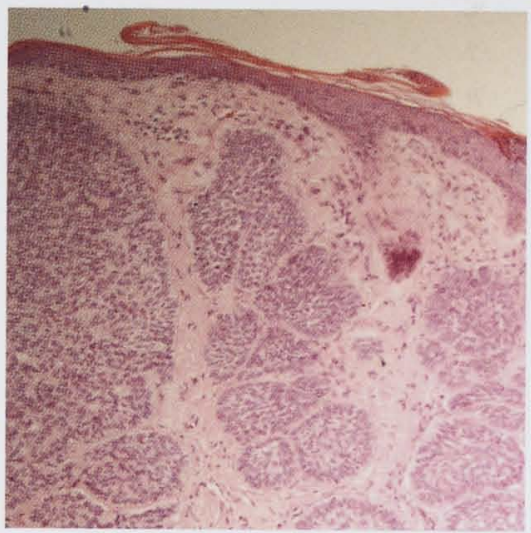

\section{Figure 1.1b.}

Nodular basal cell carcinoma (histopathology).

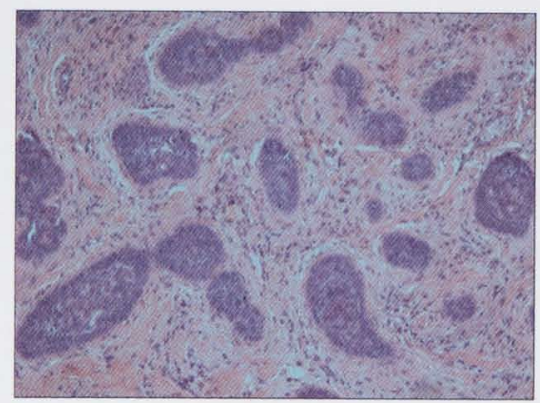

Figure 1.1c.

Micronodular basal cell carcinoma (histopathology).

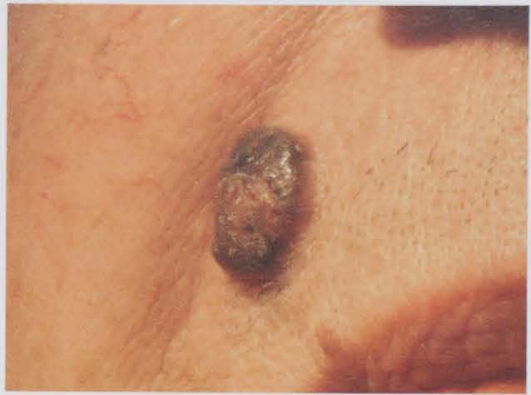

Figure 1.2.

Pigmented basal cell carcinoma.

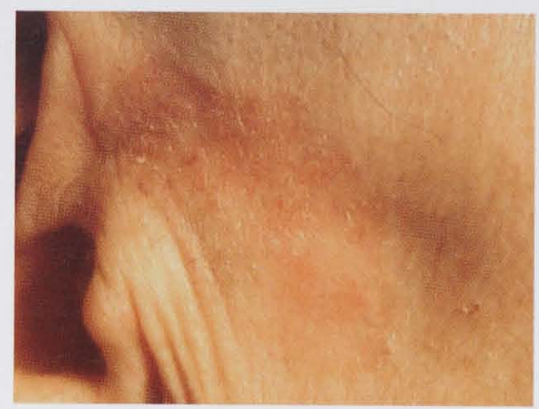

Figure 1.3a.

Superficial basal cell carcinoma.

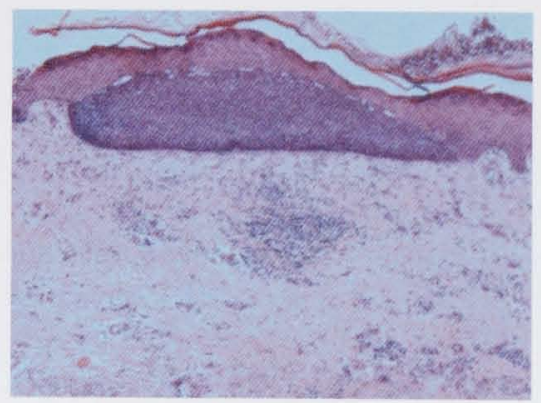

Figure 1.3b.

Superficial basal cell carcinoma (histopathology). 


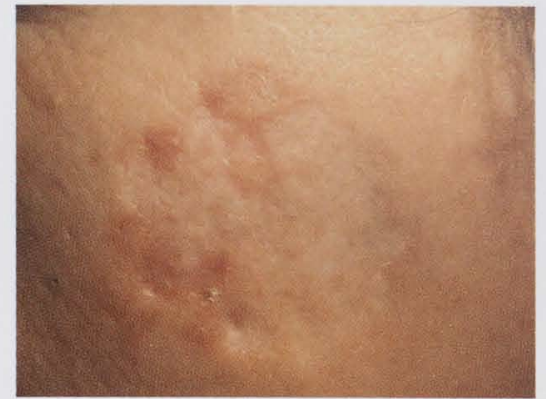

Figure 1.4a.

Morphea basal cell carcinoma.

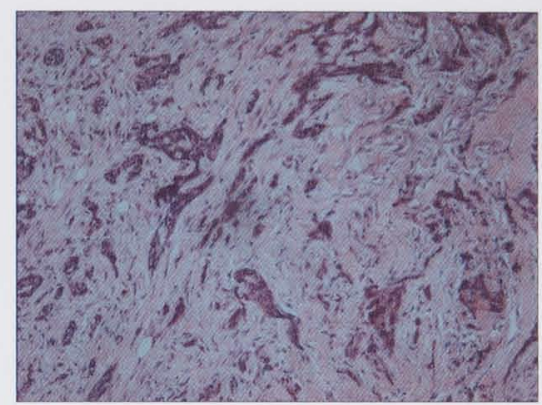

Figure 1.4b.

Morphea basal cell carcinoma (histopathology).
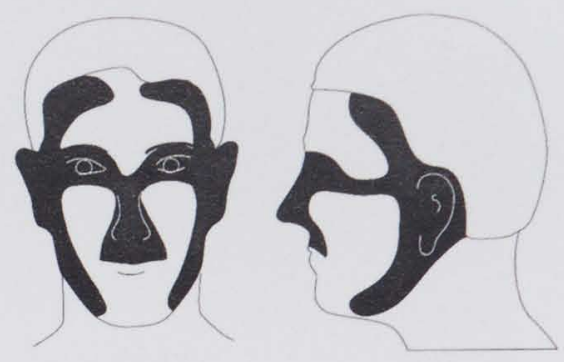

Figure 1.5.

$\mathrm{H}$-zone. 
Some authors have reported that $\mathrm{Bcl}-2$ is able to distinguish $\mathrm{BCC}$ from trichoepithelioma (Poniecka and Alexis, 1999; Verhaegh et al., 1997) but this has been rejected byothers (Abdelsayed et al., 2000). Most adnexal carcinomas stain positive for epithelial membrane antigen (EMA) and / or carcino-embryonic antigen (CEA), whereas BCCs only sporadiccally show positive staining for these markers (Beer et al., 2000; Heyderman et al., 1984).

\section{Therapy}

Before a therapeutic modality is selected, a biopsy is performed to confirm the clinical diagnosis and determine the histopathologic subtype. Because the various subtypes behave differently, a biopsy is mandatory to select the most appropriate treatment. In the future a biopsy may be replaced by a non-invasive technique like confocal microscopy. It has recently been shown that it is possible to detect BCC in vivo without any discomfort to the patient (Gonzalez and Tannous, 2002). However, further studies are needed to determine the sensitivity and specificity of this technique in detecting BCC. Another technique that might replace histopathologic examination is Raman spectroscopy, which has been shown to be a sensitive method for the in vitro detection of BCC on frozen sections (Nijssen et al., 2002). So far, however, it has not been used in vivo.

Not only tumour characteristics (histopathologic subtype, location and size) play a role in the selection of treatment, but also the patient, the skills of the physician and the availability of techniques.

Therapy modalities for BCC can be divided into 'sharp' treatments (surgical excision and Mohs micrographic surgery) and 'non-sharp' treatments (cryosurgery,

radiotherapy, curettage and electrodessication, photodynamic therapy and imiquimod). The advantage of the 'sharp' treatments is the partial (SE) or complete (MMS) histopathologic margin control. With the 'non-sharp' treatments, the physician has to rely on the clinical borders.

One of the most important issues in the treatment of BCC is setting the right clinically tumour-free margins. Although this is important in all treatment modalities, except MMS, it is particularly discussed in the context of SE.

Treatment margins

This issue has aroused a great deal of debate in the literature. Epstein reported in 1973 that in the treatment of BCC, a $2 \mathrm{~mm}$ margin yields a 98\% cure rate (Epstein, 1973). Unfortunately, this study was biased because $92 \%$ of the tumours were nonaggressive BCCs, with a mean size of $8 \mathrm{~mm}$. The $2 \%$ incompletely excised tumours had a mean size of $13 \mathrm{~mm}$. Wolf and Zitelli studied 117 primary BCCs and concluded that tumours less than $2 \mathrm{~cm}$ in size require a $4 \mathrm{~mm}$ margin to totally eradicate the tumour in $95 \%$ of all cases (Wolf and Zitelli, 1987). It should be mentioned that all these tumours showed well-defined borders. Griffith et al. used a standard $3 \mathrm{~mm}$ margin for small well-defined tumours, but treated tumours with ill-defined borders and 
recurrent tumours with a wider margin and frozen section control (Griffith and McKinney, 1973). These results led Koplin to the conclusion that a margin of $2 \mathrm{~mm}$ is recommended for tumours less than $1 \mathrm{~cm}$ in size and a margin of 3-4 $\mathrm{mm}$ for tumours of $1 \mathrm{~cm}$ and larger (Koplin and Zarem, 1980). Several recent studies have also concluded that excision margins of 2-4 $\mathrm{mm}$ are sufficient to eradicate a large percentage (90-96\%) of BCCs (Bisson et al., 2002; David et al., 1999; Lalloo and Sood, 2000; Thomas et al., 2003).

However, these results contrast with Breuninger's findings (Breuninger and Dietz, 1991). He studied subclinical tumour infiltration in 2016 BCCs, including 1757 primary and 259 recurrent BCCs and using a subdivision of histopathologic subtypes and sizes. He concluded that tumours with a size of $<1 \mathrm{~cm}$ require a $5.5 \mathrm{~mm}$ margin to eradicate $95 \%$ of all tumours, and tumours of $>2 \mathrm{~cm}$ require a margin of $13.3 \mathrm{~mm}$. Tumours with an aggressive histopathologic subtype required even larger margins (table 1.1). When the 95\% confidence interval was included, the safety margin required for complete removal of recurrent BCCs was nearly twice that for primary BCCs.

Table 1.1. Safety margins for a 95\% confidence interval in excision of BCC (Breuninger and Dietz, 1991).

\begin{tabular}{ccc}
\hline & \multicolumn{2}{c}{ Margins $(\mathrm{mm})$} \\
\hline Size & Solid & Aggressive \\
\hline$<10 \mathrm{~mm}$ & 4.8 & 6.5 \\
$10-20 \mathrm{~mm}$ & 7 & 8.4 \\
$>20 \mathrm{~mm}$ & 11 & 15 \\
\hline
\end{tabular}

The disadvantage of using these standard wide margins is that this sacrifices a large area of healthy skin and may cause large defects with more functional and cosmetic problems. Recent guidelines issued by the 'Nederlandse vereniging voor Dermatologie en Venereologie' recommend a $3 \mathrm{~mm}$ margin for small $(<2 \mathrm{~cm})$ nodular BCCs and a margin of at least $5 \mathrm{~mm}$ for large $(>2 \mathrm{~cm}$ ) nodular, morphea or recurrent BCCs (NVDV, 2003).

Another problem is that BCCs do not grow contiguously in all directions but have disproportional extensions (Breuninger and Dietz, 1991). These disproportional extensions may lead to tumour extension in only one quadrant, which means that healthy skin is unnecessarily sacrificed by using wide safety margins in all directions. Treatment modalities

- Surgical excision (SE) is the most commonly used treatment for BCC all over the world (Bower et al., 2001; Motley et al., 1995; Thissen et al., 1998). It is in most cases performed under local anaesthesia, with general anaesthesia only needed in very large cases or if a complex reconstruction is planned. Before the incision, the tumour is delineated with a margin of clinically healthy skin. At the university 
hospital of Maastricht a $3 \mathrm{~mm}$ margin is most often used. After delineation, a vertical incision is made, following the lines indicated. After the specimen has been removed, haemostasis of the defect is obtained. The defect is closed either by direct suture or with a flap or graft. If it is suitable, the defect can also be left open to heal by secondary intention. The patient can return home and the specimen is sent for definitive histopathologic margin control. Specimens are in most cases processed by the bread-loaf technique (Rapini, 1990). Other techniques include peripheral sectioning. These techniques provide only partial views of the resection margins (chapter 2 ). If the excision is found to be incomplete, re-excision is planned. Although this action seems obvious, there has been some debate about whether an incompletely excised BCC needs re-excision or whether careful follow-up is sufficient (Berlin et al., 2002; Bieley et al., 1992; Bogdanov-Berezovsky et al., 2001; Grabski and Salasche, 1998; Hallock and Lutz, 2001; Hauben et al., 1982; Koplin and Zarem, 1980; Kumar et al., 2002; Nagore et al., 2003; Robinson and Fisher, 2000; Sussman and Liggins, 1996). Two studies, one prospective and one retrospective, have reported recurrence rates of $41 \%$ and $30 \%$, respectively, after incompletely excised BCC (De Silva and Dellon, 1985; Sussman and Liggins, 1996). This is much higher than the 5.3$10.1 \%$ reported after complete excision (Rowe et al., 1989a; Thissen et al., 1999). Another study found residual tumour in the re-excision specimen in $55 \%$ of cases (Bieley et al., 1992). Sussman et al. recommended not to perform re-excision but to use only careful follow-up (Sussman and Liggins, 1996). After evaluating all incompletely excised BCC cases referred for Mohs surgery for twenty years, Robinson and Fisher concluded that immediate re-excision is necessary (Robinson and Fisher, 2000). They noted that patients with BCCs located on the nose or cheek and those who underwent a flap reconstruction, needed more extensive surgery of the recurrent tumour, especially when the interval between the first excision and the recurrence was longer. Advantages of SE are the partial histological checking of excision margins and its good cosmetic results (Petit et al., 2000; Thissen et al., 2000a).

Mohs micrographic surgery (MMS) is a specialised excision technique, whose principle and indications are described in Chapter 2.

Cryosurgery (CS) with liquid nitrogen uses low temperatures to achieve selective destruction of tissue. The liquid nitrogen is nowadays delivered by a spray-probe apparatus (Kokoszka and Scheinfeld, 2003). Before treatment, the area is anaesthetised and in some cases the tumour is debulked with a curette. The liquid nitrogen is then applied, with an adequate margin, in two to three freeze-thaw cycles of 20-60 seconds. After treatment, an exsudating wound develops which heals in several weeks, leaving an atrophic scar. An advantage of CS is that it is quick, simple, cheap and non-invasive. It can be used for small, superficial primary BCCs (Nordin, 1999; Nordin et al., 1997). 
- Radiotherapy (RT) of BCCs can be done with electrons and x-rays (50-150 kV) (Goldschmidt et al., 1994). The choice of treatment depends on tumour size (superficial $\mathrm{x}$-ray therapy for smaller and electron beam for larger tumours) and patient characteristics. As in other treatment modalities, the tumour and a margin of healthy skin are treated. Long-term complications like carcinogenesis and radiation dermatitis argue against its use in patients under the age of 50-60 years. An advantage of the technique is that it is non-invasive. However, patients have to visit the RT centre several times and it takes several weeks until the ulceration is healed. Scars are aesthetically inferior to those from SE (Petit et al., 2000).

- Curettage and electrodessication (CE) is based on the difference in consistency between tumour and normal skin, so the tumour can be felt with a curette. After thorough curettage, the defect is electro-desiccated. This procedure is usually repeated 2 to 3 times until all tumour cells have been destroyed. The wound heals by secondary intention within several weeks. Wound contraction may lead to distortion especially around the eyes and mouth. Advantages of CE are that it is easy to practice and is cheap. However, several studies have shown that CE recurrence rates are only low outside the high-risk areas ( $\mathrm{H}$-zone, fig 1.5$)$ and in the hands of very experienced physicians (Suhge d'Aubermont and Bennett, 1984; Werlinger et al., 2002).

New treatment modalities like photodynamic therapy (PDT) and imiquimod are still at an experimental stage but have shown promising results for small, non-aggressive type BCCs.

- $\quad$ PDT involves the application of 5-Aminolevulinic acid to the tumour (by means of a cream or intra-cutaneous injection), which is converted within the cells into the photosensitizer protoporphyrin IX. Surface illumination is then used to trigger the photodynamic reaction causing destruction of tumour cells. The technique has yielded good short-term results in superficial BCC, but no long-term follow-up studies are available (Morton et al., 2002). It has the advantage of being a noninvasive technique, leaving no visible scar (Morton et al., 2002).

- Imiquimod belongs to the family of immunostimulators (Marini, 2002). It is an immune modulator enhancing the production of cytokines and natural killer cells, the proliferation of B cells and the activation of Langerhans cells, thereby stimulating the immuneresponse. Like PDT, it has shown some good results in treatment of superficial BCC, but without long-term follow-up (Chen et al., 2002; Salasche, 2002).

There have been reports about treatment of $\mathrm{BCC}$ with 5 -fluorouracil, $\mathrm{CO}_{2}$-laser and systemic chemotherapy, but these modalities have shown little value in the treatment of BCC (Bandieramonte et al., 1997; Guthrie et al., 1985; Humphreys et al., 1998; Reymann, 1979; Shelley and Wood, 1982). 


\section{Comparative studies}

Only five articles have reported recurrence rates in comparative trials between two treatment modalities for primary BCC. No comparative studies of the treatment of recurrent $\mathrm{BCC}$ have been found.

Hall et al. performed a prospective randomised trial comparing RT $(n=49)$ and CS ( $n=44$ ) (Hall et al., 1986). Most tumours were located in the face and were less than 2 $\mathrm{cm}$ in size. They reported a recurrence rate two years after treatment of $4 \%$ for treatment with RT and 39\% for CS. Cosmetic results 1 year after treatment were not significantly different.

Avril et al. used a prospective randomised trial to compare RT $(n=174)$ and surgery (with and without frozen section control, $n=173$ ) (Avril et al., 1997). All BCCs were located in the face and only $6.5 \%$ were larger than $2 \mathrm{~cm}$. After 4 years of follow-up, there was a recurrence rate of $0.7 \%$ after SE and $7.5 \%$ after $\mathrm{RT}$. Cosmetic results were significantly better after surgery (Petit et al., 2000).

Wang et al. performed a prospective randomised trial comparing PDT $(n=47)$ and CS ( $n=41$ ) (Wang et al., 2001). Only 28\% of the tumours were located in the head / neck area and these were all nodular or superficial. After 1 year follow-up, the difference in recurrence rates was not statistically significant: $25 \%$ after PDT and $15 \%$ after CS. The cosmetic outcome was significantly better after PDT.

Thisssen et al. studied cosmetic outcome after treatment with CS $(n=48)$ and SE $(n=48$ ) (Thissen et al., 2000a). After a 1 year follow-up period, they found 3 recurrences after $\mathrm{CS}$ and none after SE. The cosmetic outcome was significantly better after SE.

Rhodes et al. did a multicentre randomised prospective trial on the treatment of nodular BCC, comparing SE with PDT (Rhodes et al., 2004). They noted 1 recurrence after SE and 5 recurrences after PDT after 24 months of follow-up. The cosmetic result after PDT was significantly better,

\section{Recurrence}

Because the metastasis rate in BCC is very low, the prognosis of a $\mathrm{BCC}$ depends mainly on its ability to recur. Recurrences are particularly a problem in the treatment of $\mathrm{BCC}$ of the face, as they can cause severe morbidity and carry a greater risk of further recurrence (Menn et al., 1971; Randle, 1996; Rowe et al., 1989b; Smith and Grande, 1991). Therefore, prevention of recurrence is the most important goal in treatment of BCC.

Factors that influence the ability to recur are:

- Location. BCCs located in the H-zone of the face (Figure 1.5) recur more often than other BCCs (Bogdanov-Berezovsky et al., 2004). Unsuspected deep and lateral extensions are common in these areas. In their analysis of 496 recurrent BCCs, Levine et al. concluded that the most critical factor for local recurrence is location in the mid-face area or the auricular or pre-auricular sites (Levine and Bailin, 1980). Tumours in the nasolabial fold and the medial canthal area in 
particular tend to invade deeply before spreading laterally (Panje and Ceilley, 1979). Some have suggested that this is caused by the location of embryonic fusion planes (Mora and Robins, 1978). However, this was rejected in a study and review by Wentzell at al (Wentzell and Robinson, 1990). Another explanation for the higher recurrence rates in the $\mathrm{H}$-zone could lie in the fact that this is a cosmetically and functionally important area. Surgeons might be more concerned with protecting the 'healthy' skin and anatomic structures than with removing the tumour (Dixon et al., 1989; Hauben et al., 1982).

Histopathologic subtype. Aggressively growing BCC (such as morphea, micronodular and BCC with squamous differentiation) are known for their wide subclinical spread (Breuninger and Dietz, 1991; Burg et al., 1975). Small elongated strands of tumour cells can easily be missed by standard histopathology and can therefore cause recurrence. Recurrence rates after SE have been reported to be significantly higher in aggressive type than in nonaggressive type BCC (Bumpous et al., 2000; Sloane, 1977).

- Size. Large BCCs (> $2 \mathrm{~cm}$ ) cause more problems, such as incomplete excision or recurrence. Dubin treated 1417 BCCs between 1955 and 1969 by CE, RT and SE (Dubin and Kopf, 1983). All three therapies failed most often in large BCCs. Other authors have also noted that tumours more than $2 \mathrm{~cm}$ in size have a higher local recurrence rate than small tumours (Randle, 1996; Rigel et al., 1981).

- Perineural invasion. Perineural invasion is not very common in BCC but leads to unexpected tumour extensions and therefore to more recurrences (Martin et al., 2000; Ratner et al., 2000). Recurrences can also be caused by perineural invasion being missed in standard histopathologic control (Niazi and Lamberty, 1993).

Incompletely excised BCC. Recurrence rates after complete excision of primary BCCs vary from 3.2 to $8.0 \%$ (Thissen et al., 1999) and from 2.1 to $5.8 \%$ for excision with frozen section control (Bentkover et al., 2002; Ghauri et al., 1999). Recurrence rates of incompletely excised BCCs vary from 19.0 to $41.0 \%$ (De Silva and Dellon, 1985; Ghauri et al., 1999; Nagore et al., 2003; Sussman and Liggins, 1996).

Immunosuppressive agents. Patients who use immunosuppressive agents, after transplantation, have a higher risk of developing NMSC. The risk of developing $\mathrm{BCC}$ is $5 \%$ at 10 years after the transplantation and rises to $10 \%$ after 20 years (Hartevelt et al., 1990). These patients also have a higher risk of recurrence or even metastasis (Jemec and Holm, 2003).

- Therapeutic modality. Several authors have reviewed the literature and shown that the risk of recurrence depends on the treatment modality (Rowe et al., 1989a; Rowe et al., 1989b; Thissen et al., 1999). Recurrence rates after SE vary from 5.3 to $10.1 \%$, those after CE from 5.7 to $7.7 \%$, those after CS from 4.3 to $7.5 \%$ and those after radiotherapy from 7.4 to $8.7 \%$ for primary BCC (Rowe et al., 1989a; Thissen et al., 1999). Rowe reports recurrence rates after SE of $17.4 \%$, after CE 
of $40.0 \%$ and after radiotherapy of $9.8 \%$ for recurrent BCC (Rowe et al., 1989b). Recurrence rates after treatment by MMS are lowest, ranging from 1 to $2 \%$ for primary to 5 to $6 \%$ for recurrent BCCs (Rowe et al., 1989a; Rowe et al., 1989b; Thissen et al., 1999).

- Recurrent BCC. Recurrence rates following treatment of a recurrent BCC are much higher than after treatment of a primary BCC, regardless of treatment modality. This was concluded by Rowe et al. after a review of all recurrence rates in studies published since 1945 (table 1.2) (Rowe et al., 1989a; Rowe et al., $1989 b)$. They found that the weighted average recurrence rate for the non-Mohs modalities was almost four times higher than that for MMS (5.6\% versus $19.9 \%$ ). Recurrent $B C C$ s after initial treatment with radiotherapy are even more difficult to treat than recurrences after other treatment modalities (Smith et al., 1990; Smith and Grande, 1991).

Table 1.2. Results of a literature review for treatment of BCC in 1989 (Rowe et al., 1989a; Rowe et al., 1989b)

\begin{tabular}{lcc}
\hline & \multicolumn{2}{c}{ Recurrence rates } \\
\hline Therapy & Primary & Recurrent \\
\hline Surgical excision & 10.1 & 17.4 \\
Radiotherapy & 8.7 & 9.8 \\
Cryosurgery & 7.5 & - \\
Curett. \& electrodess. & 7.7 & 40 \\
Mohs micrographic surgery & 1 & 5.6 \\
\hline
\end{tabular}

- Multiple BCCs. Recent studies have shown that patients with multiple BCCs have a greater risk of recurrence than patients with only one BCC (Bumpous et al., 2000; Czarnecki et al., 1996).

\section{Risk of developing a subsequent basal cell carcinoma}

Many studies have been done to determine the risk of developing a second BCC (Czarnecki et al., 1994; Marghoob et al., 1993; Robinson, 1987). A large review of the literature has shown that the 3-year cumulative risk of developing a second BCC is 44\% (Marcil and Stern, 2000). The greatest chance occurs within the first year after treatment of the first tumour (Marghoob et al., 1993; Robinson, 1987). The number of previous skin cancers carries an increased risk for the development of subsequent skin cancers, with a risk of $100 \%$ after 8 or more previous BCCs (Czarnecki et al., 1994; Marcil and Stern, 2000). The risk of developing SCC after BCC is $6 \%$ at 3 years. The risk is also higher for patients with skin type for II in combination with extensive sun exposure (Robinson, 1987). A recent study at a Mohs centre reported that $19.3 \%$ 
of patients present with more than one BCC and another $18.8 \%$ develop a new BCC within 2 years (Schinstine and Goldman, 2001). Patients who develop more than one $B C C$ require special attention in the treatment.

\section{Prevention}

Because exposure to sunlight is the main risk factor for developing a BCC, prevention is aimed at reducing this exposure. Sunscreens have been developed to reduce the occurrence of changes in the skin due to sunlight exposure. Aside from sunscreen use, wearing protective clothing and hats, seeking the shade and minimising the time spent outdoors at high altitudes, at low latitudes, around noon and in sunny seasons diminishes the risk of skin cancer development. Special attention should be drawn to the fact that sunscreens only provide adequate protection if they lead to the prevention of erythema and prevent tanning. Furthermore, their use should not lead to prolonged UV exposure if they are to provide UV protection. Although reports are somewhat contradictory, several studies have shown that there is sufficient evidence for a cancer-preventive effect of sunscreens (Krekels et al., 1997; Vainio et al., 2000). Nevertheless, reduction of sunlight exposure by means of clothing and hats or seeking the shade and avoiding the sun around the middle of the day should be the first approach to reducing the risk of skin cancer, with sunscreens being seen as an addition to this approach rather than a substitute. Primary prevention is especially important in children, because excessive sun exposure during the early years of life appears to increase the risk of skin cancer (Gallagher et al., 1995; Kennedy et al., 2003; Marks, 1995; van Praag et al., 2000).

Other factors that might influence the occurrence of $\mathrm{BCC}$ are life-style related habits like smoking. There is a clear correlation between the development of SCC and smoking (De Hertog et al., 2001). Whether smoking is also a causative factor for the development of BCC is still a subject of debate (Boyd et al., 2002; Corona et al., 2001; De Hertog et al., 2001; Milan et al., 2003).

Secondary prevention includes early detection of skin cancer by screening programmes. There is no evidence that routine screening by total-body skin examination reduces morbidity or mortality from BCC (Helfand et al., 2001). This is probably caused by the fact that detection and treatment of BCC in the absence of screening programmes is already nearly always curative. Although evidence from large screening programmes is lacking, campaigns to change people's sun behaviour might decrease the risk of developing skin cancer (US-Preventive-Services-TaskForce, 2001). A large campaign in the coastal area in the west of the Netherlands, focusing on the detection of melanomas, resulted in an increased incidence rate of melanomas immediately after the campaign, and a stabilisation of incidence rates in the years thereafter (van der Rhee et al., 1999). This indicates that large campaigns to increase public awareness of risk factors can stabilise and perhaps even decrease future incidence rates. 
A reduction of the development of skin cancers in high-risk patients (e.g. those with xeroderma pigmentosum or the nevoid basal cell carcinoma syndrome) can be achieved by treatment with high doses of oral retinoids $(2 \mathrm{mg} / \mathrm{kg} /$ day of isotretinoin) (DiGiovanna, 1998). However, this effect is lost within 2-3 months after therapy has stopped, and adverse effects such as abnormal liver function tests, elevated serum cholesterol/ triglyceride levels and skeletal toxicity may occur. Advantages and adverse effects should therefore be carefully weighed before starting treatment with oral retinoids. Other agents that have been evaluated for their protective role in skin cancer (beta carotene, vitamins, folate and carotenoids) have not been found valuable (Frieling et al., 2000; Fung et al., 2002).

\section{Acknowledgement}

I would like to thank drs. A. Vermeulen for providing the histopathologic slides for the photographs. 
Chapter 1 


\section{Chapter 2}

\section{Mohs Micrographic Surgery}

Nicole W.J. Smeets, H.A. Martino Neumann

Parts of this chapter will be published in

- The European Textbook for Dermatologic Surgery, Rusciani .

- The European Book Facial and Plastic Surgery, Arnold Publishers London, Vuyk \& Lohuis. 


\section{Introduction}

There are many treatment options for BCC, including surgical excision (SE), cryosurgery (CS), radiotherapy (RT), curettage and electrodessication (CE), and Mohs micrographic surgery (MMS). Treatment modalities like photodynamic therapy (PDT) and immunotherapy with imiquimod are in an investigative stadium. SE and MMS have the advantage of (partial) histopathological margin control. Although most BCCs are well treated by traditional methods like SE and CS, some BCCs require a more specialised technique like MMS. In the United States around $30 \%$ of all NMSCs are treated by MMS (Gaston et al., 1999), in Europe only very selected cases are treated by MMS(Julian and Bowers, 1997; Neumann et al., 1996; Wennberg et al., 1999). In this chapter an overview is given of MMS, the history, how to use it and when to use it.

\section{History}

Sir Humphry Davy from Bristol first discovered zinc chloride in 1815 and found out that it had an anti-tumour effect. At the beginning of the last century Cancquin in Paris and Bougard in Brussels started using zinc chloride in the treatment of all kinds of human cancers (Brodland et al., 2000).

In the early 1930's Frederic E. Mohs was working as a resident at the department of zoology with Dr. Guyer, head of the department. Zinc chloride, when intravenously injected, is toxic and can lead to death. This was the reason why Mohs searched for a way to use the effectiveness of zinc chloride to kill tissue without the general toxicity. He used other chemicals to put it in a paste form that was applied to the tissue were it was gradually released into.

Mohs and Guyer were particularly interested which effect the inflammation that these chemicals caused would have on cancer (Brodland et al., 2000; Shuster, 1999). They accidentally observed that when zinc chloride was injected into tissue, this tissue not only became apoptotic, but also was preserved in a way that tissue is fixed for histology and that it could be examined under the microscope. The zinc chloride paste was applied to the skin at the tumour site and then left in place for 24 hours. This application of zinc chloride was a very painful experience for patients and took place without local anaesthesia. The 'fixed' tumour nodules were shaved off horizontally to the skin. The tumour was then processed into horizontal, microscopical sections, so that $100 \%$ of the cutting edges became visible under the microscope. Areas of cancer found with the microscopical examination were located on maps drawn on both paper and on the tissue itself. This concept is the basis for today's micrographic surgery. Mohs gave this technique the name chemosurgery, because of the chemical interaction with zinc chloride and human tissue. Nowadays it is renamed micrographic surgery, because it combines microscopic control of the resection margins and graphical registration for indicating the remaining tumour and further surgery. In 1936, when Mohs first started to treat patients, there was a lot of scepticism, because they thought that cutting through cancer would cause local and haematologic spreading. Therefore, in his early years Mohs was only allowed to operate on patients 
that had extremely advanced cancers and were supposed incurable. Despite of these large and difficult tumours, his first results were excellent. The first data were published in the surgical literature in 1941 and eventually convinced many that his treatment was effective (Mohs, 1941b).

However the disadvantages like the extensive erythema, oedema and purulence of the wounds made it only possible to heal by secondary intention. Beside that, the procedure was time-consuming and because of the inflammation the zinc chloride paste caused, very painful for the patient.

Because Mohs was trained as a general surgeon, the first introduction in dermatology was several years later; an article published on cancer in the face in the Archives of Dermatology in 1947 (Mohs, 1947).

In 1953 Mohs for the first time used the fresh tissue technique instead of the fixed tissue technique to save time while filming the procedure. Without the fixation he excised the tumour under local anaesthesia, while remaining the graphical mapping. Later, he used this fresh tissue technique more frequently for eyelid tumours because the zinc chloride paste caused irritation to the eye.

In 1970 Theodore A. Tromovitch presented successful results using the fresh tissue technique at the American College of Chemosurgery meeting. He published his results in 1974 (Tromovitch and Stegeman, 1974).

The results of the fresh tissue technique made it clear that the real reason for success was not the chemical fixation in vivo, but the microscopic control by horizontal sections. The relative lack of pain and the fact that patients could be treated in one day, led to the transition of the fixed tissue technique into the fresh tissue technique, although this technique required more technical skills.

Another benefit of the transition from the fixed tissue technique into the fresh tissue technique was that the created defect could be reconstructed on the same day as the excision. This resulted in more interest among dermatologic surgeons in reconstructive techniques.

In 1985 the name "Chemosurgery" was changed to "Mohs micrographic surgery" at the annual meeting of the American College of Chemosurgery. In 1990 Antonio Picoto founded the European society of Micrographic surgery.

\section{Method}

Like any other surgical procedure the operating field is disinfected and covered with sterile sheets. Tumour borders can become more clearly by using iodine and floodlight. Thereafter, the area surrounding the tumour is infiltrated with lidocainne $1 \%$ and epinephrine $(1: 100,000)$. Bupivacaine $0,5 \%$ is used as additional anaesthesia because the procedure can take several hours.

The tumour is delineated and orientation drawing and suturing are made (Figure 2.12.2, page 35-36). The next step in MMS is debulking of the tumour (Figure 2.3). Debulking can be performed with a curette for small lesions or with a scalpel for the larger lesions. Using a curette most of the soft tumour tissue is taken out, so tumour 
borders become more clear. Afterwards, a small margin is delineated around the defect (Figure 2.4).

After the debulking the first "Mohs-round" is performed. A Mohs-round is a circumference incision with a $45^{\circ}$ angle, the so called round saucer shaped incision (Figure 2.5). After the incision is made, the excision continues horizontally to the surface. In this way a somewhat bowl-shaped tissue specimen is obtained (Figure 2.6).

The tissue specimen is divided into smaller pieces, with colour staining of the edges of each piece (Figure 2.7-8). For precise orientation of the tumour, the Mohs map is likewise colour-coded (Figure 2.9).

All pieces are taken to the cryostat where they are put upside down on a cryostat chuck with a few drops of tissue-tech (Figure 2.10). The tissue pieces are then crushed and because of the bowl-shape of the tissue pieces, the lateral tissue edges are brought into the same plane as the base of the specimen (Figure 2.11-12). After freezing of the tissue pieces, horizontal sections of 5 or $10 \mu \mathrm{m}$ are made and stained with toluidine blue or hematoxylin and eosin ( $\mathrm{H} \& \mathrm{E})$. When the procedure is performed properly, nearly $100 \%$ of the surgical margins are visible under the microscope (Figure 2.13). Microscopical findings of residual tumour are indicated on the Mohs map (Figure 2.14). With the drawings on the Mohs map, the surgeon is able to locate any residual tumour in the patient exactly. Only there where residual tumour is, a small piece of tissue needs to be excised (the second Mohs-round) (Figure 2.15-16). The same procedure for colour coding and horizontal sections processing starts all over again. This is repeated until tumour free margins are obtained (Figure 2.17-18).

After complete tumour removal the surgeon has to decide what functionally and cosmetically the best possible reconstruction is. The reconstruction occurs most of the time in the same session, and is preferably performed by the Mohs surgeon (Figure 2.19-20).

\section{Indications for MMS}

MMS is particularly indicated for NMSCs. Because BCC and SCC are the most common skin cancers, there is a lot of information about the outcome of treatment with MMS. The advantages of MMS are the complete margin control and preservation of healthy tissue. Therefore, indications for MMS are NMSC that have a high risk for local recurrence, or are located in cosmetically and functionally important areas. Here, the indications for BCC and SCC are given, but MMS also has been shown to be a reliable technique for the treatment of other NMSC (table 2.1). 
Table 2.1. Indications for treatment with MMS for NMSC.

\section{Indications for MMS}

Basal cell carcinoma

Squamous cell carcinoma

Dermatofibrosarcoma protuberans (Dawes and Hanke, 1996;

Huether et al., 2001)

Microcystic adnexal carcinoma (Friedman et al., 1999)

Extramammary Paget's disease (Zollo and Zeitouni, 2000)

Keratoacanthoma (Larson, 1987)

Atypical fibroxanthoma (Davis et al., 1997; Huether et al., 2001)

Sebaceous carcinoma (Spencer et al., 2001)

Verrucous carcinoma (Swanson and Taylor, 1980)

Malignant fibrous histiocytoma (Huether et al., 2001)

Merkel cell carcinoma (O'Connor et al., 1997)

Eccrine porocarcinoma (Wittenberg et al., 1999)

Leiomysarcoma (Bernstein and Roenigk, 1996; Huether et al., 2001)

Erythroplasia of Queyrat (Dixon and Mikhail, 1981)

Indications for treatment of BCC with MMS are (table 2.2)(Drake et al., 1995; Telfer et al., 1999):

As factors predictive of a recurrent $\mathrm{BCC}$ are already discussed in chapter 1 , they are only briefly mentioned here.

- BCC with clinically undefined borders (Breuninger and Dietz, 1991; Burg et al., 1975; Salasche and Amonette, 1981).

- Aggressively growing BCC ( for example morphea, micronodular and BCC with a squamous differentiation) (Breuninger and Dietz, 1991; Burg et al., 1975).

- Large BCC (>2 cm) (Dubin and Kopf, 1983).

- BCC located in the H-zone of the face (Figure 1.5) (Levine and Bailin, 1980; Panje and Ceilley, 1979).

- Incompletely excised BCC(Berlin et al., 2002; Bieley et al., 1992; De Silva and Dellon, 1985; Robinson and Fisher, 2000; Sussman and Liggins, 1996).

- $\quad B C C$ with perineural invasion. Not only the ability to recur but also the fact that it might not be detected with conventional histopathology of a traditional excision specimen, can be an indication for MMS (Ratner et al., 2000).

- Although it forms not such a hard indication, age of the patient is also an important factor. BCC is merely a disease of the elderly, but it is getting more common in younger people as well. Beside prevention of a recurrence, these patients are also more cosmetically orientated and more demanding. Cox studied 150 patients under the age of 35 years and came to the conclusion that these BCCs had a 
more aggressive histopathologic subtype compared to the total population (Cox: 1992). In a recent study, no histopathologic difference between BCC in younger patients (less than 50 years) and BCC in older patients was found (Milroy et al., 2000). They concluded that the clinically more aggressive behaviour of BCC in younger patients may probably result from inadequate SE due to cosmetic considerations.

- Recurrent BCC (Mora and Robins, 1978; Rowe et al., 1989a; Rowe et al., 1989b).

Table 2.2. Indications for treatment with MMS for BCC.

\section{Basal cell carcinoma}

Undefined borders

Aggressive histopathologic subtype

$>2 \mathrm{~cm}$

Location $\mathrm{H}$-zone

Incompletely excised

Perineural invasion

Recurrent BCC

Indications for treatment of SCC with MMS are (table 2.3) (Drake et al., 1995):

- SCC in immuno-suppressed patients. The large amount of tumours in these patients requires special care. In the general population the ratio BCC:SCC is approximately 4:1, in immuno-suppressed patients the ratio reverses to $1: 3$ (Rowe et al., 1992). Recent studies indicate that a SCC in an immuno-suppressed patient has a more aggressive behaviour in terms of both recurrence and metastasis (Jemec and Holm, 2003; Martinez et al., 2003).

- Large SCC (>2 cm). Patients who have a SCC with a size greater than $2 \mathrm{~cm}$ should be treated more carefully, because recurrence rates are double (15.2\% vs. $7.4 \%$ ) and metastases rates are triple (30.3\% vs. 9.1\%) (Mohs and Snow, 1985; Rowe et al., 1992).

- Poorly differentiated SCC show a higher rate of recurrence and metastasis (Eroglu et al., 1996). The depth of invasion of a SCC is classified by Clark level I till V. Risk of metastases/ recurrence of a SCC Clark level I-III is minimal, where the prognosis with respect to metastases/ recurrence of a SCC Clark level IV and $V$ significantly is deteriorated (Petter and Haustein, 1998; Rowe et al., 1992).

However, also well-differentiated SCC may recur or metastasise.

- SCC located in irradiated areas and scar carcinomas behave more aggressively and have a significantly higher metastases rate (Eroglu et al., 1996; Novick et al., 1977). 


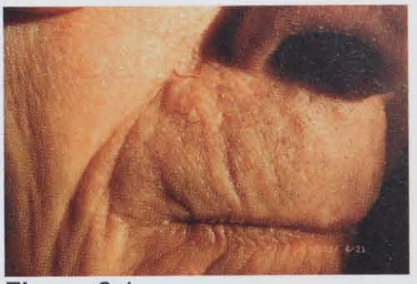

Figure 2.1.

Nodular and morphea growing BCC.

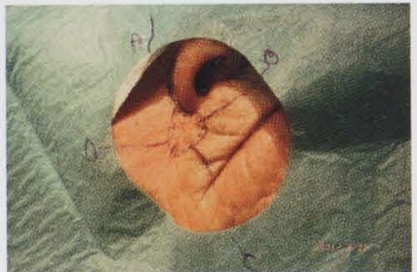

Figure 2.2.

The "Mohs' map".

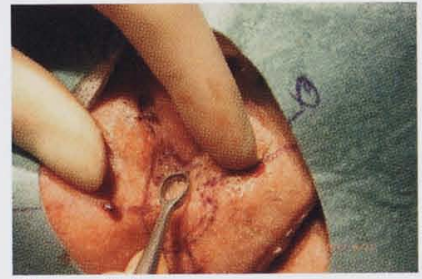

\section{Figure 2.3.}

Debulking of the tumour.

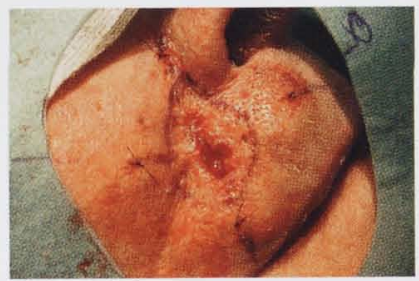

Figure 2.4.

A small margin is delineated around the curetted defect.

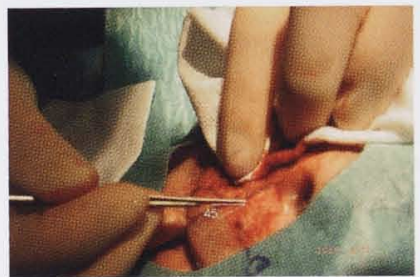

Figure 2.5.

The first Mohs' round with excision under a $45^{\circ}$ angle.

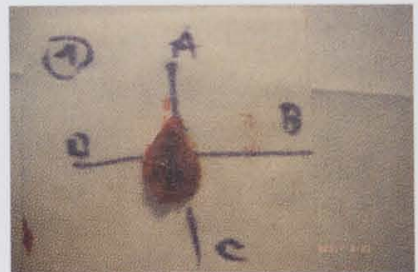

Figure 2.6.

A bowl-shaped specimen is obtained.

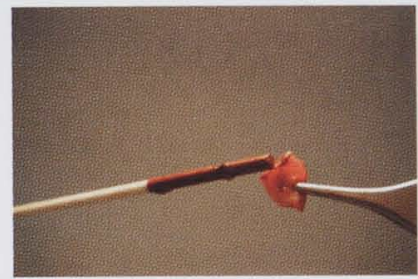

\section{Figure 2.7.}

The specimen is divided into smaller pieces and colour-coded.

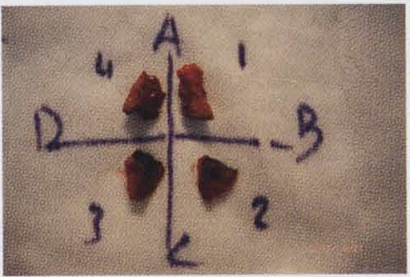

Figure 2.8.

The coloured smaller pieces
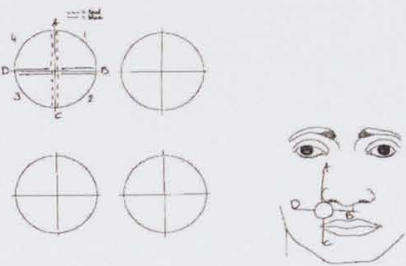

Figure 2.9.

The Mohs map is likewise colour-coded.

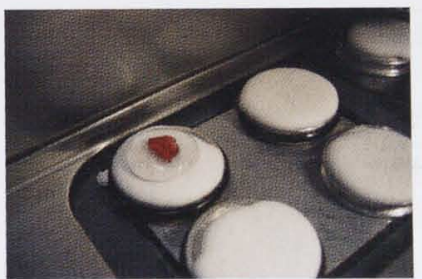

Figure 2.10.

Pieces are placed on a cryostat chuck. 


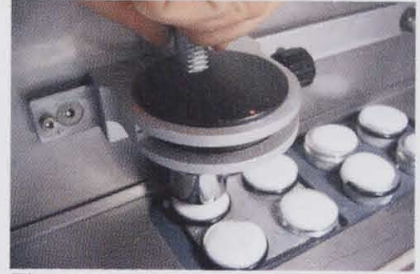

Figure 2.11.

Compression, so tissue edges are in the same plane as the base.

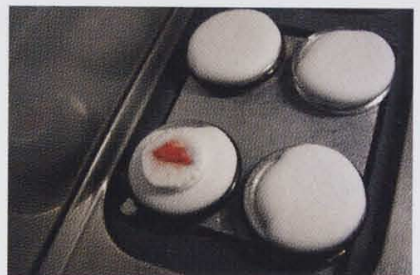

Figure 2.12.

Epidermis, dermis and subcutis are in the same horizontal plane.

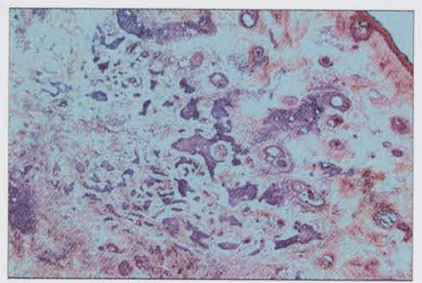

\section{Figure 2.13.}

Solid and morphea BCC in a frozen section

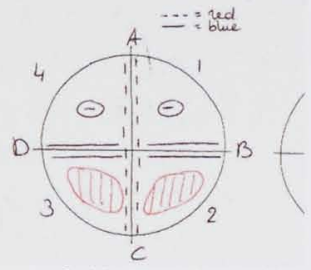

Figure 2.14.

Microscopical findings on Mohsmap.

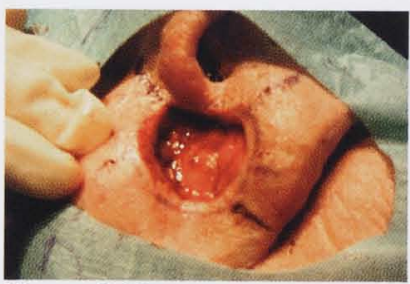

Figure 2.15.

The second Mohs-round is planned and drawn on the patient.

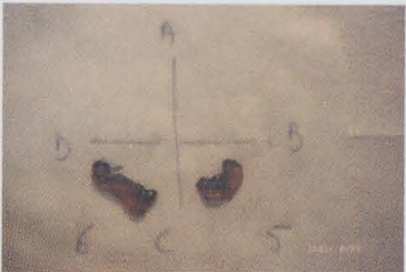

Figure 2.16 .

The specimen of the second Mohs-round is colour-coded and processed.

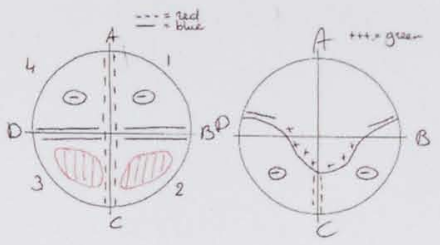

Figure 2.17.

No tumour is left in the tissue, as is indicated on the Mohs-map.

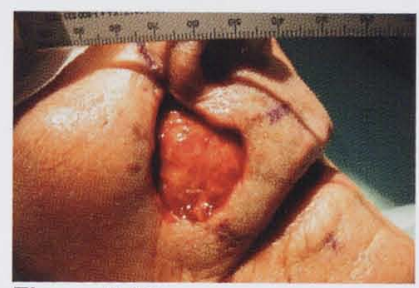

Figure 2.18.

The final defect.

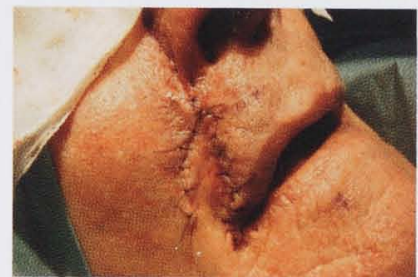

Figure 2.19.

Final results after reconstruction.

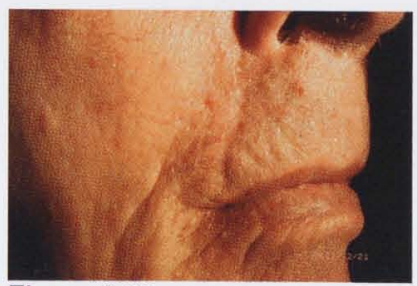

Figure 2.20 .

Post-operative result after 6 months. 
- SCC located on the ear and lip are more aggressive, showing more local recurrences and regional metastases (Rowe et al., 1992).

- Perineural spread is present in 4.9-14\% of SCCs and is correlated to a high incidence of local recurrence and metastasis (Cottel, 1982; Goepfert et al., 1984).

- A local recurrent SCC is more likely to recur again after treatment (Rowe et al., 1992).

Table 2.3. Indications for treatment with MMS for SCC.

\begin{tabular}{l} 
Squamous cell carcinoma \\
\hline Immunosuppressed patients \\
$>2 \mathrm{~cm}$ \\
Poorly differentiated SCC \\
Scar carcinomas \\
Location in irradiated area \\
1Location on ear or lip \\
Perineural invasion \\
Recurrent SCC \\
\hline
\end{tabular}

\section{Discussion}

In the first parts of this chapter history, technique and indications of MMS were described. In the discussion we will compare the advantages of MMS to other therapy modalities.

\section{MMS and margin control.}

As mentioned before, the advantage of MMS and SE is the histopathological margin check. In other treatment modalities like RT and CS, the physician needs to rely on visual margins. The most important difference between SE and MMS is the way the excised tissue is histologically examined. As explained before, with MMS theoretically $100 \%$ of the excision borders can be inspected under the microscope (fig 2.12). In case of a SE the tissue specimen is examined oiten with the bread-loaf-method, with which only part of the resection borders is viewed (Abide et al., 1984). Using the bread-loaf method, there is a low risk that tumour is missed in case of a solid growing tumour, but in aggressive tumours growing with finger-like extensions, tumour cells can be missed easily. in case of large tumours, tissue specimens are often examined by peripheral sections and a deep horizontal section to check all the borders. In this way all the resection margins can be visualised, however, there is no continuity between the slides. Many different methods for histopathologic margin check have been described, but none of them has the advantage of 100\% margin control and exact mapping of tumor (Rapini, 1990). The important difference between a Mohs slide and a slide of the conventional bread-loaf technique is what they represent. Because 
of the special histopathological technique, a Mohs slide represents the complete resection border. If there is tumour in a Mohs slide, the excision is per definition incomplete. A slide in conventional pathology is a transverse section through the specimen and through the tumour. If the lateral and deep borders are free of tumour: with tumour only in the centre of the slide, the excision is considered complete.

$\mathrm{BCC}$ is normally well recognised in frozen sections coloured with $\mathrm{H} \& \mathrm{E}$. However, it can sometimes be difficult to detect BCC amongst inflammatory cells, and some suggest that these inflammatory cells could mask tumour cells. Katz et al. showed with an adjuvant Ber-EP4 (monoclonal antibody directed against an epithelial-specific membrane antigen) staining that these inflammatory cells don't mask tumour during MMS (Katz et al., 2001). In case of a tumour with perineural invasion or a morphea type BCC adjuvant cytokeratin stains can be of help (Jimenez et al., 1995; Ramnarain et al., 1995). Also in selected high risk SCC, for example in large tumours and SCC with perineural invasion, rapid cytokeratin stains enhance the sensitivity of detecting tumour cells (Zachary et al., 1994).

\section{MMS in comparison with other micrographic techniques.}

There are two groups in Germany who describe another microscopically controlled technique to excise BCCs. Breuninger and Holzschuh also described a method to monitor all margins of the excised tumour material (Breuninger and Holzschuh, 1994). They excise the tumour with a small margin $(3 \mathrm{~mm})$ of healthy looking skin in the traditional way into the subcutaneous fat. The specimen is marked at 12 o'clock. The tumour is then removed from this specimen leaving a $2 \mathrm{~mm}$ thick border. This outer border is then folded using the soft subcutis as a hinge. This technique is called the Breuninger or "Flounder technique". The advantage of this technique in comparison to the Mohs technique is that there is no need for the $45^{\circ}$ angle leaving $45^{\circ}$ edges that sometimes need to be straitened before reconstruction. The disadvantage of this technique is that there is only one mark and not a graphical mapping of tumour borders. It is known that in Breuningers hands good results are obtained in large series of patients (Breuninger et al., 1989). However, there are no publications from other groups that confirm these results. In the ISI Web of Sciences almost thousand references with MMS are listed. This indicates that in the world this is the most frequently used microscopically controlled technique based on its obtained results in primary and recurrent BCCs (Julian and Bowers, 1997; Mohs et al., 1988; Mohs, 1986; Neumann et al., 1996; Vuyk and Lohuis, 2001; Wennberg et al., 1999).

Another microscopically controlled excision technique is the "Münchner"- technique (Kopke and Konz, 1995). With this technique the excision is the same as in any routine excision. The specimen is put on a cryostat chuck after a $180^{\circ}$ turn of the specimen, so the epidermis is closest to the chuck. Then each $150-200 \mu \mathrm{m}$ a slide is made, horizontal to the epidermis starting at the bottom of the specimen until the epidermis is reached. In this way many slides are made in which tumour and borders can be judged. A disadvantage of this technique is that lots of slides are made that all need to 
be judged for tumour presence. Another disadvantage is that not all resection margins are inspected, and that there is no continuity in the resection margins because of the slide thickness, so finger-like extensions of BCC with an aggressive histopathologic subtype can be missed. An advantage of this technique is that no special laboratory skills are required.

MMS and excision margins.

The most important advantage of MMS compared with SE is the direct

histopathological margin check. In SE the surgeon has to rely on the visible margins and takes an extra margin of clinically uninvolved skin to achieve histopathologic tumour free margins. The problem of setting the right margins has been thoroughly discussed in chapter 1.

MMS and results of studies treating $B C C$.

MMS has produced its best results in the treatment of BCC. Although there has never been any prospective randomised trial to compare MMS with another treatment modality for BCC, several different studies describe high cure rates with MMS.

We reviewed all databases of Medline, Pubmed and Embase from 1966 until 2003 for studies reporting recurrence rates after treatment of BCC by MMS. The studies had to fulfil the following inclusion criteria: patients had to have at least five years of follow-up or survival analysis had to be performed, recurrence rates of $\mathrm{BCC}$ and other types of non-melanoma skin cancer (NMSC) and of primary and recurrent BCC had to be reported separately. Recurrence rates after treatment of BCC by MMS were reported in 32 studies. Only 9 studies fulfilled the inclusion criteria (follow-up of at least 5 years or survival analysis, separate recurrence rates for different NMSC's and for primary and recurrent BCCs, table 2.4)(Julian and Bowers, 1997; Malhotra et al., 2004; Mohs et al., 1988; Mohs, 1986; Mohs and Zitelli, 1981; Robins et al., 1985; Sakura and Calamel, 1979; Tromovitch et al., 1966; Wennberg et al., 1999). In the early studies, the fixed tissue technique is used while in studies in the 1990 s only the fresh tissue technique is used. Recurrence rates vary from $0.0-6.5 \%$ after treatment of primary BCC and from 4.8-12.0\% after treatment of recurrent BCC. Most studies report recurrence rates of $0-1 \%$ for primary and 6-7\% for recurrent BCCs, only Wennberg and Sakura report higher recurrence rates (Sakura and Calamel, 1979; Wennberg et al., 1999). 


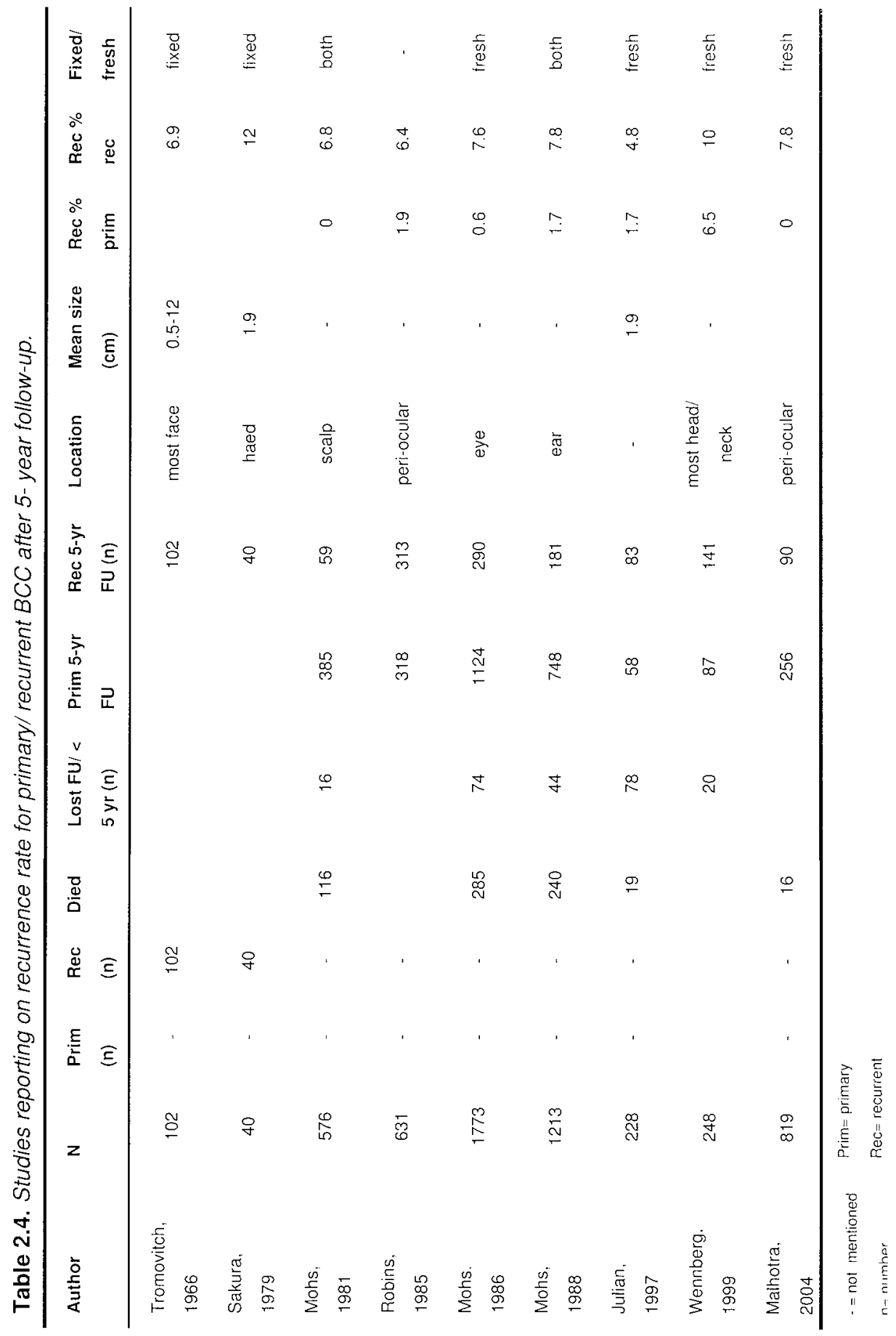


Wennberg et al. uses a survival analysis to estimate the 5-year recurrence rates were all other studies report on the strict 5 -year recurrence rates. When recalculating recurrence rates and drop-outs in follow-up of Julian et al., we noticed a discrepancy between numbers of patients that completed the follow-up $(n=131)$ and number of primary and recurrent BCC (58 and 83, which is 141) (Julian and Bowers, 1997). So the actual recurrence rate might be a little higher.

In 1989 Rowe et al. reviewed all studies (since 1947) reporting recurrence rates of primary and recurrent BCC using SE, RT, CS, CE and MMS (table 1.2) (Rowe et al., 1989a; Rowe et al., 1989b). More recently Thissen et al. reviewed all prospective studies systematically and reported recurrence rates of primary BCC (table 2.5) (Thissen et al., 1999). Both Rowe and Thissen reported the lowest recurrence rates after treatment by MMS in comparison with other treatment modalities.

Table 2.5. Results of a literature review for treatment of primary BCC in 1999.(Thissen et al., 1999)

\section{Recurrence rates}

$(\%)$

Therapy

\begin{tabular}{ll}
\hline Surgical excision & 5.3 \\
Radiotherapy & 4.3 \\
Cryosurgery & 7.4 \\
Mohs Micrographic Surgery & 1.1 \\
\hline
\end{tabular}

MMS and results of studies treating SCC.

Rowe et al. reviewed all studies that have been reported since 1940 regarding cure and recurrence rates of SCC treated with MMS and non-MMS modalities. They found cure rates favourable for MMS in comparison with conventional methods (Rowe et al., 1992). Unfortunately, these results are acquired from non-comparative studies so results will depend on patient selection. This might be an explanation for the large differences between some treated groups. Recent studies report recurrence and metastases rates of $7-8 \%$ for both primary and recurrent SCC after MMS (Holmkvist and Roenigk, 1998; Turner et al., 2000). However, Turner et al. received these numbers by a modified MMS procedure using formalin fixed sections, the 'slow-Mohs technique (Turner et al., 2000). This technique uses formalin-fixed sections instead of frozen sections, that take longer to process. Although subsequent stages are taken on an alternate day, it has the advantage of high-quality permanent histological sections as well as the complete margin control of MMS. In some SCC adjuvant keratin staining can enhance the sensitivity in detecting SCC cells (Zachary et al., 1994). 
MMS and cost-effectiveness.

Performing MMS requires trained doctors and laboratory technicians. Creating horizontal frozen sections also takes more time than a traditional pathological examination after SE. However, Cook and Zitelli, and Bialy et al. performed a cost comparison analysis and concluded that MMS is a method that is still cost-effective in comparison to traditional SE (Bialy et al., 2004; Cook and Zitelli, 1998). Also other authors state that the costs of MMS are comparable with the costs of other surgical procedures with/ without frozen section control (Bernstein, 1999; Welch et al., 1999). This is because recurrence rates after MMS are lower and defects are often closed in a more simple manner, since more uninvolved skin is preserved. It should be noted that MMS is to be performed in centres with trained and experienced Mohs surgeons and a well-equipped department. In this way several patients can be treated at the same time, which keeps efficiency high and costs low. Very important in keeping the cost low is restricting the indications for MMS. 


\section{Chapter 3}

\section{Mohs micrographic surgery for treatment of basal cell carcinoma of the face; results of a retrospective study and comparison with literature results}

Nicole W.J. Smeets, Daniëlle I.M. Kuijpers, Patty Nelemans, Judith U. Ostertag, Marc E.J.M. Verhaegh, Gertruud A.M. Krekels, H.A. Martino Neumann. 


\section{Abstract}

Background. The incidence of skin cancer and especially basal cell carcinoma (BCC) has increased the last decennia and is still increasing. Many treatment modalities can be used to treat $\mathrm{BCC}$, with surgical excision being most frequently used. Mohs micrographic surgery (MMS) is an advanced excision technique which is often used to treat BCC in the USA. In Europe it is practised at a lower scale.

Objective. The goal of this article was to evaluate the efficiency of MMS in the treatment of facial BCC.

Methods. In a retrospective study recurrence rates after treatment of facial BCC by MMS were estimated by reviewing the records of all patients with BCCs (720 BCCs) treated by MMS at our department from April 1992 until December 1999.

Results. The 5-year recurrence rates estimated from this study were $3.2 \%$ for primary $\mathrm{BCC}$ and $6.7 \%$ for recurrent BCC. Prognostic factors for recurrence are: an aggressive histopathologic subtype, more than 4 Mohs stages, a large defect size and a recurrent BCC.

Conclusion. Based on the fact that MMS provides the lowest recurrence rates, it is the treatment of first choice in primary facial BCCs with an aggressive histopathologic subtype and in recurrent BCCs in the face. 


\section{Introduction}

Basal cell carcinoma (BCC) is the most common cancer in Caucasians, occurring in 1 out of every 5-6 persons in a lifetime and the incidence is still rising every year (Holme et al., 2000; Marghoob, 1997; Rigel et al., 1996). For treatment of BCCs multiple modalities can be used, with surgical excision being most frequently used (Bower et al., 2001; Kuijpers et al., 2002).

Mohs micrographic surgery (MMS) was first described by Dr. Frederic E. Mohs in 1941 (Mohs, 1941a). His fixed tissue technique (chemosurgery) was based on the principle that when zinc chloride was applied to tissue (tumour), the tissue was fixed and the tumour could be horizontally shaved off, after which $100 \%$ of the resection margins could be examined microscopically. Areas of cancer found with the microscopic examination were located on maps, drawn on both paper and on the tissue itself. This way only there where residual tumour was located a re-excision was performed. The technique was refined and is nowadays performed under local anaesthesia without fixation of the tumour in vivo. The horizontally frozen sections and the graphically mapping remained. Mohs named his technique chemosurgery, because of the chemical interaction with zinc chloride and human tissue. Nowadays it is renamed micrographic surgery, because it combines microscopic control of tumour and graphical registration for indicating the remaining tumour and further surgery (Shriner et al., 1998).

In the USA, MMS is used for approximately $30 \%$ of all BCCs (Gaston et al., 1999).In Europe, MMS was introduced in the early 1980 s and is still practised at a lower scale, mostly in (referral) university hospitals (Neumann et al., 1996). Because there are less facilities to practice MMS, only a very select group of skin cancers is treated by it (Neumann et al., 1996; Wennberg et al., 1999). MMS has been introduced in 1992 in our university clinic and during the first years it was the only hospital in the Netherlands were MMS was practised.

The goal of this article was to evaluate the efficiency of MMS in the treatment of BCC of the face. We therefore retrospectively analysed the 5-year follow-up results of the cases treated in the University Hospital of Maastricht and compare these with literature results.

\section{Methods}

At the University Hospital of Maastricht, all BCCs treated with MMS from April 1992 until December 1999 were included in the clinical analysis. The analysis was performed in June 2002 so the majority of the patients with a BCC had completed a 5 year follow-up period. Inclusion criteria for treatment with MMS in our department in this period were;

- a BCC located in the H-zone of the face (Figure 1.5), and/ or,

- a BCC of a, biopsy proven, aggressive histopathologic subtype (morphea, micronodular and BCC with squamous differentiation) located in the face, and/or,

- a large $\mathrm{BCC}(>2 \mathrm{~cm}$ ) (of the face), and/ or, 
- a recurrent BCC (located in the face).

in MMS, the tumour (with a small margin of 2-3 mm) was excised at an angle of $45^{\circ}$ as described before. ${ }^{7}$ The specimen was then processed into horizontal frozen sections in such a way that theoretically $100 \%$ of the margins could be viewed. The slides were examined by both a dermatopathologist and the Mohs surgeon. In case of positive resection margins, a second excision (Mohs stage) was performed. This procedure was repeateo until complete tumour removal was achieved. In most cases. the defect was reconstructed immediately postoperatively. All patients entered an oncologicái follow-up system for 5 years at the University Hospital of Maastricht or at their own (referring) dermatologist.

All data were retrospectively collected by reviewing patient files in the University Hospital of Maastricht as well as in referring non-academic clinics in the region. Data were collected on: occurrence of a recurrence, length of follow-up, reasons for not completing follow-up and prognostic factors, such as location, size. histological subtype, type of previous therapy, previous BCC, defect size and number of Mohs stages. A recurrent $B C C$ was defined as a histologically confirmed BCC within $5 \mathrm{~mm}$ from a scar. In approximately 150 patients the follow-up was extended by 2 . questionnaire among general practitioners which inquired about the date of the last control visit and whether a recurrence had occurred.

\section{Statistical analysis}

Data were analysed using SPSS-PC for Windows. The 5-year cumulative probability of recurrent $\mathrm{BCC}$ after treatment by MMS was estimated by using a Kaplan-Meier survival analysis. The difference in time until a recurrence after primary and recurrent BCC was tested by the non-parametric Mann-Whitney test. In order to evaluate which factors are prognostic for a recurrent BCC after treatment, patients were classified into groups with or without the specific prognostic factors. Survival functions across groups of patients were compared using the log rank test, which computes the weighted difference between the observed and expected number of recurrences at each of the time points. A p-value of 0.05 or less was considered to indicate statistical significance.

\section{Results}

A total of 633 patients with 737 BCCs were treated from April 1992 until December 1999. Eleven patients with 11 BCCs were excluded because these BCCs were not located in the head/ neck area. Two patients with in total 6 BCCs, known with the nevoid basal cell carcinoma syndrome (NBCCS), were also excluded. So 620 patients with 720 BCCs remained. More men than women were treated $(55.6 \%, n=345$ vs. $44.4 \%, n=275$ ). The mean age of the patients was 65 years (median 67 years, range 22-94). For most patients $(70.2 \%, n=427)$, this BCC was the first skin malignancy. Sixty-six percent $(n=404)$ of the patients was referred from other hospitals. The majority of the BCCs was located on the nose $(30.3 \%, n=219)$ and on the forehead/ temporal zone (23.1\%, $n=167$, Figure 3.1). 


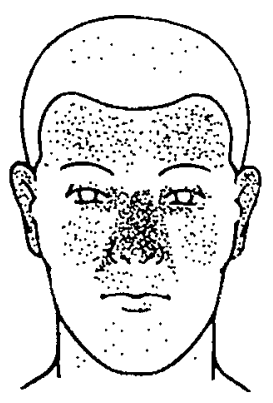

Figure 3.1. Distribution of tumours.

The tumours had a mean size of $15.78 \mathrm{~mm}$ (SD 12.40), with $21.5 \%(\mathrm{n}=139)$ having a diameter of more than $20 \mathrm{~mm}$. Other tumour characteristics are mentioned in Table 3.1 .

Table 3.1. Tumour characteristics.

\begin{tabular}{|c|c|c|}
\hline & Number $(\%)$ & Mean (SD) \\
\hline \multicolumn{3}{|l|}{ Size $(\mathrm{mm})$} \\
\hline$-\quad \leq 10$ & $294(45.4)$ & $15.78(12.40)$ \\
\hline$-\quad 11-20$ & $214(33.1)$ & \\
\hline - $\quad 21-30$ & $84(13.0)$ & \\
\hline$-\quad 31>$ & $55(8.5)$ & \\
\hline Missing & 73 & \\
\hline Total & 720 & \\
\hline \multicolumn{3}{|l|}{ Histologic type } \\
\hline - non-aggressive & $325(45.3)$ & \\
\hline aggressive & $393(54.7)$ & \\
\hline - $\quad$ missing & & \\
\hline Total & 720 & \\
\hline \multicolumn{3}{|l|}{ Primary/ recurrence } \\
\hline - Primary & $365(50.8)$ & \\
\hline $1^{e}$ recurrence & $142(19.7)$ & \\
\hline $2^{\circ}$ recurrence & $46(6.4)$ & \\
\hline $3^{\mathrm{e}}$ or more recurrence & $38(5.3)$ & \\
\hline Incomplete primary & $100(13.9)$ & \\
\hline Incomplete recurrence & $28(3.9)$ & \\
\hline - $\quad$ Missing & 1 & \\
\hline Total & 720 & \\
\hline \multicolumn{3}{|l|}{ Previous therapy (recurrence) } \\
\hline - Surgical excision & $115(45.3)$ & \\
\hline Radiotherapy & $13(5.1)$ & \\
\hline Cryosurgery & $44(17.3)$ & \\
\hline Curettage + electrodesiccation & $9(3.5)$ & \\
\hline MMS & $12(4.7)$ & \\
\hline Others & $16(6.3)$ & \\
\hline - Several & $45(17.7)$ & \\
\hline Total & 254 & \\
\hline
\end{tabular}


Only $24.7 \%(n=177)$ of all BCCs was eradicated in 1 Mohs stage (Figure 3.2). In $46 \%$ $(\mathrm{n}=331)$ of cases two stages were needed to achieve tumour free resection borders.

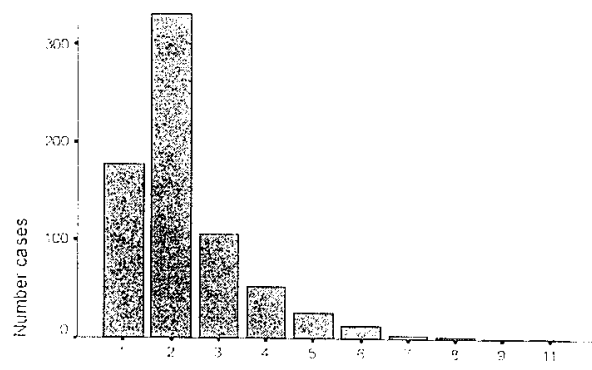

Mohs' stages

Figure 3.2. Number tumours per Mohs stage.

The mean defect size was $28.55 \mathrm{~mm}$, with $32 \%(n=203)$ having a defect size less than $2 \mathrm{~cm}$ and $22 \%(n=136)$ a size more than $4 \mathrm{~cm}$. The procedure took place under local anaesthesia in $86 \%(n=616)$ and in $14 \%(n=101)$ general anaesthesia was required. In two cases $(0.4 \%)$, the procedure was started under local anaesthesia and continued under general anaesthesia because of the unexpected extension of the tumour.

The median follow-up was 3.57 years (range: $0.0-9.61$ ) with 292 tumours (37\%) having a follow-up period of 5 years or more. Recurrences occurred in 27 of 720 BCCs $(3.8 \%$, Table 3.2$) ; 11(2.4 \%)$ after treatment of a primary $\mathrm{BCC}$ and $16(6.3 \%)$ after treatment of a recurrent $\mathrm{BCC}$. Two patients had a $\mathrm{BCC}$ that recurred twice after treatment with MMS.

Table 3.2. Recurrence and follow-up.

\begin{tabular}{lll}
\hline & Number (\%) & Mean (SD) \\
\hline Recurrence & & \\
$-\quad$ No & $693(96.2)$ & \\
$-\quad$ Yes & $27(3.8)$ & \\
Total & 720 & \\
Follow-up time & & \\
$-\quad 5$ or more & $272(37.6)$ & $3.53(2.10)$ \\
$-\quad 4$ & $94(13.1)$ & \\
$-\quad 3$ & $86(11.9)$ & \\
$-\quad 2$ & $133(18.5)$ & \\
$-\quad 1$ & $75(10.4)$ \\
$-\quad$ less than 1 year & $60(8.3)$ \\
Total & 720 \\
Reason non-follow-up & \\
$-\quad$ died $<1$ year after last FU & $90(19.9)$ \\
- others & $4(0.9)$ \\
$-\quad$ unknown & $359(79.2)$ \\
total & 453 \\
\hline
\end{tabular}


The 5-year cumulative probability of recurrence after treatment by MMS was estimated by using Kaplan-Meier survival analysis (Figure 3.3). The overall 5-year recurrence rate is $4.5 \% ; 3.2 \%$ for primary $\mathrm{BCC}$ and $6.7 \%$ for recurrent $\mathrm{BCC}$.

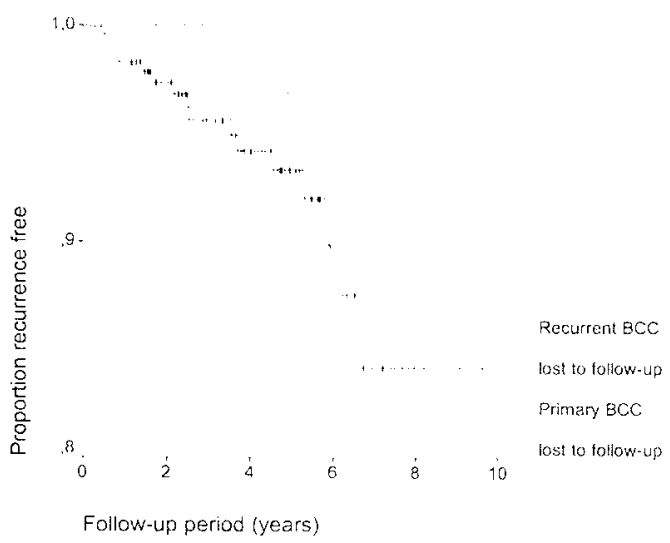

Figure 3.3. Kaplan-Meier survival analysis .

The difference between primary and recurrent $B C C$ is statistically significant $(p=0.0233)$. The 7-year recurrence rate is for primary $B C C$ the same as the 5 -year recurrence rate. However, the 7-year recurrence rate for a recurrent $\mathrm{BCC}$ is $15.8 \%$ which is much higher than the 5-year recurrence rate. The median time for a recurrent BCC to appear after treatment of a primary BCC is 1.92 years (range 0.52-3.41), while after treatment of a recurrent BCC this median time is 2.51 years (range 0.44-6.62). So, a recurrence after treatment of a recurrent BCC develops later and in a high percentage of cases after 5 years of follow-up, but this difference is not statistically significant (Mann-Whitney, $\mathrm{p}=0.169$ ).

Of the 27 recurrences in the total study group, most recurrences date from the early treatment years. Of all BCCs treated in $19926.7 \%$ recurred, in $199311.9 \%$ recurred, in $199412.0 \%$ recurred, in $19956.7 \%$ recurred and in $19962.5 \%$ recurred. There is a significant difference in recurrence rates between the first two years (1992-1993) and the last two years (1998-1999, $\mathrm{p}=0.0012$ ).

Comparing survival curves of groups of patients with and without relevant prognostic factors (Table 3.3), we note that non-aggressive BCCs (solid and superficial) have a significant lower 5-year cumulative probability to recur than aggressive type BCCs; $2.9 \%$ versus $5.8 \%(p=0.0150)$. With an increasing number of Mohs stages, the 5 -year cumulative probability of recurrence increases significantly to a probability of $9.0 \%$ in case of 4 or more Mohs stages ( $p=0.0013$ ). If the defect after MMS exceeds $4 \mathrm{~cm}$ in diameter, there is also a significant higher 5 -year probability of recurrence $(p=0.0027)$ compared with smaller defects. 
Table 3.3. Factors possible influencing recurrence.

\begin{tabular}{|c|c|c|c|}
\hline & $\begin{array}{c}\text { Recurrence } \\
\text { free }\end{array}$ & Recurrences & \\
\hline & Number & Number $(\%)^{\star}$ & $\begin{array}{l}\text { Log rank } \\
\text { test, } p=\end{array}$ \\
\hline \multicolumn{4}{|l|}{ Location } \\
\hline - forehead/temporal & 156 & $10(9.1)$ & \\
\hline - peri-ocular & 73 & $1(1.7)$ & \\
\hline - nose & 212 & $6(2.3)$ & \\
\hline - paranasal & 76 & $4(7.6)$ & \\
\hline - cheek & 63 & $3(3.7)$ & \\
\hline ear/peri-auricular & 59 & $3(3.5)$ & \\
\hline - $\quad$ upper lip & 20 & - & \\
\hline - $\quad$ lips & 2 & - & \\
\hline - $\quad$ chin & 10 & - & \\
\hline $\begin{array}{ll}\text { - } & \text { vertex } \\
\text { - } & \text { neck }\end{array}$ & $\begin{array}{l}14 \\
4\end{array}$ & $\begin{array}{l}- \\
-\end{array}$ & \\
\hline Total & 689 & $27(4.5)$ & 0.7383 \\
\hline \multicolumn{4}{|l|}{ Size $(\mathrm{mm})$} \\
\hline$\quad<20 \mathrm{~mm}$ & 437 & $13(3.7)$ & \\
\hline$-\quad \geq 20 \mathrm{~mm}$ & 186 & $11(7.8)$ & \\
\hline Total & 623 & $24(4.5)$ & 0.0648 \\
\hline \multicolumn{4}{|l|}{ Histologic type } \\
\hline - $\quad$ non-aggressive & 319 & $6(2.9)$ & \\
\hline - aggressive & 372 & $21(5.8)$ & \\
\hline Total & 691 & $27(4.5)$ & 0.0150 \\
\hline \multicolumn{4}{|l|}{ Previous therapy (recurrence) } \\
\hline - $\quad$ Surgical excision & 106 & $9(8.7)$ & \\
\hline - $\quad$ Radiotherapy & 13 & $0(0.0)$ & \\
\hline Cryosurgery & 43 & $1(2.9)$ & \\
\hline Curettage + electrodesiccation & 8 & $1(12.5)$ & \\
\hline MMS & 11 & $1(0.0)$ & \\
\hline Several & 41 & $4(10.7)$ & \\
\hline - Others & 16 & $0(0.0)$ & \\
\hline Total & 238 & $16(6.7)$ & 0.5034 \\
\hline \multicolumn{4}{|l|}{ Previous BCC } \\
\hline - no BCC & 428 & $20(5.3)$ & \\
\hline - $\quad$ previous BCC & 239 & $7(3.7)$ & \\
\hline - Total & 667 & $27(4.5)$ & 0.3195 \\
\hline \multicolumn{4}{|l|}{ Mean defect size (mm) } \\
\hline$-\quad \leq 20$ & 198 & $5(2.4)$ & \\
\hline$-\quad 20-40$ & 275 & $9(3.0)$ & \\
\hline$-\quad \geq 40$ & 123 & $12(12.7)$ & \\
\hline Total & 596 & $26(4.5)$ & 0.0027 \\
\hline \multicolumn{4}{|l|}{ Mohs stages } \\
\hline-1 & 169 & $8(4.5)$ & \\
\hline-2 & 328 & $3(0.9)$ & \\
\hline-3 & 101 & $5(4.7)$ & \\
\hline - $\quad 4$ or more rounds & 91 & $11(10.8)$ & \\
\hline Total & 689 & $27(3.8)$ & 0.0013 \\
\hline
\end{tabular}

* as estimated by the Kaplan-Meier survival analysis

- no recurrences 
Large BCCs $(>3 \mathrm{~cm})$ have a higher 5 -year probability to recur $(7.8 \%)$ than smaller $(<1$ $\mathrm{cm})$ tumours $(3.7 \%)$ but this difference is not statistically significant. We found that the location of the BCC, previous therapy or a history of a previous BCC had no prognostic significance.

\section{Discussion}

Our data show that high cure rates can be obtained when high risk BCCs are treated by MMS. When reviewing the literature it became clear that although much has been written about MMS in the treatment of BCC (479 articles reporting about MMS and $\mathrm{BCC}$ ), there are only eight studies that report on valid 5-year recurrence rates which is a major criterion to judge the effectiveness of any cancer treatment (Chapter 2) (Julian and Bowers, 1997; Mohs et al., 1988; Mohs, 1986; Mohs and Zitelli, 1981; Robins et al., 1985; Sakura and Calamel, 1979; Tromovitch et al., 1966; Wennberg et al., 1999). In addition, there is a great diversity in study design and different studies are not comparable for several reasons. Some (older) articles report recurrence rates of the fixed tissue technique or combine these with the results of the fresh tissue technique (Mohs et al., 1988; Mohs and Zitelli, 1981; Sakura and Calamel, 1979; Tromovitch et al., 1966). Recently published studies report on the fresh tissue technique (Julian and Bowers, 1997; Mohs, 1986; Wennberg et al., 1999). Furthermore, these studies report about different locations and size of tumours whenever reported. In all studies recurrence rates after treatment of a primary BCC are lower than after treatment of a recurrent $\mathrm{BCC}$, around 1\% versus approximately $6-7 \%$. Recurrence rates mentioned by Wennberg et al. are much higher than recurrence rates mentioned in other studies (Wennberg et al., 1999). They explain their higher recurrence rates by being the only Mohs centre in a large area, so only very large and aggressive BCCs were treated. Wennberg et al. are the only group reporting recurrence rates by means of a survival analysis (Wennberg et al., 1999). The other authors use the strict 5-year recurrence rates, thereby leaving out the results of the patients who did not complete the 5-year follow-up period.

This study is the largest study since the reports of recurrence rates by Mohs, with a high percentage of patients with BCC who completed a 5-year follow-up. Although it is a retrospective study, the strength of this study is that the inclusion criteria for MMS did not change during the study period and a large percentage of patients completed the 5 -year follow-up period. As mentioned by reviewers previously, the best way to calculate the recurrence rate is by using survival analysis, because it takes all tumours into account for the time they have been in follow-up, even if there was no completed five-year follow-up (Silverman et al., 1991a; Thissen et al., 1999; Werlinger et al., 2002). Thissen et al. concluded in their systematic review of treatment for primary BCC that because of lack in uniformity in calculating the recurrence rates, different treatment modalities are difficult to compare (Thissen et al., 1999). However, they proved that the lowest recurrence rates are provided by MMS. They found recurrence rates for other treatment modalities between 5.3\% after surgical excision and $18.8 \%$ 
after curettage and electrodesiccation for primary BCCs (Thissen et al., 1999).

Recurrence rates after treatment of a recurrent BCC lie between $9.8 \%$ after radiotherapy and $40 \%$ after curettage and electrodesiccation (Rowe et al., 1989b). The best way to compare two treatment modalities is by a prospective randomised trial. From this large study we can conclude that very low recurrence rates after treatment of facial BCC by MMS can be obtained.

We noticed that $75 \%$ of all recurrences appeared within 3 years after the operation. This matches with the results of other reviewers of recurrence rates (Rowe et al., 1989a; Silverman et al., 1991a). Recurrences after treatment of a primary BCC appear not significantly sooner than after treatment of a recurrent BCC. However, a large percentage of recurrent BCCs still recurred after 5 years of follow-up. For this reason we recommend a follow-up period of 5 years for single primary BCCs and a period of 7 till 10 years after treatment of a recurrent $B C C$. A person with a BCC has a $44 \%$ chance of developing a second BCC (Marcil and Stern, 2000). Because the highest chance is within the first years, this follow-up period will also lead to early recognition of these BCCs.

Most $\mathrm{BCC}$ were eradicated within 2 stages suggesting that most Mohs procedures were finished in a few hours. Other authors have shown that costs of a Mohs procedure are comparable to that of a surgical excision and that cost of a Mohs procedure will rise with increasing stages (Cook and Zitelli, 1998; Welch et al., 1999). So because $71 \%$ of all BCCs was eradicated within 2 stages, we conclude that most Mohs procedures are not that time-consuming and therefore, not that expensive as sometimes is suggested. From the fact that only $25 \%$ of all BCCs was eradicated in one stage, one could conclude that only tumours with a strict indication (indistinct tumour borders, aggressive histopathologic subtype and/ or large tumours) were included for treatment by MMS. So when these strict selection criteria for MMS are lived up to, MMS is less expensive than a recurrence treated too late.

We found that predictive values for recurrence are an aggressive histopathologic subtype, 4 or more Mohs stages and a large defect size ( $>4 \mathrm{~cm}$ in diameter). We also found a significant difference between recurrence rates after a primary and a recurrent $B C C$. These predictive values are also known to be of importance in the treatment of BCC by other therapy modalities (Rodriguez-Sains et al., 1988; Rowe et al., 1989b; Silverman et al., 1992; Silverman et al., 1991b).

This study is an extension of research in MMS, first described in 1996 (Neumann et al., 1996). In that study a 5 -year recurrence rate of $2 \%$ was reported which is less than the recurrence rates in this study. In that group of patients an extra safety margin (2-3 $\mathrm{mm}$ ) was taken after the area was tumour free. So perhaps one of the largest advantages of MMS, namely the tissue sparing aspect, is a disadvantage in these large tumours. However, compared to other treatment modalities, recurrence rates are consistently lower. We found significantly higher recurrence rates in the first two treatment years. This might be explained by the fact that in the first years that MMS was practised at the University Hospital of Maastricht, only very large, aggressive and 
recurrent tumours were treated. Another explanation might be the fact that the surgeons were less experienced indicating that the learning curve is also an important factor. A Mohs surgeon has to control besides the surgical technique also the graphically mapping and histopathological examination.

Other authors have tried to explain why recurrences still can occur after treatment with MMS, where theoretically $100 \%$ of the resection margins is viewed (Dzubow, 1988; Eliezri and Cohen, 1992; Hruza, 1994; Smeets et al., 2003). Eliezri and Cohen, and Dzubow both report cases where the scar tissue (in case of biopsy scar or a recurrent BCC) is not completely excised and therefore tumour is missed (Dzubow, 1988; Eliezri and Cohen, 1992). These cases stress the importance of complete excision of all scar tissue to ensure that all tumour cells are eradicated and to prevent a recurrence. Hruza analysed their recurrences and found an explanation for recurrence in $77 \%$ of cases (Hruza, 1994). The most common causes for recurrence were due to incomplete Mohs slides (lacking part of the epidermis or dermis) so resection margins were not completely visible and tumour could be missed. We recently reported that there is a $2 \%$ fault in detecting BCC in Mohs sections stained with haematoxylin and eosin, especially in morphea BCC (Smeets et al., 2003). Another consideration in analysis of recurrence is the possibility of non-contiguous growth of the $\mathrm{BCC}$. There has been some discussion whether, especially the superficially growing BCC, is a noncontiguously growing tumour. However, a three-dimensional study proved that even a superficial growing BCC is a contiguously growing tumour (Lang et al., 1987). So, in our opinion, if the Mohs procedure is properly performed and all scar tissue is excised, the reason for local recurrence is a technical failure and therefore complete frozen sections, visibly controlled with colour matching of the edges, are mandatory in MMS. As we mentioned before, besides a technical failure, mistakes in colouring or mapping can, especially during the training period, occur and may be a cause of recurrence.

\section{Conclusion}

Our data show that very low recurrence rates in treatment of facial BCC can be obtained even in a selected group of large and aggressive BCCs. Comparing our results with literature results MMS consistently continues to provide the lowest recurrence rates. It therefore is the treatment of first choice for primary facial BCCs of an aggressive histopathologic subtype and recurrent BCCs of the face. 
Chapter 3 


\section{Chapter 4}

\section{Surgical excision versus Mohs micrographic surgery for basal cell carcinoma of the face: a prospective randomised trial}

Nicole W.J. Smeets, Gertruud A.M. Krekels, Judith U. Ostertag, Brigitte A.B. Essers, Carmen D. Dirksen, Fred H.M. Nieman, H.A. Martino Neumann 


\section{Abstract}

\section{Background}

In terms of recurrence rates, Mohs micrographic surgery (MMS) has shown to be consistently superior to other treatment modalities for facial basal cell carcinoma (BCC). However, MMS is also a more timely and therefore a more expensive procedure than surgical excision (SE). We investigated in which facial BCC MMS was more effective than SE.

\section{Methods}

408 primary and 204 recurrent facial BCCs were included in this prospective randomised study. Patients were assigned to SE or to MMS. Analysis was by intention-to-treat .

\section{Findings}

Of the BCCs included the trial, 397 (198 MMS, 199 SE) and 201 recurrent $(99,102)$ tumour were actually treated. Of patients with primary $B C C, 21$ received both MMS en SE on different tumours. Nine recurrent BCCs had both treatments on different tumours. 66 primary en 13 recurent BCCs were lost to follow-up.

There were $5(2.9 \%)$ recurrences after SE compared with $3(1.9 \%)$ after MMS in primary BCCs after a follow-up of 30-months. There were 3 recurrences (3.3\%) after SE and none $(0 \%)$ after MMS in recurrent BCCs after a follow-up of 18 months. Both differences were not statistically significant. There were significantly more incomplete excisions in SE of primary BCCs showing aggressive histopathology ( $n=21,24 \%$ ) versus primary BCCs showing no aggressive histopathology $(n=14,12 \%)$, and of recurrent $B C C s(n=31,32 \%)$ versus primary BCCs $(n=35,18 \%)$. In case of an incomplete first excision, the final size of the defect for SE was significantly larger than for MMS. The costs of MMS were higher than those of SE.

\section{Interpretation}

Because defects are significantly larger and cosmetic results are consequently less after an incomplete SE MMS should be used for histopathologically aggressive primary facial BCCs of $1-\mathrm{cm}$ or more and for recurrent facial BCCs, even though it is more expensive. At present it is too early to arrive at a definitive conclusion about recurrence rates. However, there is a trend that lowest recurrence rates occur after MMS. 


\section{Introduction}

Skin cancer is the most common cancer in Caucasians in the world and it continues to increase. Basal cell carcinoma $(B C C)$ is the most common type of skin cancer (Holme et al., 2000; Ko et al., 1994). Although a BCC rarely metastasises, some BCCs (especially large and neglected or incompletely treated primary and recurrent tumours) may cause substantial morbidity and even mortality (Robinson and Dahiya, 2003). The following items are important in the treatment of this predominantly facial skin cancer: tumour removal (prevention of recurrent tumour), preservation of healthy skin, aesthetic outcome and costs.

A previous prospective randomised trial showed that surgery is preferable to radiotherapy in the treatment of BCC (Avril et al., 1997). The majority of BCC are treated world-wide by surgical excision (SE) (Goldberg, 1996; Motley et al., 1995). Cure rates for BCCs treated with Mohs micrographic surgery (MMS) have proved to be consistently superior to all other treatment modalities (including SE, radiotherapy and cryosurgery) (Rowe et al., 1989b; Thissen et al., 1999). However, the necessity of MMS was disputed, because the procedure is more time-consuming and therefore more expensive than SE (Lawrence, 1999; Shuster, 1999).

We report the results of the first prospective randomised trial comparing SE with MMS for primary and recurrent facial BCCs.

\section{Methods}

\section{Patients}

Patients were eligible for the primary BCC group; if they had a primary (untreated), histologically confirmed facial BCC of at least $1 \mathrm{~cm}$ in diameter, located in the $\mathrm{H}$-zone (Figure 1.5) or of an aggressive histopathological subtype (morpheaform, micronodular, BCC with squamous differentiation, trabecular, infiltrative). Patients were eligible for the recurrent $\mathrm{BCC}$ group if they had a first or second time recurring, histologically confirmed, facial BCC. Patients with a life-expectancy of less than 3 years were excluded.

The trial was approved by the ethics and scientific committee of the University Hospital Maastricht. All patients had given written informed consent to participate in the study.

\section{Randomisation and treatment}

Patients with a primary or a recurrent BCC were randomised separately for each group using a computer programme for SE or MMS. The research physician assigned patients either to MMS or SE after telephoning the secretary who performed the randomisation.

SE was performed under standard conditions at the University Hospital Maastricht or the Laurentius Hospital Roermond. The area was anaesthetised with lidocain (1\%)/ epinephrine (1:100000) and the BCC together with a precise $3 \mathrm{~mm}$ margin was excised at an angle of $90^{\circ}$ into the subcutaneous fat. The procedure took place under general anaesthesia in incidental cases. The obtained specimen was 
histopathologically examined by the "bread-loafing" (vertical sections) technique if it was $16 \mathrm{~mm}$ or less in diameter, or if larger, by the quadrant method (Rapini, 1990). The defect was immediately reconstructed or left open (in selected cases) awaiting histopathological results. In case of positive resection margins (incomplete excision), a re-excision with again a $3 \mathrm{~mm}$ margin was performed. In case of positive margins in a re-excised BCC (second incomplete excision), MMS was performed.

Patients randomly assigned to the MMS group received treatment at the University Hospital Maastricht. A precise margin of $3 \mathrm{~mm}$ was drawn around the $\mathrm{BCC}$ (in some cases after curettage). The area was anaesthetised with lidocain (1\%)/ epinephrine $(1: 100 \cdot 000)$ and bupivacaine $(0.5 \%)$ and an incision at a $45^{\circ}$ angle was made (Shriner et al., 1998). Next, a bowl-shaped specimen was obtained and processed by the laboratory technician into horizontal frozen sections. The frozen section slides were examined by a pathologist and the Mohs surgeon. If BCC was observed in the slides, a second Mohs stage took place. This procedure was repeated until the area was tumour-free. Reconstruction was immediate in most cases.

The primary outcome was recurrence, while secondary outcomes were incomplete excision, suboptimal aesthetic results and excessive costs.

\section{Photography}

Overall and close-up photographs were taken before each treatment. During both treatments, the BCCs, with and without the $3 \mathrm{~mm}$ margin and tape-measure, the defect and its reconstruction were photographed.

\section{Clinical evaluation}

The regular oncological follow-up was conducted by the patients own (referring) dermatologist. Moreover, all patients were examined at 6 and 18 months after the operation by the research physician. Photographs (overall and close-up) were also taken at that time. The aesthetic result was judged 6 and 18 months postoperatively by the patient and a selected group (the first 139 primary and the first 89 recurrent BCCs) retrospectively from the photographs by a panel of 6 individuals ( 3 professionals and 3 laymen).

\section{Cost analysis}

The total operation-related costs included the direct personnel and material costs of the surgical procedure (taking into account the costs of a possible re-excision) as well as the processing and examination of histopathological slides, pre- and post-operative visits, additional treatments and overhead costs. The personnel costs for each procedure were based on empirical time registrations by the dermatologist who performed surgery. The material- and pathology-related costs were based on actual cost prices as calculated by the financial department of the University Hospital 
Maastricht. The costs of both treatment modalities were calculated in euros for each BCC.

\section{Statistical analysis}

The study was designed to have a $90 \%$ likelihood (one-side type I error 0.05 ) in detecting a $6.5 \%$ difference in recurrence rate of primary BCC (MMS 1.5 vs. SE $8.0 \%$ ) and a $13.5 \%$ difference in recurrence rate of recurrent BCC (3.5 vs. 17.0\%). Loss to follow-up was estimated at $10 \%$ for primary and $15 \%$ for recurrent BCC. Given these figures we aimed to include 408 primary BCCs and 204 recurrent BCCs.

Recurrence rates for primary or recurrent $\mathrm{BCC}$ were analysed according to the intention-to-treat principle. Overall frequencies and percentages of recurrence are given. The percentage difference as well as their $95 \%$ confidence intervals and $p$ values were calculated using the exact method.

Other tests that were used for statistical analysis are the log-likelihood chi-square, the Mann-Whitney test (cost analysis, defect size), the Student Independent t-test (defect size), ANOVA and the Pearson product-moment correlation coefficient (aesthetic evaluation).

In all tests a p-value of less than 0.05 was considered to be statistically significant. All data were analysed by SPSS-pc, version 11.5

\section{Results}

\section{Primary BCC}

From October 1999 to January 2001, 408 primary BCCs were included. A total of 69 patients with 78 primary BCCs did not want to participate in the study, mostly because they preferred either SE or MMS.

\section{Protocol violations}

Eight randomised patients with 8 BCCs were not treated because of the following reasons; two patients died beforehand of an unrelated cause, two patients refused treatment, one patient moved to another part of the country, one patient had a large squamous cell carcinoma (SCC) on the same ear as where the BCC was located for which the ear had to be amputated, one BCC appeared to be a recurrence and was again randomised in that part of the study and one $B C C$ turned out to be actinic keratosis after revision of the histopathology. Another three biopsy-proven BCC in three patients who were treated with SE, turned out to be SCC in the excision specimen.

So a total of 11 cases were missing from the total of 408 BCCs, 5 from the SE group and 6 from the MMS group. Empirical data were present for 397 cases, 199 for the SE and 198 for the MMS group (Scheme 4.1). 


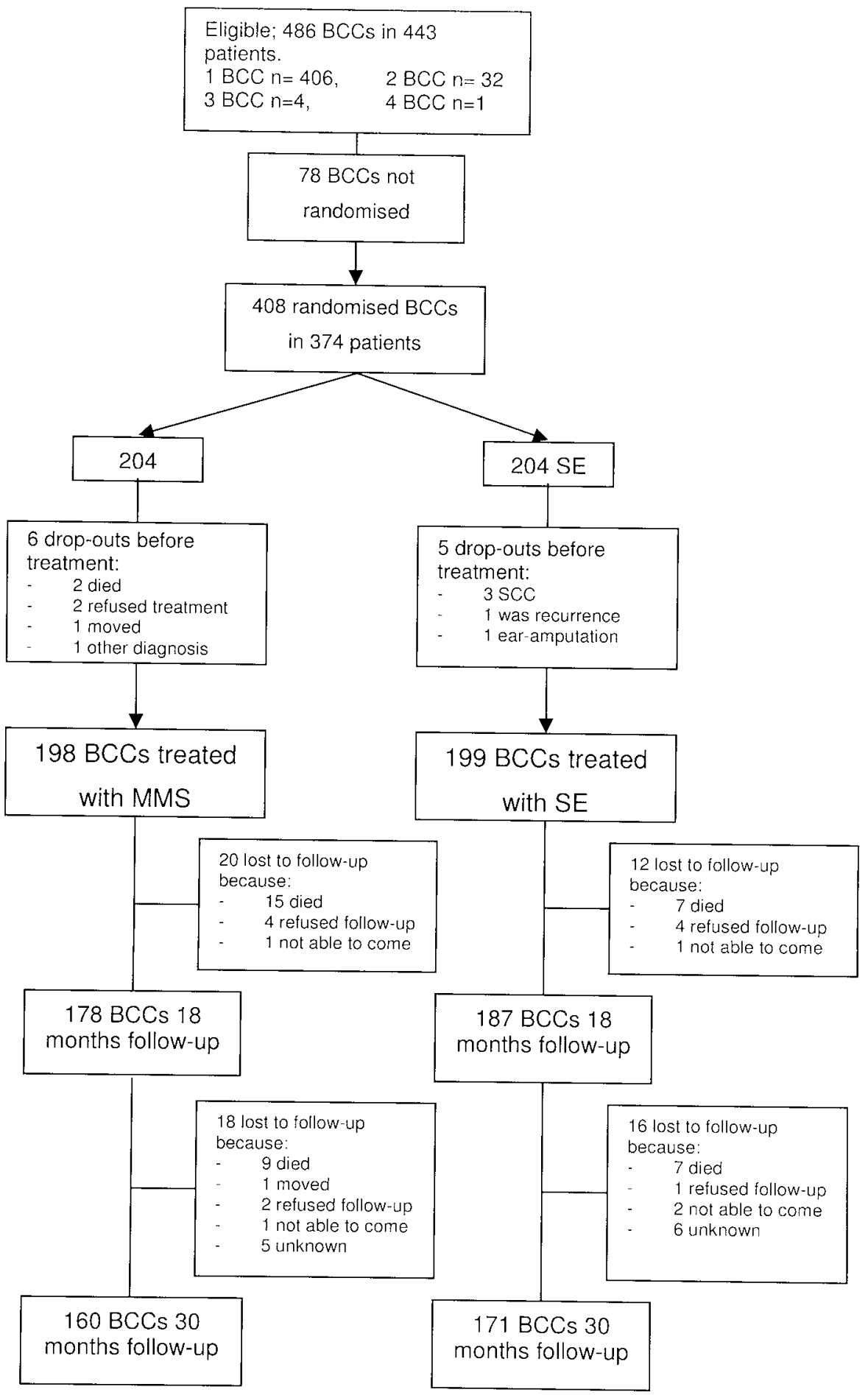

Scheme 4.1. Trial profile of primary basal cell carcinomas 


\section{Patient and BCC characteristics}

There were 342 patients who had 1 BCC, 30 patients had 2 BCCs and 2 patients had 3 BCCs (Table 4.1). A total of 374 patients had 408 BCCs and 397 BCCs (in 364 patients) were actually treated. The mean age of the patients was 67.7 years (SD $12.65)$, there were more males $(59.9 \%, n=224)$ than females $(40.1 \%, n=150)$. The majority of the patients had never had a previous BCC $(63.6 \%, n=232)$. Most BCCs were from referred patients $(62.0 \%, \mathrm{n}=232)$.

Table 4.1. Patient characteristics of primary BCCs.

\begin{tabular}{lccccc}
\hline & Number & $\%$ & Mean & Min & Max \\
\hline Number BCCs in & & & & & \\
study per patient & & & & & \\
1 BCC & 342 & 91.4 & & & \\
2 BCC & 30 & 8.0 & & & \\
3 BCC & 2 & 0.5 & & & \\
Total & 374 & 100 & & & \\
Age & & & 67.7 & 23 & 92 \\
Men & & & 67.7 & 25 & 92 \\
Women & & & 67.7 & 23 & 91 \\
Sex & & & & & \\
Men & 224 & 59.9 & & & \\
Women & 150 & 40.1 & & & \\
Total & 374 & 100 & & & \\
Previous BCC & & & & & \\
None & 232 & 63.6 & & & \\
$<3$ & 85 & 23.3 & & & \\
$>$ or 3 & 48 & 13.2 & & \\
Unknown & 9 & & & \\
Total & 364 & 100 & & \\
\hline & & & & \\
\hline & & & &
\end{tabular}

The majority of BCCs were located on the forehead/ temporal zone and on the nose or paranasal (Table 4.2). Despite randomisation, there were significantly more BCCs located in the $\mathrm{H}$-zone in the MMS group than in the SE group $(p=0.015)$. There seem to be more histopathologically aggressive type BCCs in the MMS group than in the SE group, but this difference was not significant $(p=0.067)$. The mean maximum diameter of the primary BCCs was $14.88 \mathrm{~mm}$ (SD 7.43). Tumours in the SE group were significantly larger than in the MMS group (15.97 mm vs. $13.76 \mathrm{~mm}, \mathrm{p}=0.002$ ). 
Table 4.2. Tumour characteristics of primary BCCS.

\begin{tabular}{|c|c|c|c|c|c|c|}
\hline & \multicolumn{3}{|c|}{ SE } & \multicolumn{3}{|c|}{ MMS } \\
\hline & number & $\%$ & Mean & Number & $\%$ & Mean \\
\hline \multicolumn{7}{|l|}{ Location } \\
\hline Forehead/ temporal & 55 & 31.9 & & 53 & 26.0 & \\
\hline Cheek/chin & 16 & 7.8 & & 19 & 9.3 & \\
\hline Nose/ paranasal & 62 & 30.4 & & 69 & 33.8 & \\
\hline Lips & 8 & 3.9 & & 14 & 6.9 & \\
\hline Peri-ocular & 16 & 7.8 & & 16 & 7.8 & \\
\hline Ears & 16 & 7.8 & & 9 & 4.4 & \\
\hline Peri-auricular & 21 & 10.3 & & 24 & 11.8 & \\
\hline Total & 204 & 100 & & 204 & 100 & \\
\hline \multicolumn{7}{|l|}{ H-zone } \\
\hline Yes & 196 & 96.1 & & 181 & 90.0 & \\
\hline No & 8 & 3.9 & & 20 & 10.0 & \\
\hline Unknown & 0 & & & 3 & & \\
\hline Total & 204 & 100 & & 204 & 100 & \\
\hline \multicolumn{7}{|l|}{ Hist type } \\
\hline Non-aggressive & 116 & 56.9 & & 96 & 47.8 & \\
\hline Aggressive & 88 & 43.1 & & 105 & 52.2 & \\
\hline Total & 204 & 100 & & 204 & 100 & \\
\hline Diameter $(\mathrm{mm})$ & & & 15.97 & & & 13.76 \\
\hline Area $\left(\mathrm{cm}^{2}\right)$ & & & 1.77 & & & 1.28 \\
\hline
\end{tabular}

\section{Operation characteristics}

In the SE group, 35 (18\%) primary BCCs were incompletely excised after the first excision (Table 4.3). Thirty-one BCCs were re-excised, 3 were treated by MMS and 1 refused further therapy. Four BCCs $(2 \%)$ were still incompletely excised after two excisions with a total $6 \mathrm{~mm}$ margin and were retreated by MMS. The mean number of Mohs stages was 1.77 (SD 0.71). 182 BCCs (>80\%) were completely excised after 2 Mohs stages. 
Table 4.3. Operation characteristics of primary BCCs.

\begin{tabular}{|c|c|c|c|c|c|c|c|c|}
\hline & \multicolumn{3}{|c|}{$S E$} & \multicolumn{5}{|c|}{ MMS } \\
\hline & number & $\%$ & mean & number & $\%$ & mean & $\min$ & $\operatorname{Max}$ \\
\hline Mohs rounds & & & & & & 1.77 & & \\
\hline 1 & & & & 68 & 34.3 & & & \\
\hline 2 & & & & 114 & 57.6 & & & \\
\hline 3 & & & & 13 & 6.6 & & & \\
\hline 4 & & & & 1 & 0.5 & & & \\
\hline 5 & & & & 1 & 0.5 & & & \\
\hline 6 & & & & 1 & 0.5 & & & \\
\hline Total & & & & 198 & 100 & & & \\
\hline Frozen sections & & & & & & 6.19 & 4 & 25 \\
\hline \multicolumn{9}{|l|}{ First excision } \\
\hline Complete & 164 & 82 & & & & & & \\
\hline Incomplete & 35 & 18 & & & & & & \\
\hline Total & 199 & 100 & & & & & & \\
\hline \multicolumn{9}{|c|}{$\begin{array}{l}\text { Therapy if first excision } \\
\text { was incomplete }\end{array}$} \\
\hline SE & 31 & 88.6 & & & & & & \\
\hline MMS & 3 & 8.6 & & & & & & \\
\hline no therapy & 1 & 2.8 & & & & & & \\
\hline Total & 35 & 100 & & & & & & \\
\hline \multicolumn{9}{|l|}{ Second excision } \\
\hline Complete & 27 & 87 & & & & & & \\
\hline Incomplete & 4 & 13 & & & & & & \\
\hline Total & 31 & 100 & & & & & & \\
\hline \multicolumn{9}{|c|}{$\begin{array}{l}\text { Therapy if second } \\
\text { excision was incomplete }\end{array}$} \\
\hline SE & 0 & 0 & & & & & & \\
\hline MMS & 3 & 75 & & & & & & \\
\hline no therapy & 1 & 1 & & & & & & \\
\hline Total & 4 & 100 & & & & & & \\
\hline
\end{tabular}




\section{Recurrence}

After a mean follow-up of 2.66 years (SD 0.78) there were 6 recurrences in the SE group and 3 in the MMS group. At 30 months follow-up there were $8(2.4 \%)$

recurrences from a total of $331 \mathrm{BCCs}$ (Scheme 4.1 ). Three (1.9\%) recurrences were after MMS and five (2.9\%) were after SE (Table 4.4 ). Thus, the difference is $1.0 \%$ in favour of MMS, $95 \%$ confidence interval $-2.5 \%$ to $3.7 \%(p=0.724)$.

Table 4.4. Intention-to-treat analysis of primary BCCs at 30 months.

\begin{tabular}{lccc}
\hline & MMS & SE & Total \\
\hline No recurrence & 157 & 166 & 323 \\
Recurrence & 3 & 5 & 8 \\
Total & 160 & 171 & 331 \\
\hline
\end{tabular}

\section{Recurrent BCC}

For the recurrent BCC the inclusion period lasted from October 1999 to February 2002. A total of 43 patients with 43 recurrent BCCs were not included in the study, mostly because the patient or the referring physician preferred MMS.

\section{Protocol violations}

One patient died before surgery. One patient having two BCCs died after treatment of the first $\mathrm{BCC}$ and before treatment of the second BCC. One BCC randomised in the MMS group turned out to be a third recurrence. So 3 cases were missing from a total of 204 BCCs, all in the MMS group (Scheme 4.2).

Four BCCs of four patients, although randomised to the SE group, were treated by MMS. These were large (varying from $2-5 \mathrm{~cm}$ ) recurrent tumours, that required general anaesthesia and were located on the medial canthus, the upper lip or the nose.

According to the intention-to-treat principle of the protocol, the follow-up and results of these four BCCs were analysed as belonging to the SE group.

\section{Patient and BCC characteristics}

Of the 204 randomised BCCs, 201 were actually treated. Tumours randomised to SE but treated by MMS were excluded from the empirical analysis of the operation characteristics. According to the intention-to-treat principle of the protocol, they were included in other analyses.

One-hundred-eighty patients had 1 BCC, 10 patients had 2 BCCs and one patient had 4 recurrent BCCs. Thus there were 191 patients with 204 recurrent BCCs. A total of 189 patients with 201 tumours were treated because one other patient died before the treatment, one patient with two BCCs died before the second BCC was treated and one patient had 1 falsely included BCC. 


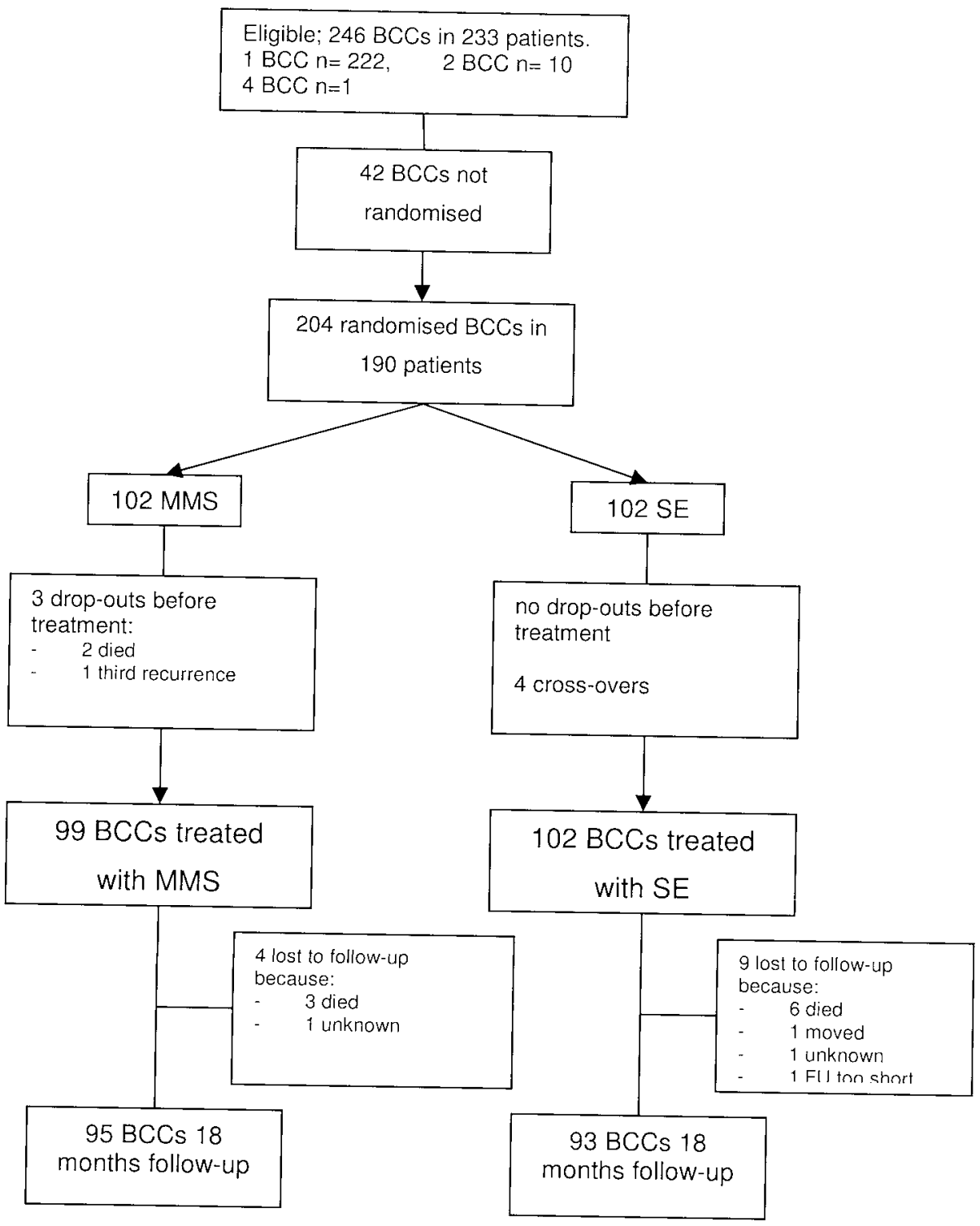

Scheme 4.2. Trial profile of recurrent basal cell carcinoma 
The mean age of the patients was 67.9 years (SD 11.7), 110 males and 81 females (Table 4.5). There was a previous BCC in $56 \%(n=106)$ of the patients. Eighty-seven percent $(n=166)$ of the patients were referred to the University Hospital Maastricht.

Table 4.5. Patient characteristics of recurrent BCCs.

\begin{tabular}{|c|c|c|c|c|c|}
\hline & Number & $\%$ & mean & $\min$ & Max \\
\hline \multicolumn{6}{|c|}{$\begin{array}{l}\text { Number BCCs in } \\
\text { study per patient }\end{array}$} \\
\hline $1 \mathrm{BCC}$ & 180 & 94.2 & & & \\
\hline $2 \mathrm{BCC}$ & 10 & 5.2 & & & \\
\hline $4 \mathrm{BCC}$ & 1 & 0.5 & & & \\
\hline Total & 191 & 100 & & & \\
\hline Age & & & 67.9 & 31 & 95 \\
\hline Men & & & 67.0 & 31 & 89 \\
\hline Women & & & 69.2 & 35 & 95 \\
\hline \multicolumn{6}{|l|}{ Sex } \\
\hline Men & 110 & 57.6 & & & \\
\hline Women & 81 & 42.4 & & & \\
\hline Total & 191 & 100 & & & \\
\hline \multicolumn{6}{|c|}{ Previous BCC } \\
\hline None & 84 & 44.2 & & & \\
\hline$<3$ & 71 & 37.4 & & & \\
\hline$>$ or 3 & 35 & 18.4 & & & \\
\hline Unknown & 1 & & & & \\
\hline Total & 191 & 100 & & & \\
\hline
\end{tabular}

Most recurrent BCCs were located on the forehead/ temporal zone $(41.1 \%, n=84)$ and on the nose $(25.5 \%, n=52$, table 4.6$)$. There were slightly more histopathologically aggressive than non-aggressive type BCC (54.0\%, $n=109$ vs. $46.0 \%, n=93,2$ missing). The mean diameter of the recurrent BCC was $18.64 \mathrm{~mm}$ (SD 11.38). 
Table 4.6. Tumour characteristics of recurrent BCCS.

\begin{tabular}{|c|c|c|c|c|c|c|}
\hline & \multicolumn{3}{|c|}{$S E$} & \multicolumn{3}{|c|}{ MMS } \\
\hline & number & $\%$ & Mean & number & $\%$ & Mean \\
\hline \multicolumn{7}{|l|}{ Location } \\
\hline Forehead/temporal & 46 & 45.1 & & 38 & 37.3 & \\
\hline Cheek/chin & 10 & 9.8 & & 12 & 11.8 & \\
\hline Nose/ paranasal & 29 & 28.4 & & 23 & 22.5 & \\
\hline Lips & 1 & 1.0 & & 6 & 5.9 & \\
\hline Peri-ocular & 5 & 4.9 & & 6 & 5.9 & \\
\hline Ears & 4 & 3.9 & & 8 & 7.8 & \\
\hline Peri-auricular & 7 & 6.9 & & 9 & 8.8 & \\
\hline Total & 102 & 100 & & 102 & 100 & \\
\hline \multicolumn{7}{|l|}{ H-zone } \\
\hline Yes & 81 & 79.4 & & 85 & 83.3 & \\
\hline No & 21 & 20.6 & & 17 & 16.7 & \\
\hline Total & 102 & 100 & & 102 & 100 & \\
\hline \multicolumn{7}{|l|}{ Hist type } \\
\hline Non-aggressive & 52 & 51.5 & & 41 & 40.6 & \\
\hline Aggressive & 49 & 48.5 & & 60 & 59.4 & \\
\hline Unknown & 1 & & & 1 & & \\
\hline Total & 102 & 100 & & 102 & 100 & \\
\hline Diameter (mm) & & & 19.42 & & & 17.86 \\
\hline Area $\left(\mathrm{cm}^{2}\right)$ & & & 2.70 & & & 1.97 \\
\hline
\end{tabular}

\section{Operation characteristics}

Thirty-two percent $(n=31)$ of the recurrent BCCs were incompletely excised after the first excision in the SE group. Twenty-five of these BCCs were re-excised, 5 BCCs were treated by MMS and one, superficial growing BCC, was treated by photodynamic therapy (PDT). Eight percent $(n=8)$ of all BCCs were incompletely excised after the second excision (within a total $6 \mathrm{~mm}$ margin) and were retreated by MMS. The mean number of Mohs stages in MMS was 2.00 (SD 0.93); tumour was completely eradicated in $78 \%(n=78)$ after 2 stages. 
Table 4.7. Operation characteristics of recurrent BCCS.

\begin{tabular}{|c|c|c|c|c|c|c|c|c|}
\hline & \multicolumn{3}{|c|}{ SE } & \multicolumn{5}{|c|}{ MMS } \\
\hline & Number & $\%$ & Mean & Number & $\%$ & Mean & $\operatorname{Min}$ & Max \\
\hline Mohs rounds & & & & & & 2.00 & 1 & 6 \\
\hline 1 & & & & 31 & 31 & & & \\
\hline 2 & & & & 47 & 47 & & & \\
\hline 3 & & & & 16 & 16 & & & \\
\hline 4 & & & & 3 & 3 & & & \\
\hline 5 & & & & 3 & 3 & & & \\
\hline 6 & & & & 0 & 0 & & & \\
\hline Total & & & & 100 & 100 & & & \\
\hline Frozen sections & & & & & & 7.27 & 3 & 34 \\
\hline \multicolumn{9}{|l|}{ First excision } \\
\hline Complete & 67 & 68.4 & & & & & & \\
\hline Incomplete & 31 & 31.6 & & & & & & \\
\hline Total & 98 & 100 & & & & & & \\
\hline \multicolumn{9}{|c|}{$\begin{array}{l}\text { Therapy if first excision } \\
\text { was incomplete }\end{array}$} \\
\hline Excision & 25 & 80.7 & & & & & & \\
\hline Mohs & 5 & 16.1 & & & & & & \\
\hline no therapy & 0 & 0 & & & & & & \\
\hline PDT & 1 & 3.2 & & & & & & \\
\hline Total & 31 & 100 & & & & & & \\
\hline \multicolumn{9}{|l|}{ Second excision } \\
\hline Complete & 17 & 68 & & & & & & \\
\hline Incomplete & 8 & 32 & & & & & & \\
\hline Total & 25 & & & & & & & \\
\hline \multirow{2}{*}{\multicolumn{9}{|c|}{$\begin{array}{l}\text { Therapy if second } \\
\text { excision was incomplete }\end{array}$}} \\
\hline & & & & & & & & \\
\hline Excision & 1 & 12.5 & & & & & & \\
\hline Mohs & 7 & 87.5 & & & & & & \\
\hline no therapy & 0 & 0 & & & & & & \\
\hline PDT & 0 & 0 & & & & & & \\
\hline Total & 8 & 100 & & & & & & \\
\hline
\end{tabular}




\section{Recurrences}

There were 2 recurrences after MMS and 8 after SE after a mean follow-up of 2.08 years (SD 0.75). One-hundred-eighty-eight (94\%) patients completed a follow-up of 18 months (Scheme 4.2). At 18 months follow-up, there were no recurrences after MMS and 3 recurrences $(3.2 \%$ ) after SE (Table 4.8 ). The difference is $3.2 \%$ in favour of MMS, 95\% confidence interval $-2.0 \%$ to $5.0 \%(p=0.119)$.

Table 4.8. Intention-to-treat analysis of recurrent BCCs at 18 months.

\begin{tabular}{lccc}
\hline & MMS & SE & Total \\
\hline No recurrence & 95 & 90 & 185 \\
Recurrence & 0 & 3 & 3 \\
Total & 95 & 93 & 188 \\
\hline
\end{tabular}

\section{Primary and recurrent $B C C$}

incomplete excisions

$18 \%$ of all primary BCCs and $32 \%$ of all recurrent BCCs were incompletely excised in the SE group after the first excision $(p=0.007)$. There were significantly more incomplete excisions of primary BCCs with aggressive histopathology $(24 \%(n=21)$ versus $12 \%(n=14))$ than of the non-aggressive type $(p=0.022$; Table 4.9$)$.

Table 4.9. The relationship between (in) completeness of excision for primary BCCs and clinical parameters.

\begin{tabular}{|c|c|c|c|c|c|c|c|}
\hline & \multicolumn{3}{|c|}{ Complete } & \multicolumn{3}{|c|}{ Incomplete } & \multirow[b]{2}{*}{$p=$} \\
\hline & numbers & $\%$ & mean & numbers & $\%$ & mean & \\
\hline \multicolumn{8}{|l|}{ Histopathology } \\
\hline Non-aggressive & 101 & & & 14 & 12.2 & & \\
\hline Aggressive & 63 & & & 21 & 25.0 & & 0.022 \\
\hline Total & 164 & & & 35 & & & \\
\hline \multicolumn{8}{|l|}{ Location } \\
\hline Forehead/temp & 54 & & & 10 & 16 & & \\
\hline Cheek/chin & 12 & & & 3 & 19 & & \\
\hline Nose/paranasal & 50 & & & 11 & 18 & & \\
\hline Lips/mouth & 8 & & & 0 & 0 & & \\
\hline Peri-ocular & 12 & & & 4 & 25 & & \\
\hline Ears & 8 & & & 6 & 43 & & \\
\hline Peri-auricular & 20 & & & 1 & 5 & & 0.066 \\
\hline Total & 164 & & & 35 & & & \\
\hline \multicolumn{8}{|l|}{ Size } \\
\hline Diameter (mm) & & & 15.25 & & & 16.43 & 0.298 \\
\hline Area $\left(\mathrm{cm}^{2}\right)$ & & & 1.61 & & & 1.88 & 0.360 \\
\hline
\end{tabular}


Furthermore there was a strong relationship between incomplete excision and location of primary BCC. $25 \%$ percent $(n=4)$ of the peri-ocular and $43 \%(n=6)$ of the BCCs on the ear were incompletely excised. However, this difference was not statistically significant $(p=0.066)$.

\section{Defect size}

The mean defect size after MMS was similar to the mean defect size after SE (Table 4.10). However, in cases in which more than one excision (SE) or two or more Mohs stages were required to eradicate all tumour, defects after SE were significantly larger than after MMS for primary $(p<0.001)$ and recurrent BCCs $(p=0.026)$.

Table 4.10. Comparison of defect sizes following multiple Mohs stages or incomplete SE.

\begin{tabular}{|c|c|c|c|c|c|c|}
\hline Defect $\left(\mathrm{cm}^{2}\right)$ & $\begin{array}{l}\text { Overall } \\
\text { mean }\end{array}$ & $\begin{array}{l}\text { Standard } \\
\text { deviation }\end{array}$ & $\mathrm{p}={ }^{* 1}$ & $\begin{array}{c}\text { Mean of } \\
\text { incomplete } \\
\text { excision/ MMS } \\
\text { with more than } 1 \\
\text { stage }\end{array}$ & $\begin{array}{l}\text { Standard } \\
\text { deviation }\end{array}$ & $p={ }^{* 2}$ \\
\hline \multicolumn{7}{|l|}{ Primary } \\
\hline SE & 4.64 & 3.62 & & 8.66 & 4.15 & \\
\hline MMS & 4.06 & 4.85 & 0.386 & 4.86 & 7.55 & $<0.001$ \\
\hline \multicolumn{7}{|l|}{ Recurrent } \\
\hline SE & 7.78 & 10.11 & & 14.52 & 15.28 & \\
\hline MMS & 7.50 & 8.38 & 0.598 & 7.95 & 8.11 & 0.026 \\
\hline
\end{tabular}

\section{Postoperative results}

There was no difference between the complications of SE and MMS in the primary BCC group. There were significantly more complications after SE than after MMS ( $n=19,19 \%$ vs. $n=8,8 \% ; p=0.021$ ) in recurrent BCCs. Complications included wound infections, necrosis of grafts, postoperative bleeding or a combination of these.

\section{Aesthetic results}

Overall, there was no significant difference between MMS and SE. The aesthetic outcome of a primary BCC was assessed significantly better than a recurrent BCC $\left(F_{(1.224)}=4.34, p=0.038\right)$. Cosmetic results decreased significantly with increasing defect size for both primary $(r=0.383, p<0.001)$ and recurrent BCCs $(r=0.351$, $p=0.001)$. See also Chapter 5 . 


\section{Cost analysis}

For primary BCC, the personnel costs of MMS (253.50 euros, SD 106.94) were significantly higher than personnel costs of a single SE (80.40 euros, SD 45.71; $\mathrm{p}<0.001$ ). Also for recurrent BCC the personnel costs of MMS (304.17 euros, SD 45.71) were significantly higher than those of a single SE (82.46 euros, SD 58.60; $p<0.001$ ). The total operative costs for a primary BCC were 798.07 euros for $S E$ and 1050.35 euros for MMS ( $p<0.001$ ). For a recurrent BCC these costs amount to 904.35 euros for SE and 1136.01 euros for MMS $(p<0.001)$.

\section{Discussion}

The results of this study show that there are fewer recurrences after MMS than after $\mathrm{SE}$ in the treatment of primary and recurrent facial BCC. However, this difference was not statistically significant. Moreover, the $95 \%$ confidence intervals made it unlikely that the benefit of MMS would be more than $3.7 \%$ in primary $\mathrm{BCC}$ or more than $5.0 \%$ in recurrent BCC. This is considerably smaller than the differences postulated in our power analysis that was mostly based on retrospective studies. Of course, a five-year follow-up period is required to determine definite recurrence rates in both groups. However, our preliminary results show that there is a trend that lower recurrence rates are obtained after MMS. Comparing our results with the short-term recurrence rates reported by Rowe et al. we noted similar recurrence rates in primary BCCs whereas we obtained much lower recurrence rates in recurrent BCCs (Rowe et al., 1989a; Rowe et al., 1989b). In a study comparing the recurrence rate and the aesthetic outcome of radiotherapy versus surgery (intra-operative frozen sections), it was shown that radiotherapy is inferior to surgical treatment after a follow-up of 4 years (Avril et al., 1997).

This is the first prospective randomised trial comparing MMS and SE in the treatment of a large group of BCCs. However, it is possible that the groups were not large enough to detect a significant difference. As in the daily practice, a small number of patients are lost to follow-up.

It was consistently shown in the past that MMS has the lowest recurrence rates in $\mathrm{BCC}$ compared to all other treatment modalities. For MMS recurrence rates of 1.0 $1.1 \%$ were reported for primary $\mathrm{BCC}$ and $5.6 \%$ for recurrent $\mathrm{BCC}$, whereas for SE these rates were $5.3-10.1 \%$ for primary $\mathrm{BCC}$ and $17.4 \%$ for recurrent $\mathrm{BCC}$ (Rowe et al., 1989a; Rowe et al., 1989b; Thissen et al., 1999). The present study is different from the earlier studies not only in that we compared two treatments prospectively, but aiso because the surgical margins in both treatment modalities were exactly $3 \mathrm{~mm}$. Although in MMS smaller margins are more common, this margin was chosen to standardise both treatment modalities.

Notably we found a substantially higher percentage of incomplete excisions and lower recurrence rate in the SE group in this study than reported elsewhere. Several investigators have reported that complete excisions with $95 \%$ accuracy may be achieved using margins varying from 2 to $4 \mathrm{~mm}$ (Bisson et al., 2002; Epstein, 1973; 
Lalloo and Sood, 2000; Wolf and Zitelli, 1987). Very recently, authors state that a margin of $3 \mathrm{~mm}$ for BCCs with distinct tumour borders and $4 \mathrm{~mm}$ for others should be sufficient for $96 \%$ of all BCCs (Thomas et al., 2003). However, these studies reported cases of tumours which were mostly well-defined and with a mean diameter of approximately $1 \mathrm{~cm}$. Unfortunately, there is no uniformity about excision margins. According to Breuningers analysis of excision margins in 2016 BCCs, much larger excision margins are required (Breuninger and Dietz, 1991). He advised to excise a $\mathrm{BCC}$ of less than $10 \mathrm{~mm}$ with $5.5 \mathrm{~mm}$ margin, a BCC of more than $20 \mathrm{~mm}$ with 13.3 $\mathrm{mm}$ margin and aggressive type or recurrent $\mathrm{BCC}$ s with even larger margins. Ratner et al. observed that without curettage before the excision, the tumour was incompletely excised in $57.9 \%$ of the cases with a $3 \mathrm{~mm}$ margin excision (Ratner and Bagiella, 2003). With curettage, $76.6 \%$ of all BCCs was eradicated after 1 Mohs stage. However, the histopathological subtype was not mentioned. Curettage may help to delineate the tumour borders especially in nodular BCCs (Ratner and Bagiella, 2003). The fact that we curettaged the BCCs in MMS probably had no influence on the larger final defect size in SE because incomplete excisions were mostly encountered in aggressively growing BCCs. In this study we observed no positive correlation between tumour size and incomplete excision. Although larger margins would lower the rate of incomplete excisions, it would also cause considerably more aesthetic and functional problems, which would in most cases be unnecessary. Another advantage of MMS in aggressively growing BCCs is the nearly $100 \%$ margin control in histopathology so that even small tumour nests are detected that might be missed in conventional histopathology. The number of aggressive primary BCCs was in the MMS group not significantly higher than in the SE group. This may explain why there were more BCCs that required a second Mohs stage than a second excision.

Since not all incompletely excised BCCs recur (30-41\%), (De Silva and Dellon, 1985; Robinson and Fisher, 2000) there is discussion whether all incompletely excised BCCs need to be re-excised or to wait if a recurrence appears (Friedman et al., 1997; Grabski and Salasche, 1998; Kumar et al., 2002; Telfer et al., 1999). However, treatment of a recurrence leads to larger defects, even higher recurrence rates and may lead to extra aggressiveness like extensive local destruction, invasion of nerves or other vital structures and even metastasis of the tumour (De Silva and Dellon, 1985). Therefore, a direct re-excision should follow in case of an incomplete excision (De Silva and Dellon, 1985; Friedman et al., 1997; Telfer et al., 1999). In this study, all incompletely excised BCCs were re-treated immediately. This consequential approach may explain the lower recurrence rates obtained in this study after SE compared with those reported in the literature (Rowe et al., 1989a; Rowe et al., 1989b; Thissen et al., 1999).

It was remarkable in this study that in recurrent BCCs more complications occurred after SE than after MMS. This is explained by the fact that more operations were needed to eradicate all tumour and therefore the chance of a complication per tumour increased. 
There are no published randomised studies that compare excision margins with the recurrence rate and the rate of incomplete excision. We observed that SE in primary BCCs with aggressive histopathology resulted in significantly more incomplete excisions than in primary BCCs without aggressive histopathology. It was reported previously that an aggressive histopathology led to more incomplete excisions because of subclinical extensions (Batra and Kelley, 2002; Breuninger and Dietz, 1991; Jacobs et al., 1982; Sexton et al., 1990). We observed that in incompletely excised BCCs the defect size increased significantly and the aesthetic result also decreased. This increase in defect size, and the consequently decrease in aesthetic outcome, was significantly less in MMS with more than 1 stage. This is explained by the graphical mapping in MMS that allows the surgeon to preserve healthy skin and to excise only where tumour cells remain. The complete scar is re-excised in SE. Operative costs of MMS are significantly higher than those of SE. The largest part of this cost-difference can be explained by the fact that MMS is more time-consuming and therefore personnel costs are higher.

In this trial (the largest prospective study so far in patients with facial BCC) treatment with MMS lowered the recurrence rate by $1.0 \%$ for primary $\mathrm{BCC}$ at 30 months postoperatively compared with SE and by $3.2 \%$ at 18 months postoperatively for recurrent BCC. Although this is not statistically significant, there is a tendency that recurrence rates are lower in MMS than in SE. Furthermore, $24 \%$ of all aggressive type BCCs of $1 \mathrm{~cm}$ or more and $32 \%$ of all recurrent BCCs were incompletely excised with a $3 \mathrm{~mm}$ margin. It is preferable to use MMS for these BCCs to avoid larger defects, a poor aesthetic outcome, and functional problems.

\section{Acknowledgements}

We thank the patients who agreed to participate in this study.

The study was financed by the Dutch fund for Investigative medicine. This is a governmental institution financing research to improve health care in the Netherlands. Prof. Dr. M.H. Prins, Department of Clinical Epidemiology and Medical Technology Assessment, University Hospital Maastricht is thanked for helping with the statistical analysis.

Dr. B. Tank, department of Dermatology and Venereology, Erasmus MC Rotterdam, is thanked for correcting the English. 
Chapter 4 


\section{Chapter 5}

\section{Cosmetic results of treatment of facial basal cell carcinoma; a comparison between Mohs micrographic surgery and surgical excision}

Nicole W.J. Smeets, Judith U. Ostertag, Fred H.M. Nieman, Gertruud A.M. Krekels, H.A. Martino Neumann

Submitted 


\section{Abstract}

Background. The cosmetic results after surgical excision (SE) of facial basal cell carcinoma (BCC) have proven to be superior to both radiotherapy and cryosurgery. Good cosmetic results after treatment of facial BCC with Mohs micrographic surgery (MMS) are reported, but no comparative study has been performed so far.

Objective. To compare treatment with MMS to treatment with SE in a randomised group of tumours and establish whether treatment with MMS yields a better aesthetic result.

Methods. Patients and a panel scored the aesthetic result of the scar after SE and MMS at 6 and 18 months postoperatively.

Results. Overall, the cosmetic results of SE and MMS in the treatment of facial BCC were similar. The mean cosmetic result after treatment of a primary $\mathrm{BCC}$ was significantly better than after treatment of a recurrent BCC. In case of an incomplete excision or a Mohs procedure of 2 stages or more, the mean defect size showed a significantly larger increase after SE than after MMS. Cosmetic results deteriorated significantly as the defect size increased.

Conclusion. In a large group of identical BCCs, the cosmetic results after treatment with MMS and SE are similar. However, for those facial BCCs that run an increased risk of being incompletely excised, MMS results in a significantly smaller defect and therefore provides a better cosmetic outcome. 


\section{Introduction}

As around $80 \%$ of all BCCs are located in the face, preservation of healthy skin and an excellent cosmetic outcome are important in treatment of BCC (Coebergh et al., 1991; Gallagher et al., 1990; Holme et al., 2000; Kumar et al., 2002). Two studies comparing the cosmetic result of radiotherapy versus surgical excision (SE) and cryosurgery versus SE have demonstrated that results are better after surgery (Petit et al., 2000; Thissen et al., 2000a). Mohs micrographic surgery (MMS) is a specialized surgical technique in which complete tumour eradication is accompanied by conservancy of healthy tissue (Neumann et al., 1996). There have been reports of good cosmetic results after MMS, but so far no comparative study has been performed to substantiate this claim (Wennberg et al., 1999).

Surgery is the most frequently applied treatment modality for BCC worldwide (Bower et al., 2001; Goldberg, 1996; Kuijpers et al., 2002). In 1999 we started a prospective randomised comparative trial in the treatment of $\mathrm{BCC}$ with MMS as opposed to SE, to determine for which BCC MMS is indicated. Next to this trial, we evaluated the cosmetic outcome after both treatment modalities to determine whether there is a subgroup of BCCs that show a better aesthetic result after treatment with MMS than after treatment with SE.

\section{Methods}

\section{- Study design}

The prospective randomised comparative trial included 408 primary (untreated) and 204 recurrent BCCs (Chapter 4 ). The inclusion criteria for this study were: a primary $\mathrm{BCC}$ of $1 \mathrm{~cm}$ or more and an aggressive histopathologic subtype (morphea,

micronodular and BCC with squamous differentiation) located in the face, or a BCC of $1 \mathrm{~cm}$ or more located in the $\mathrm{H}$-zone of the face (Figure 1.5). All first and second recurrent BCC located in the face could be included. All patients signed an informed consent form. The study was approved by the medical ethics committee of the University Hospital Maastricht. To evaluate the cosmetic results, an aselect sample of the first 151 primary and 95 recurrent randomised BCCs was used and these results were evaluated retrospectively.

\section{- Treatment methods}

After randomisation, the BCC was treated by SE or MMS. In both procedures the tumour was delineated with a $3 \mathrm{~mm}$ margin. We made the decision for this standard margin of $3 \mathrm{~mm}$ in both treatment modalities to enable proper comparison between the two. The excision was performed at a $90^{\circ}$ angle in SE and at a $45^{\circ}$ angle in MMS (Shriner et al., 1998). In MMS the defect was reconstructed on the same day. In SE the defect was either reconstructed immediately or left open in await of histopathologic control and was reconstructed one week later after "refreshing" the wound edges with a curette. With the exception of four defects of primary BCCs and 2 defects of recurrent $\mathrm{BCCs}$ that were reconstructed by the plastic surgeon, all other defects were 
reconstructed by the operating dermatologist. In case of incomplete excision (SE), a re-excision was carried out. In case of incomplete re-excision, the BCC was treated by MMS.

\section{- Assessment of cosmetic results}

\section{By patient}

At 6 and 18 months postoperatively, patients assessed the aesthetic appearance of the scar and noted their score on a four-point scale (excellent, good, fair and bad).

By panel

The panel consisted of three professionals (a dermatologist/ Mohs surgeon, a plastic surgeon and a dermatologic nurse) and three laymen (a civil engineer, a senior m.t.a. researcher and a skin therapist). They assessed the cosmetic result of the scar, blinded to treatment modality and time, on the basis of digital photographs. At 6 and 18 months postoperatively, standard photographs of the scar were taken with operation light in the plane of the scar. An overall picture showed the whole face and a close-up picture showed the scar and its immediate surrounding area. The photographs were not manipulated with an imaging program.
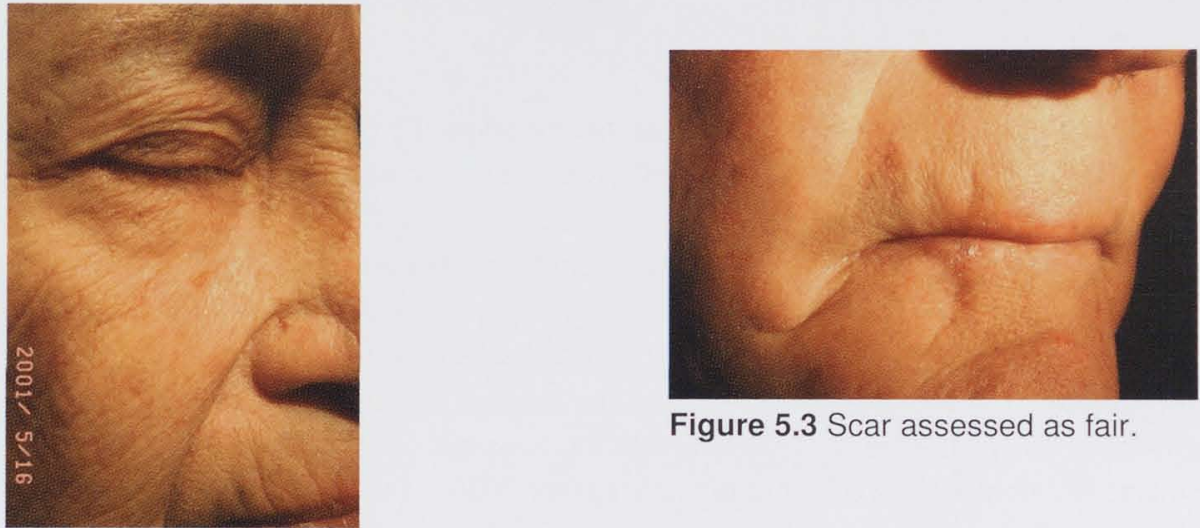

Figure 5.3 Scar assessed as fair.

Figure 5.1 Scar assessed as

excellent.

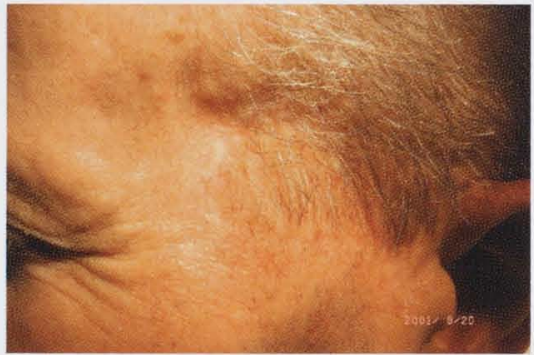

Figure 5.2 Scar assessed as good.

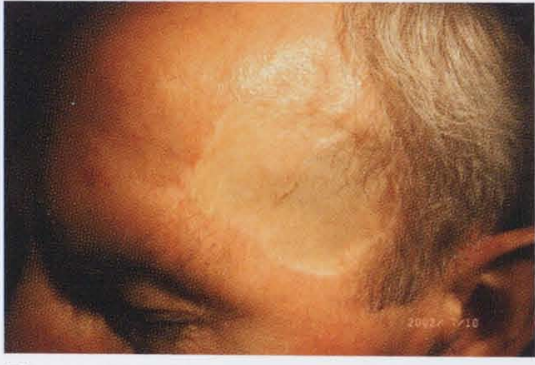

Figure 5.4 Scar assessed as bad. 
They were shown in random order on a computer by means of a Power Point (Microsoft(B) presentation which showed an overall and a close-up photo of each scar next to each other. All panel members noted their score individually on a four-point scale (excellent, good, fair and bad). Examples of scars that were given an excellent (1), good (2), fair (3) or bad (4) score by all panel members are shown in figures 5.15.4. If panel members were unable to perceive a scar, they could score "nonapplicable" on the registration form.

Statistical analysis

Means and standard deviations are calculated for the complete, non-missing (i.e. balanced) set of data. If panel members scored 'non-applicable' on their scoring form, their evaluations were transformed into 'excellent'.

Fixed-factors Analysis of Variance (ANOVA) is done for 18 months evaluations with treatment modality, type of panel judge (layman or professional) and type of tumour (primary or recurrent) as between factors. Fixed-factors repeated measures ANOVA with the same between factors is done to test rating differences within time ( 6 and 18 months) between laymen and professionals, and between patient and laymen panel members. Mixed-model repeated measures ANOVA is done to test for the difference in time of the evaluation of panel members, in which the random factor ('judge number') is nested within fixed factor 'type of judge' (layman or professional): this is done by a quasi-F-ratio (Kirk, 1982). To assess the relationship with typical characteristics of the operated area (localization, histologic type, diameter in $\mathrm{mm}$, reconstruction type and defect size in $\mathrm{cm}^{2}$ ) fixed-factors (repeated) analysis of covariance (ANCOVA) is done.

In testing, a p-value of less than 0.05 is considered to be statistically significant. The quasi-F test is calculated with the GENOVA-program (version 2.1) of J.E.Crick and R.L.Brennan, and all other types of analysis are done with SPSS-pc, version 11.0 (SPSS-inc., Chicago, III).

\section{Results}

\section{Primary BCC}

The cosmetic results of 151 primary BCCs were assessed. Due to missing data at either 6 or 18 months postoperatively, 12 cases had to be excluded from analysis, which left 134 patients with 139 primary BCCs. As some patients were unable to judge the aesthetic result due to its localization (e.g. retro-auricular), the patient analysis reflects the complete data for just 118 scars.

The mean age of the patients was $66.4 \pm 13.6$ years with male patients ( 82 or $61 \%$ ) outnumbering female patients (52 or $39 \%$ ).

Tumour characteristics regarding localization, histologic subtype and size are noted in Table 5.1, operation characteristics in Table 5.2. 
Table 5.1. Tumour characteristics of primary and recurrent BCC.

\begin{tabular}{|c|c|c|c|c|c|c|c|c|c|c|}
\hline & \multicolumn{5}{|c|}{ Primary } & \multicolumn{5}{|c|}{ Recurrent } \\
\hline & \multicolumn{2}{|c|}{ MMS } & \multicolumn{2}{|c|}{ SE } & \multirow[b]{2}{*}{ Total } & \multicolumn{2}{|c|}{ MMS } & \multicolumn{2}{|c|}{ SE } & \multirow[b]{2}{*}{ Total } \\
\hline & $N(\%)$ & $\begin{array}{c}\text { Mean } \\
\pm S D \\
\end{array}$ & $N(\%)$ & $\begin{array}{c}\text { Mean } \\
\pm S D\end{array}$ & & $N(\%)$ & $\begin{array}{c}\text { Mean } \\
\pm S D\end{array}$ & $N(\%)$ & $\begin{array}{c}\text { Mean } \\
\pm S O\end{array}$ & \\
\hline \multicolumn{11}{|l|}{ Localization } \\
\hline Forehead/ temp. & $18(26)$ & & $23(32)$ & & 41 & $14(28)$ & & $18(46)$ & & 32 \\
\hline Cheek/chin & $9(13)$ & & $5(7)$ & & 14 & $6(12)$ & & $2(5)$ & & 8 \\
\hline Nose/paranasal & $19(28)$ & & $19(27)$ & & 38 & $11(22)$ & & $13(33)$ & & 24 \\
\hline Lips & $5(7)$ & & $5(7)$ & & 10 & $3(6)$ & & - & & 3 \\
\hline Peri-ocular & $8(12)$ & & $4(6)$ & & 12 & $5(10)$ & & $1(3)$ & & 6 \\
\hline Ears & $3(5)$ & & $3(4)$ & & 6 & $5(10)$ & & $2(5)$ & & 7 \\
\hline Peri-auricular & $6(9)$ & & $12(17)$ & & 18 & $6(12)$ & & $3(8)$ & & 9 \\
\hline Total & $68(100)$ & & $\begin{array}{c}71 \\
(100)\end{array}$ & & 139 & $50(100)$ & & $\begin{array}{c}39 \\
(100)\end{array}$ & & 89 \\
\hline \multicolumn{11}{|l|}{ Histologic type } \\
\hline Non-aggressive & $29(43)$ & & $37(52)$ & & 66 & $20(40)$ & & $24(62)$ & & 45 \\
\hline Aggressive & $39(57)$ & & $34(48)$ & & 73 & $30(60)$ & & $15(38)$ & & 44 \\
\hline Total & $68(100)$ & & $\begin{array}{c}71 \\
(100)\end{array}$ & & 139 & $50(100)$ & & $\begin{array}{c}39 \\
(100)\end{array}$ & & 89 \\
\hline \multirow{2}{*}{ Diameter } & & 14.51 & & 16.33 & 15.43 & & 16.88 & & 16.56 & 16.74 \\
\hline & & \pm 7.08 & & \pm 8.22 & \pm 7.70 & & \pm 10.79 & & \pm 7.82 & \pm 9.55 \\
\hline \multirow{2}{*}{ Area $\left(\mathrm{cm}^{2}\right)$} & & 1.40 & & 1.83 & 1.62 & & 1.81 & & 1.59 & 1.71 \\
\hline & & \pm 1.31 & & \pm 2.02 & \pm 1.71 & & \pm 2.70 & & \pm 1.32 & \pm 2.19 \\
\hline
\end{tabular}

The panel assessed the mean cosmetic result as $2.14 \pm 0.68$ on a scale of 1 to 4 , summed over both time and treatment modalities. There was no significant difference between the mean cosmetic result after MMS $(2.33 \pm 0.66)$ and SE $(2.05 \pm 0.69$; $p=0.117)$. The results were given a significantly better assessment at 18 months postoperatively than at 6 months ( $p=0.0108)$.

Patients were significantly more satisfied with the aesthetic result of the scar after 18 months than laymen, which applies both to treatment with MMS $(2.02 \pm 0.78$ versus $2.33 \pm 0.86)$ and with SE (1.78 \pm 0.72 vs. $2.07 \pm 0.87 ; p=0.002)$. Seventy-eight percent of the patients ( $n=103)$ assessed the aesthetic result of the scar as 'good' or 'excellent', $8 \%(n=9)$ assessed the result as 'bad'. 
Introduction

As around $80 \%$ of all BCCs are located in the face, preservation of healthy skin and an excellent cosmetic outcome are important in treatment of BCC (Coebergh et al., 1991; Gallagher et al., 1990; Holme et al., 2000; Kumar et al., 2002). Two studies comparing the cosmetic result of radiotherapy versus surgical excision (SE) and cryosurgery versus SE have demonstrated that results are better after surgery (Petit et al., 2000; Thissen et al., 2000a). Mohs micrographic surgery (MMS) is a specialized surgical technique in which complete tumour eradication is accompanied by conservancy of healthy tissue (Neumann et al., 1996). There have been reports of good cosmetic results after MMS, but so far no comparative study has been performed to substantiate this claim (Wennberg et al., 1999).

Surgery is the most frequently applied treatment modality for BCC worldwide (Bower et al., 2001; Goldberg, 1996; Kuijpers et al., 2002). In 1999 we started a prospective randomised comparative trial in the treatment of $B C C$ with MMS as opposed to SE, to determine for which BCC MMS is indicated. Next to this trial, we evaluated the cosmetic outcome after both treatment modalities to determine whether there is a subgroup of BCCs that show a better aesthetic result after treatment with MMS than after treatment with SE.

\section{Methods}

- Study design

The prospective randomised comparative trial included 408 primary (untreated) and 204 recurrent BCCs (Chapter 4). The inclusion criteria for this study were: a primary $\mathrm{BCC}$ of $1 \mathrm{~cm}$ or more and an aggressive histopathologic subtype (morphea, micronodular and BCC with squamous differentiation) located in the face, or a BCC of $1 \mathrm{~cm}$ or more located in the $\mathrm{H}$-zone of the face (Figure 1.5). All first and second recurrent $B C C$ located in the face could be included. All patients signed an informed consent form. The study was approved by the medical ethics committee of the University Hospital Maastricht. To evaluate the cosmetic results, an aselect sample of the first 151 primary and 95 recurrent randomised BCCs was used and these results were evaluated retrospectively.

\section{Treatment methods}

After randomisation, the BCC was treated by SE or MMS. In both procedures the tumour was delineated with a $3 \mathrm{~mm}$ margin. We made the decision for this standard margin of $3 \mathrm{~mm}$ in both treatment modalities to enable proper comparison between the two. The excision was performed at a $90^{\circ}$ angle in SE and at a $45^{\circ}$ angle in MMS (Shriner et al., 1998). In MMS the defect was reconstructed on the same day. In SE the defect was either reconstructed immediately or left open in await of histopathologic control and was reconstructed one week later after "refreshing" the wound edges with a curette. With the exception of four defects of primary BCCs and 2 defects of recurrent $\mathrm{BCC}$ s that were reconstructed by the plastic surgeon, all other defects were 
reconstructed by the operating dermatologist. In case of incomplete excision (SE), a re-excision was carried out. In case of incomplete re-excision, the BCC was treated by MMS.

\section{- Assessment of cosmetic results By patient}

At 6 and 18 months postoperatively, patients assessed the aesthetic appearance of the scar and noted their score on a four-point scale (excellent, good, fair and bad). By panel

The panel consisted of three professionals (a dermatologist/ Mohs surgeon, a plastic surgeon and a dermatologic nurse) and three laymen (a civil engineer, a senior m.t.a. researcher and a skin therapist). They assessed the cosmetic result of the scar, blinded to treatment modality and time, on the basis of digital photographs. At 6 and 18 months postoperatively, standard photographs of the scar were taken with operation light in the plane of the scar. An overall picture showed the whole face and a close-up picture showed the scar and its immediate surrounding area. The photographs were not manipulated with an imaging program.

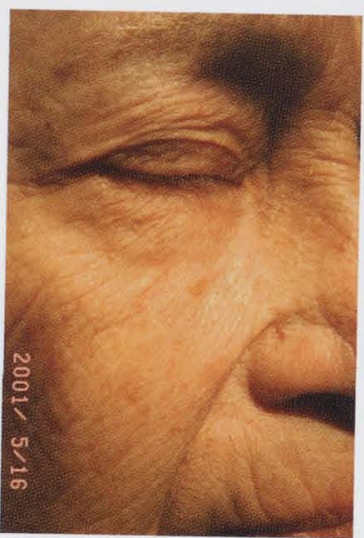

Figure 5.1 Scar assessed as excellent.

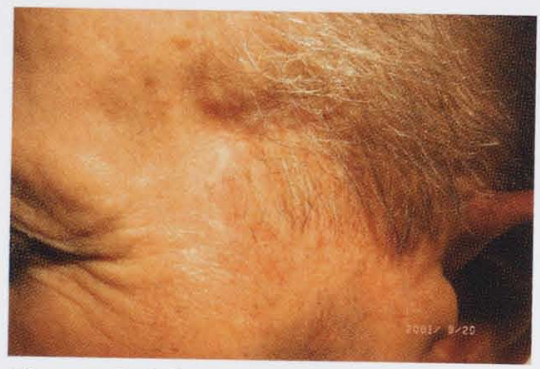

Figure 5.2 Scar assessed as good.

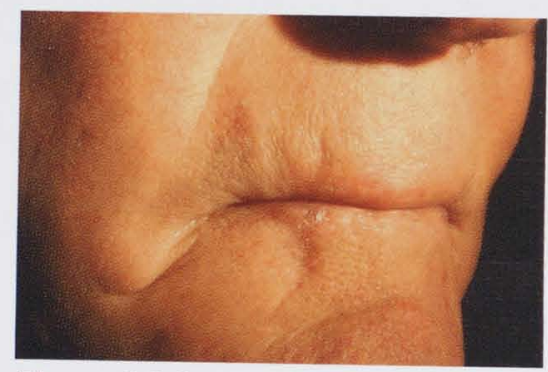

Figure 5.3 Scar assessed as fair.

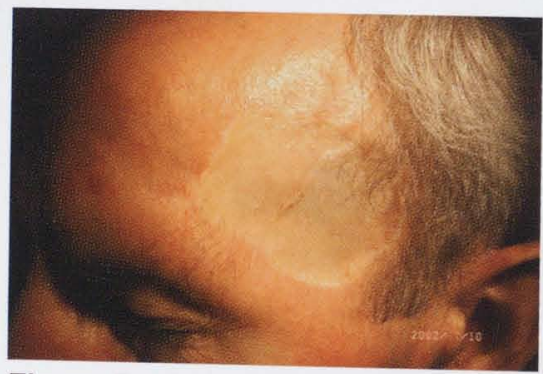

Figure 5.4 Scar assessed as bad. 
Table 5.2. Operation characteristics of primary and recurrent BCC.

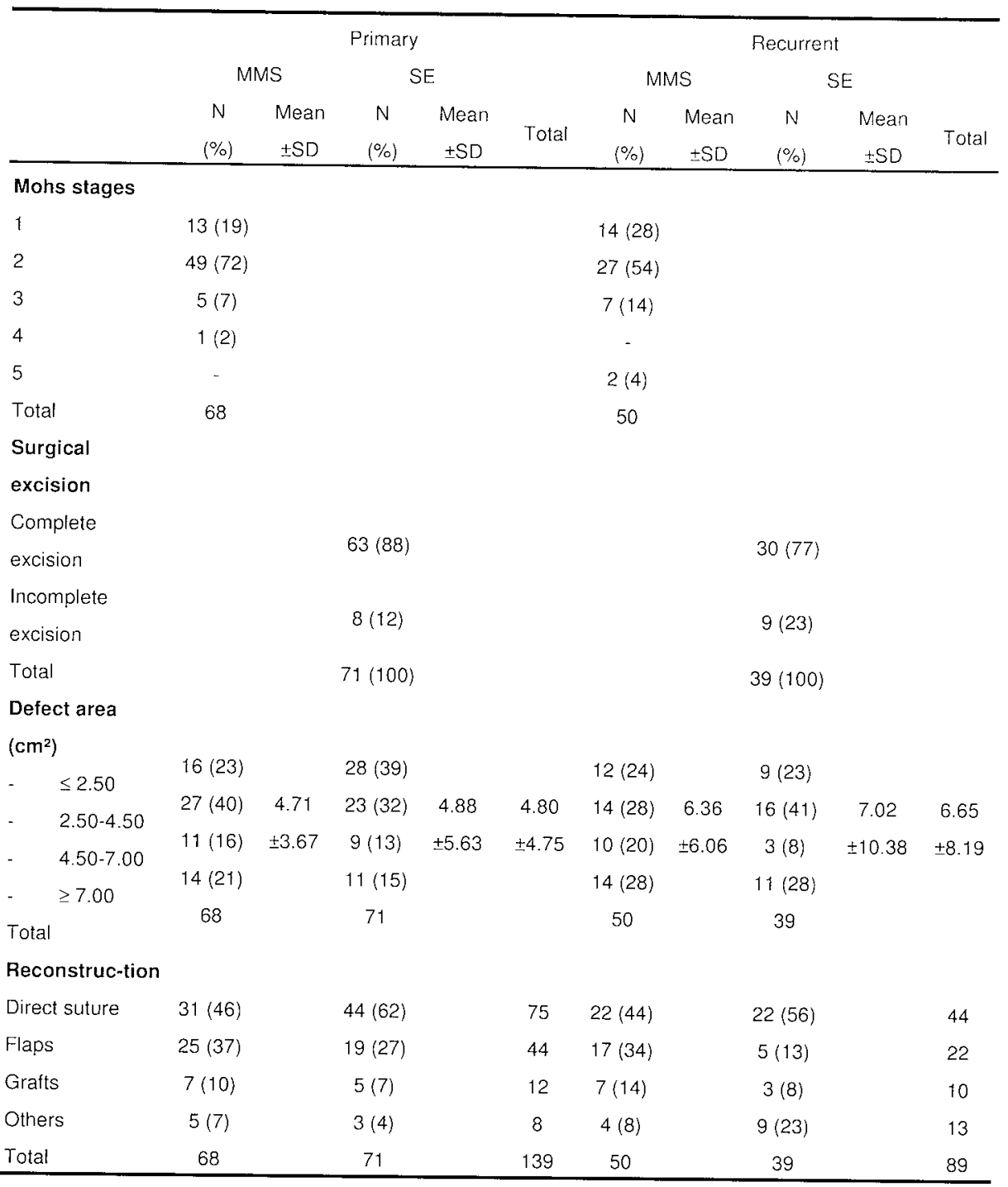


Table 5.3. Cosmetic results of primary BCC for different tumour and operation characteristics.

\begin{tabular}{|c|c|c|c|c|c|c|c|}
\hline & & \multicolumn{3}{|c|}{ Primary $(n=139)$} & \multicolumn{3}{|c|}{ Recurrent $(n=89)$} \\
\hline & & \multicolumn{3}{|c|}{ Mean $\pm S D$} & \multicolumn{3}{|c|}{ Mean \pm SD } \\
\hline & & MMS & SE & Mean & MMS & SE & Mean \\
\hline \multicolumn{8}{|c|}{ Diameter } \\
\hline - & $\leq 10 \mathrm{~mm}$ & $2.02 \pm 0.63$ & $1.79 \pm 0.82$ & $1.91 \pm 0.72$ & $2.00 \pm 0.74$ & $2.15 \pm 0.83$ & $2.06 \pm 0.76$ \\
\hline - & $11-20 \mathrm{~mm}$ & $2.20 \pm 0.66$ & $1.93 \pm 0.59$ & $2.06 \pm 0.64$ & $2.39 \pm 0.70$ & $2.37 \pm 0.68$ & $2.38 \pm 0.68$ \\
\hline - & $\geq 21 \mathrm{~mm}$ & $2.48 \pm 1.06$ & $2.49 \pm 0.88$ & $2.48 \pm 0.93$ & $2.70 \pm 0.83$ & $2.03 \pm 0.81$ & $2.38 \pm 0.87$ \\
\hline \multicolumn{8}{|c|}{ Localization } \\
\hline - & Forehead/temporal & $2.01 \pm 0.71$ & $2.02 \pm 0.87$ & $2.02 \pm 0.79$ & $2.64 \pm 0.70$ & $2.23 \pm 0.75$ & $2.41 \pm 0.74$ \\
\hline - & Cheek/chin & $2.15 \pm 0.53$ & $1.90 \pm 0.28$ & $2.06 \pm 0.46$ & $2.78 \pm 0.82$ & $2.25 \pm 1.06$ & $2.65 \pm 0.84$ \\
\hline - & Nose/ paranasal & $2.61 \pm 0.68$ & $2.28 \pm 0.72$ & $2.44 \pm 0.71$ & $2.33 \pm 0.87$ & $2.45 \pm 0.76$ & $2.40 \pm 0.80$ \\
\hline - & Lips/ around mouth & $2.30 \pm 0.57$ & $2.17 \pm 0.66$ & $2.23 \pm 0.58$ & $2.39 \pm 0.86$ & - & $2.39 \pm 0.86$ \\
\hline - & Peri-ocular & $1.88 \pm 0.66$ & $1.08 \pm 0.09$ & $1.61 \pm 0.66$ & $2.00 \pm 0.83$ & $2.50 \pm 0.00$ & $2.08 \pm 0.77$ \\
\hline - & Ear & 2.391 .18 & $2.00 \pm 0.73$ & $2.19 \pm 0.90$ & $2.03 \pm 0.56$ & $1.92 \pm 0.59$ & $2.00 \pm 0.52$ \\
\hline - & Peri-auricular & $1.61 \pm 0.55$ & $1.71 \pm 0.55$ & $1.68 \pm 0.53$ & $1.86 \pm 0.44$ & $1.39 \pm 0.26$ & $1.70 \pm 0.44$ \\
\hline \multicolumn{8}{|c|}{ Recurrence } \\
\hline- & First recurrence & & & & $2.30 \pm 0.72$ & $2.19 \pm 0.74$ & $2.26 \pm 0.73$ \\
\hline- & Second recurrence & & & & $2.69 \pm 0.99$ & $2.35 \pm 0.77$ & $2.49 \pm 0.85$ \\
\hline \multicolumn{8}{|c|}{ Mohs stages } \\
\hline- & 1 & $1.88 \pm 0.53$ & & & $2.24 \pm 0.55$ & & \\
\hline- & 2 & $2.20 \pm 0.71$ & & & $2.26 \pm 0.75$ & & \\
\hline- & $>2$ & $2.67 \pm 0.97$ & & & $2.83 \pm 0.98$ & & \\
\hline \multicolumn{8}{|c|}{ Surgical excision } \\
\hline - & Complete & & $1.92 \pm 0.69$ & & & $2.11 \pm 0.73$ & \\
\hline - & Incomplete & & $2.54 \pm 0.96$ & & & $2.63 \pm 0.69$ & \\
\hline \multicolumn{8}{|c|}{ Reconstruction } \\
\hline - & Direct suture & $1.94 \pm 0.53$ & $1.77 \pm 0.62$ & $1.84 \pm 0.59$ & $2.24 \pm 0.69$ & $1.96 \pm 0.61$ & $2.10 \pm 0.66$ \\
\hline - & Flap & $2.23 \pm 0.77$ & $2.24 \pm 0.77$ & $2.23 \pm 0.76$ & $2.07 \pm 0.51$ & $2.03 \pm 0.64$ & $2.06 \pm 0.53$ \\
\hline - & Graft & $2.52 \pm 0.84$ & $2.83 \pm 0.95$ & $2.65 \pm 0.86$ & $2.79 \pm 1.04$ & $2.89 \pm 0.95$ & $2.82 \pm 0.96$ \\
\hline - & Other & $3.00 \pm 0.61$ & $2.11 \pm 0.67$ & $2.67 \pm 0.75$ & $3.46 \pm 0.16$ & $2.78 \pm 0.71$ & $2.99 \pm 0.67$ \\
\hline \multicolumn{8}{|c|}{ Defect $\left(\mathrm{cm}^{2}\right)$} \\
\hline & $\leq 2.50$ & $1.93 \pm 0.57$ & $1.79 \pm 0.72$ & $1.84 \pm 0.67$ & $2.07 \pm 0.84$ & $1.89 \pm 0.66$ & $1.99 \pm 0.76$ \\
\hline - & $2.50-4.50$ & $2.06 \pm 0.62$ & $1.91 \pm 0.63$ & $1.99 \pm 0.62$ & $2.21 \pm 0.71$ & $2.32 \pm 0.77$ & $2.27 \pm 0.73$ \\
\hline - & $4.50-7.00$ & $2.53 \pm 0.73$ & $1.98 \pm 0.64$ & $2.28 \pm 0.73$ & $2.07 \pm 0.38$ & $2.28 \pm 0.92$ & $2.12 \pm 0.51$ \\
\hline- & $\geq 7.00$ & $2.43 \pm 0.91$ & $2.64 \pm 0.81$ & $2.52 \pm 0.85$ & $2.95 \pm 0.67$ & $2.36 \pm 0.75$ & $2.69 \pm 0.75$ \\
\hline
\end{tabular}
no tumors treated

Significant differences are highlighted 
Table 5.3 lists the cosmetic results for various tumour characteristics. For each of the following comparisons the mean score of all panel members at 18 months was used. As the diameter of the tumor increased, the mean cosmetic result decreased significantly (mean $1.91-2.48, p=0.011$ ). This increase was the same in both therapy groups $(p=0.723)$.

The cosmetic outcome at 18 months differed significantly for the various localizations of the scar $(p=0.001)$, but there was no difference between the results of MMS and SE $(p=0.666)$. The nasal/ paranasal localization was rated significantly lower than the highest rated peri-ocular region $(p=0.009)$.

Reconstruction techniques were categorized into 4 types: 'direct suture', 'flaps', 'grafts' and an 'others' category ('delayed closure', 'closure by plastic surgeon' and a 'combination of an advancement and a full thickness graft'). There were significant differences between the 4 types of reconstruction $(p<0.001)$; the best cosmetic results were obtained after direct suturing and the poorest results after a graft $(p=0.001)$. There was no difference between MMS and SE in cosmetic result after different types of reconstruction $(p=0.261)$.

The size of the defect was categorized into 4 groups $\left(\leq 2.50 \mathrm{~cm}^{2}, 2.51-4.50 \mathrm{~cm}^{2}, 4.51\right.$ $6.99 \mathrm{~cm}^{2}$ and $\geq 7.00 \mathrm{~cm}^{2}$ ). An increase in defect size led to a significant deterioration of the cosmetic result $(p=0.001)$. The use of MMS or SE made no difference in terms of deterioration of cosmetic result as a result of an increasing defect size $(p=0.359)$. In Table 5.4 a comparison is made between defect sizes and cosmetic results of complete excisions versus incomplete excisions, or, respectively, a one-stage Mohs procedure or a two or more stage procedure. A comparison between these groups is possible because in both procedures the first excision was performed with a $3 \mathrm{~mm}$ margin. In case of 2 or more Mohs stages, defects were significantly larger than defects occurring after a single stage $(p=0001)$, but if the SE was incomplete, defects were even more larger than after a complete SE $(p<0.001)$. There is a significant difference in correlation between MMS and SE in favour of MMS $(p=0.035)$.

Table 5.4. Relation between defect size and cosmetic result for complete and incomplete SE and a Mohs procedure with 1 stage and > 1 stage, for primary $B C C$.

\begin{tabular}{|c|c|c|c|}
\hline & & \multicolumn{2}{|c|}{$\begin{array}{c}\text { Primary }(n=139) \\
\text { Mean } \pm S D\end{array}$} \\
\hline & & Defect in $\mathrm{cm}^{2}$ * & Cosmetic result \\
\hline \multirow{2}{*}{ MMS } & 1 & $2.43 \pm 0.79$ & $1.88 \pm 0.53$ \\
\hline & $2+$ & $5.25 \pm 3.87$ & $2.25 \pm 0.74$ \\
\hline \multirow{2}{*}{ SE } & Complete & $3.81 \pm 3.41$ & $1.92 \pm 0.69$ \\
\hline & Incomplete & $13.29 \pm 11.09$ & $2.54 \pm 0.96$ \\
\hline
\end{tabular}

${ }^{*}$ log-transformed

Significant differences are highlighted 


\section{Recurrent BCC}

In the recurrent group 95 cases were assessed, 6 of which had to be excluded due to missing values. Thus 86 patients with 89 recurrent tumours remained in this group. In analyses that reflect patients' judgements, the numbers are lower ( $n=82)$ as not all patients were able to assess the cosmetic result.

The mean age of the patients was $67.5 \pm 11.7$ years, with male patients ( 49 or $57 \%$ ) outnumbering female patients ( 37 or $43 \%$ ).

The tumour and operation characteristics are listed in Table 5.1 and 5.2.

The overall mean cosmetic result as assessed by the panel is $2.31 \pm 0.73$ on a scale from 1 to 4 , summed over both time and treatment modalities. The cosmetic results at 18 months were similar for MMS and SE ( $2.36 \pm 0.76$ vs. $2.23 \pm 0.74 ; p=0.437)$.

There was a significant difference in assessment of cosmetic result by patients and laymen both after 6 and 18 months $(p=0.042)$, but there was no difference between treatment modalities $(p=0.227)$. The mean cosmetic evaluation of the panel members showed no overall change between 6 and 18 months $(p=0.840)$.

Table 5.3 lists the results of the analysis for factors that may bear a relation to the 18 months cosmetic outcome. There was no significant difference for categorized tumour size or localization $(p=0.272$ and $p=0.085)$. There were no different conclusions for MMS or SE.

The 18 months cosmetic result of a recurrent $B C C$ was given a significantly lower assessment than that of a primary $B C C(2.08 \pm 0.73$ vs. $2.30 \pm 0.75, p=0.038)$. The cosmetic result of a first recurrent $B C C(n=72)$ was assessed as not significantly better than that of a second recurrent $B C C(n=17)(2.26 \pm 0.73$ vs. $2.49 \pm 0.85, p=0.188)$. As in the primary group, a closure by direct suture or a flap yielded a significantly better cosmetic result $(2.10, n=44$ and $2.06, n=22$, ) than closure by a graft $(2.82$, $n=10, p<0.001$ ). With respect to reconstruction, there was no difference in cosmetic results between SE and MMS ( $p=0.540)$.

As defects increased, the overall cosmetic result deteriorated significantly $(1.99, n=21$ vs. 2.67, $n=25, p=0.017$ ). There was no difference in assessment of cosmetic results between MMS and SE for defect size (2.95, $n=14$ vs. 2.36, $n=11, p=0.237$ ).

Defects were not significantly larger in case of a Mohs procedure of 2 or more stages than in case of a single Mohs stage ( $p=0.200$; Table 5.5), but defects of an incomplete SE were significantly larger than that of a complete $S E(p<0.001)$. This difference between MMS and SE was significant in favour of MMS $(p=0.001)$. 
Table 5.5. Relation between defect size and cosmetic result for complete and incomplete SE and a Mohs procedure with 1 stage and $>1$ stage, for recurrent $B C C$.

\begin{tabular}{cccc}
\hline & & \multicolumn{2}{c}{ Recurrent $(\mathrm{n}=89)$} \\
Mean \pm SD \\
& & Defect in $\mathrm{cm}^{2 *}$ & Cosmetic result \\
\hline \multirow{2}{*}{ M.MS } & 1 & $4.41 \pm 2.84$ & $2.24 \pm 0.55$ \\
& $2+$ & $7.12 \pm 6.80$ & $2.40 \pm 0.83$ \\
& Complete & $3.53 \pm 1.93$ & $2.11 \pm 0.73$ \\
& Incomplete & $18.66 \pm 17.32$ & $2.63 \pm 0.69$ \\
\hline
\end{tabular}

* log-transformed

Significant differences are highlighted

\section{Discussion}

In this study, the cosmetic outcomes of two surgical treatment modalities (surgical excision and Mohs micrographic surgery) for both primary and recurrent facial BCC were compared in a randomised group of patients. In the past, two prospective randomised comparative studies have revealed that surgical treatment for primary BCC provides a significantly better cosmetic outcome than radiotherapy and cryosurgery (Petit et al., 2000; Thissen et al., 2000a). So far no studies have been performed into the cosmetic result after treatment of recurrent BCC. On the basis of this study we may conclude that good cosmetic results can be achieved for facial BCC after either treatment modality and that, in general, no significant differences can be found between treatment with MMS or with SE. This might be explained by the standard $3 \mathrm{~mm}$ in both operation modalities, which is not standard in MMS. However, this margin was taken with the purpose of comparing both treatment modalities on the same basis. With this study we have demonstrated that scars that develop after MMS, with wound edges at a $45^{\circ}$ angle, are cosmetically similar to scars developing after SE. Comparing the overall postoperative outcome at 6 and 18 months for primary BCC, the cosmetic outcome after 18 months was given a significantly better assessment than that after 6 months: this applied to both treatment modalities. Petit et al. reported cosmetic results after 4 years of follow-up and concluded that this period is necessary to evaluate the cosmetic result (Petit et al., 2000). However, the reported improvement of the surgical scar was more substantial during the first two years than in later years, while the cosmetic aspect of the scar following radiotherapy deteriorated with time (Petit et al., 2000). This has been demonstrated before as well (Kopf, 1979). We chose this period of time because a scar needs to be acceptable to a patient within 18 months postoperatively. In the recurrent group there was a slight but not significant improvement. This lack of statistical difference may be explained by the smaller size of this group. On the other hand, as the operation concerned was the second or third one 
in the area, it might be the inability of the skin to adjust again that results in a less satisfactory cosmetic result.

The evaluation of the cosmetic outcome revealed that patients were more satisfied with the appearance of the scar than laymen, an observation that supports the findings of Petit et al (Petit et al., 2000).

Another interesting result is that the cosmetic outcome of a primary $\mathrm{BCC}$ is significantly better than that of a recurrent BCC. This may be due to the fact that the average size of defect after treatment of a recurrent BCC is larger than after treatment of a primary BCC. So, not only from a curative point of view, but also from a cosmetic point of view, prevention of a recurrent BCC remains of significant importance. From literature results we already know that the lowest recurrence rates are obtained when treated by MMS (Rowe et al., 1989a; Rowe et al., 1989b; Thissen et al., 1999).

When evaluating reconstruction types we noticed that a simple closure by direct suture or reconstruction by a flap was given a better assessment than reconstruction by a graft. Marchac came to the similar conclusion that the best results were obtained with direct suture and that in $20 \%$ of cases the result after a graft was unsatisfactory (Marchac, 1988).

Finally, when combining all the results it is possible to identify subtypes of BCC that yield a better cosmetic outcome with MMS than with SE. This is the first study in which defects after SE and MMS have been compared prospectively in a randomised group of $\mathrm{BCCs}$ and related to the cosmetic result. We saw that as the defect size increased, cosmetic results decreased significantly. Consequently, all treatments that lead to a smaller defect are preferable. We also noticed that in tumours that can not be completely cured by a single excision, defects are significantly larger after SE than after MMS. From literature we know that BCCs with indistinct borders, of an aggressive histopathologic subtype, located in the $\mathrm{H}$-zone of the face, as well as large $\mathrm{BCC}$ and recurrent BCCs often grow with subclinical tumour extensions, which may lead to incomplete excisions (Batra and Kelley, 2002; Breuninger and Dietz, 1991; Orengo et al., 1997). From a cosmetic point of view we would therefore advise to treat these BCCs with MMS to minimize the defect size and, consequently, maximize the chances of a better cosmetic result.

\section{Conclusion}

Prevention of a recurrent $\mathrm{BCC}$ remains the most important goal in treatment of BCC, not only from an oncological point of view but also for the final cosmetic result. In a large group of identical BCCs the cosmetic results after treatment with MMS and SE are similar. However, for those facial BCC that have an increased chance of being incompletely excised, MMS results in a significantly smaller defect and therefore provides a better cosmetic outcome. 


\section{Acknowledgements}

We would like to thank the following persons for participation in the panel of judges;

Dr. R.R. van der Hulst, plastic surgeon; Dr. A. Sommer, dermatologist/ Mohs surgeon; Mrs. I. Habets, dermatologic nurse; Mrs. P.A. van de Wiel-Sieben, skin therapist, Dr. C.D. Dirksen, senior m.t.a researcher, Ir. N.P.A.W. Kelleners, civil engineer. 
Chapter 5 


\section{Chapter 6}

\section{Adjuvant cytokeratin staining in Mohs Micrographic Surgery for basal cell carcinoma}

Nicole W.J. Smeets, Angela J.W. Stavast-Kooy, Gertruud A.M. Krekels, Mat J.A.P. Daemen, H.A. Martino Neumann 


\section{Abstract}

Background. Mohs micrographic surgery (MMS) is a technique that offers excellent cure rates in the treatment of basal cell carcinoma (BCC). One of the reasons for its success is the $100 \%$ visualization of the resection margins. Still, recurrences do occur in 2-5\% of the treated BCCs. It has been suggested that BCC cells in frozen sections stained with hematoxylin and eosin (H\&E) may be missed.

Objective. To determine whether an additional immunohistochemical staining with a cytokeratin marker (MNF 116) indicates BCC cells in sections in which the H\&Estained frozen sections were negative.

Methods. The Mohs procedure was performed under standard conditions in which H\&E-stained slides were judged by the Mohs surgeon and the pathologist. After the H\&E slides were judged negative, an extra slide was stained using immunohistochemistry and a monoclonal antibody against cytokeratin (MNF 116).

Results. A total of 143 complete slides were stained and judged by two Mohs surgeons and a pathologist. One of the 143 slides stained with MNF 116 showed positive staining where the H\&E slides were negative, which is $0.7 \%$ of the slides. However, this single slide represents a failure of nearly $2 \%$ of the treated patients.

Conclusion. Frozen sections stained with H\&E in MMS offer enough security in detecting BCC cells during surgery; however, adjuvant cytokeratin staining can be useful in very selected cases of aggressive growing BCC. 


\section{Introduction}

Mohs micrographic surgery (MMS) is a treatment for many (difficult) skin cancers, especially for non-melanoma skin cancers (NMSC). Approximately $30 \%$ of all NMSC are treated with MMS in the United States.(Gaston et al., 1999) In Europe, MMS is primarily used for high risk NMSCs (Julian and Bowers, 1997; Wennberg et al., 1999). Of all the NMSCs, basal cell carcinoma (BCC) is most common and is the most treated with MMS.

Recurrence rates after MMS are 1-2\% for primary BCCs and 5-6\% for recurrent BCCs, compared with 5.3-10.1\% and 17.4\% after surgical excision (Rowe et al., 1989a; Rowe et al., 1989b; Thissen et al., 1999).

MMS has the advantage of examining $100 \%$ of the surgical margins, in comparison with other treatment modalities (Shriner et al., 1998). In surgical excision, where tissue is examined with the breadloaf method, only part of the resection margins is viewed (Abide et al., 1984). In cryosurgery and radiotherapy, there is no histopathologic examination at all. The meticulous histopathologic examination might be the main reason for the low recurrence rates following MMS.

In spite of the $100 \%$ visualization of the resection margins, even with MMS, a recurrence can occur. This can be due to improper processing, incorrect mapping or misinterpretation of the frozen sections by the Mohs surgeon/ pathologist. Although in most cases BCC cells are easy to detect in frozen sections, in some cases, this might be more difficult (e.g., when BCC cells are surrounded by dense inflammation); however, a recent study showed that inflammation does not mask tumour, but tumour is often nearby (Katz et al., 2001). It was suggested that BCC cells can be more easily recognized when slides in MMS are stained with an additional immunohistochemical marker (Jimenez et al., 1995; Zachary and Perkins, 1998). In another study the sensitivity of tumour identification improved with cytokeratin staining in squamous cell carcinoma (Zachary et al., 1994).

There is no specific tumour marker for BCC, but cytokeratins (for instance MNF 116) and Ber-EP 4 can be used as immunohistochemical markers for BCC cells (Mondragon and Barrett, 2000; Ramnarain et al., 1995). MNF-116 detects a number of cytokeratins like 5,6,8 17 and 19. It stains the basal layer of the epidermis, adnexal structures and all BCC cells (Prieto et al., 1996).

The aim of our study was to identify whether additional immunohistochemical staining with a cytokeratin marker (MNF 116) would indicate BCC cells in sections where hematoxylin and eosin (H\&E) showed no BCC cells.

\section{Patients and methods}

Forty-nine patients with a mean age of 65 years (varying from $23-89$ years) with in total 51 BCCs were consecutively treated with MMS. Selection criteria for MMS were histopathologically aggressive-type BCC located in the face, nonaggressive-type BCC in the $\mathrm{H}$-zone, and recurrent $\mathrm{BCC}$ in the face. The BCCs had a variety of histopathologic subtypes, all biopsy proven (Table 6.1). There were 32 primary 
Table 6.1. Histopathologic subtypes of the tumours and the relation between tumour positivity in MNF 116 and histopathologic subtype.

\begin{tabular}{lcccc}
\hline Type & Number & $\%$ & $\begin{array}{c}\text { Not } \\
\text { matching }\end{array}$ & $\%$ \\
\hline Superficial & 3 & 5.88 & & \\
Solid & 21 & 41.18 & & \\
Aggressive & 14 & 27.45 & 1 & 7.14 \\
Combination solid & 13 & 25.49 & & \\
+ aggressive & & & & \\
Total & 51 & & & \\
\hline
\end{tabular}

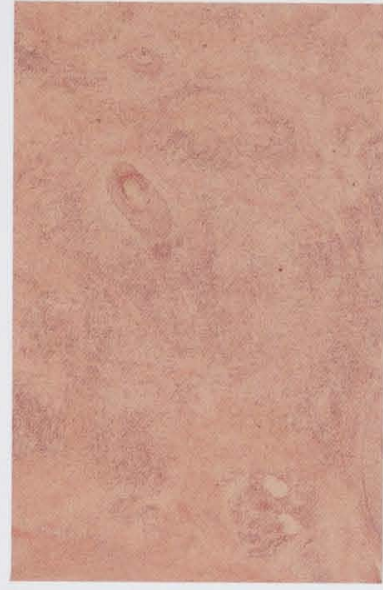

Figure 6.1.

H\&E stained slide (original magnification 40x). No tumour cells seen.

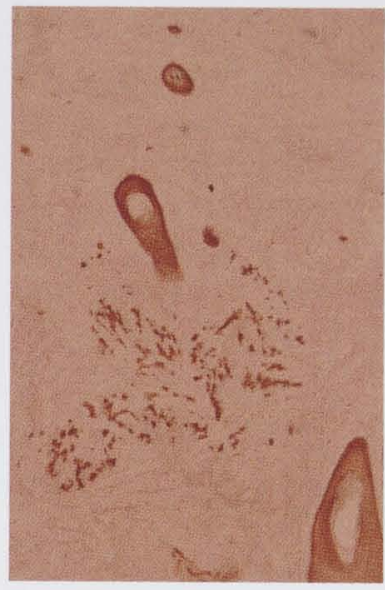

Figure 6.2.

MNF 116 stained slide (original magnification 40x). Positive stained tumour cells. 
tumours and 19 recurrent tumours. The Mohs operation was performed under standard conditions as described before (Shriner et al., 1998). Horizontal frozen sections were prepared and stained with H\&E as in any Mohs procedure. The Mohs surgeon and a pathologist judged all of the frozen sections.

After the area was tumour free, an extra frozen section $(5 \mu \mathrm{m})$ was taken for a cytokeratin staining. The extra slides were stained using an anticytokeratin monoclonal antibody MNF 116 (DAKO A/S, Glostrup, DK). The staining was performed using the avidin-bionin complex method as described elsewhere (Cattoretti et al., 1988). A total of 166 keratin slides were examined by two Mohs surgeons, independent of the results of the H\&E-sections. In case of suspected positive staining, the slides were also independently judged by a pathologist.

\section{Results}

The Mohs-procedure took 1 to 6 rounds (with a mean of 1.9 rounds) and from 2 to 20 frozen sections (with a mean of 7.6 frozen sections).

There were 166 slides stained with monoclonal antibody MNF 116, of which 23 slides could not be judged because there was too little material left. Of the remaining 143 slides, 1 slide showed positive staining and 142 were negative for tumour, where all of the $\mathrm{H} \& \mathrm{E}$-stained slides were negative for tumour. When re-evaluating the H\&E slide of this positive MNF 116 slide, there was no tumour visible. However, there is a large amount of inflammation in the same area. Therefore, there is a mismatch of one slide $(0,7 \%)$ while in $99.3 \%$ of the cases the $\mathrm{H} \& \mathrm{E}$ and the MNF 116 stained slides matched (Figures 6.1 and 6.2).

The slide that did not match was a recurrence of the aggressive histopathologic type, which is $7.14 \%$ of all the aggressive BCCs (Table 6.1).

The patient had no sign of tumour recurrence after a follow-up of 12 months. She then died of an unrelated cause. 


\section{Discussion}

In this study, one slide out of 166 showed a positive staining result in the MNF 116 slides, whereas all the H\&E were negative; thus, the gross of the slides did match $(99.7 \%)$. However, from the perspective of recurrences, this single slide represents a fault in nearly $2 \%$ of the patients. The slides taken for this study were taken after the standard procedure so it represents the skin several $\mu \mathrm{m}$ from the resection margin and tumour presence will probably have no consequences for this patient. But this fault could be an explanation why there are, despite of the $100 \%$ visualization, still recurrences after MMS.

Several studies showed that not all incomplete excised tumours lead to a recurrence but only 30-41\% of them (De Silva and Dellon, 1985; Sussman and Liggins, 1996). Combining these numbers with our $2 \%$ fault this leads to lower recurrence rates than obtained from results in the literature (Rowe et al., 1989a; Rowe et al., 1989b). Thus, this mismatch that we found between the MNF 116 and H\&E slides cannot be the only reason that there are still recurrences after MMS.

When re-evaluating the $\mathrm{H} \& \mathrm{E}$ slide we noticed an area of infiltration. As already studied by Katz et al., infiltration does not mask tumour cells but tumour is often nearby (Katz et al., 2001). However, detecting BCC cells between inflammatory cells can be more difficult.

The slide that did not match was a recurrent tumour of the aggressive histopathologic type. Comparing for histopathologic subtype in this study, we noticed a fault of $7 \%$ for the aggressive growing BCCs. These results show that in most cases BCC cells are easy to detect, but adjuvant cytokeratin staining might be helpful in BCCs of an aggressive histopathologic subtype. This has been suggested before by Ramnarain et al. who studied immunohistochemical markers Dako PL34, MNF 116 or Novocastra NCL-Pan CK on morphoeic (aggressive) growing BCCs (Ramnarain et al., 1995). They concluded that these markers could be helpful in tumours with morphea (aggressive) growing BCC. Thus, when the strands of BCC cells become smaller, the chance of missing BCC cells becomes bigger. From our results one has to consider adjuvant cytokeratin staining in aggressive growing BCCs. This will be a choice based on time and cost aspects. Performing a cytokeratin staining takes extra skills and needs an experienced laboratory technician. The benefit of conventional frozen sections stained with H\&E is the short time that it takes to prepare them. However, many authors have proven that immunohistochemical staining can be prepared within one hour (Jimenez et al., 1995; Zachary et al., 1994).

While trying to find an explanation about why there are still recurrences after MMS, we evaluated the sensitivity of the histopathology during the Mohs procedure. Although it is not the complete answer, a fault of nearly $2 \%$ of the patients can be part if this answer. Probably in a larger study population, distinct indications for adjuvant cytokeratin staining in MMS can be formed. 
In conclusion, frozen sections stained with H\&E in MMS offer enough security in detecting BCC cells during surgery; however, adjuvant cytokeratin staining can be useful in very selected cases of aggressively growing BCC. 
Chapter 6 


\section{Chapter 7}

\section{Photodynamic therapy as adjuvant treatment of extensive basal cell carcinoma treated with Mohs micrographic surgery}

Daniëlle I.M. Kuijpers, Nicole W.J. Smeets, Gertruud A.M. Krekels, Monique R.T.M. Thissen 


\section{Introduction}

Mohs micrographic surgery (MMS) has proven to be an effective treatment for many skin cancers and especially non-melanoma skin cancers (NMSC) (Thissen et al., 1999). Because of the $100 \%$ margin control during the operation, maximum conservation of healthy tissue and high cure-rates are obtained. This makes MMS a very suitable treatment modality for aggressive, large and recurrent basal cell carcinomas (BCC) especially in the face (Rowe et al., 1989b; Swanson, 1983). Photodynamic therapy (PDT) is a treatment modality still under investigation. Nevertheless, it is increasingly being used in the treatment of superficial BCC and Bowen's disease and pre-malignant skin disorders, such as actinic keratosis (Morton et al., 2002; Morton et al., 2001; Pariser et al., 2003). In dermatology, often deltaaminolevulenic acid (5-ALA) is used in topical application. Delta-aminolevulinic acid is a precursor in the heme biosynthesis pathway and is converted into the photosensitizer protoporphyrin IX (PpIX). After several hours, a sufficient amount of PplX is synthesized for an effective response to PDT. Generally, single illuminations with total light dose between 50 and $150 \mathrm{~J} / \mathrm{cm}^{2}$ and fluence rates between 50 and 100 $\mathrm{mW} / \mathrm{cm}^{2}$ are used with wavelenghts around $635 \mathrm{~nm}$ (Svanberg et al., 1994). Good results have been reported after treatment of superficial BCC's, with complete response rates of 90-100\% (Fink-Puches et al., 1998; Morton et al., 1998; Wang et al., 2001; Wennberg et al., 1996). For nodular BCC however, complete response rates of only 10-71\% are obtained with PDT (Morton et al., 1998; Peng et al., 1997; Svanberg et al., 1994).

A wide variety of $\mathrm{BCC}$ histopathological subtypes have been described. Classification by growth pattern BCC's can be subdivided into aggressive (morphea, micronodular and $\mathrm{BCC}$ with squamous differentation) and non-aggressive (nodular and superficial type) tumors (Saldanha et al., 2003). Small buds of basaloid tumour cells that arise from and are in continuity with the epidermis and extend into the superficial dermis histologically characterize superficial BCC. Previously, this tumour type was inappropriately being described in literature as multifocal or multicentric superficial BCC. In three-dimensional reconstruction, the tumour buds have been shown to form anastomosing or interconnecting complexes (Lang et al., 1987).

Before surgery is performed, a biopsy is taken to determine the histopathologic subtype. However, it is well understandable that a biopsy only gives an impression of a small part of the entire tumour, which often, in more than $35 \%$ of cases, consists of mixed subtypes (Sexton et al., 1990). In accordance, we noticed that, especially in patients with multiple skin cancers in the face, a solid or aggressive type BCC can be superficial at the borders. These fields of superficial growing BCC can cause large defects when treated surgically.

We report four cases of facial BCC treated with MMS, where we used PDT as an adjuvant therapy for the remaining superficial tumour parts. During the Mohs procedure, situations presented themselves that gave rise to reconsideration of continuation of our started treatment. 
We treated the surroundings of the surgical defect with PDT by using a light source of $600-730 \mathrm{~nm}$ (Waldmann PDT 1200 unit), with fluence rates ranging from 90 to 100 $\mathrm{mW} / \mathrm{cm}^{2}$ and light doses from 60 to $100 \mathrm{~J} / \mathrm{cm}^{2}$, after 4 hours application of freshly prepared 20\% 5-aminolevulinic acid oil in water. The area treated was delineated with 2 to 5 centimetres surrounding the wound or scar. This was not a fixed area in all patients. Where possible, for instance on a forehead, a margin of $5 \mathrm{~cm}$ was used, where this was not possible, for instance near the medial or lateral canthal region, a smaller margin was taken.

\section{Case reports}

\section{Patient 1}

A 75-year-old male patient with a severe sun exposure in history, had a primary tumour of $10 \times 7 \mathrm{~mm}$, located on his glabella. Histopathologic examination performed by punch-biopsy showed an infiltrative growing BCC. His medical history revealed Merkelcell carcinoma cranial to his right eye that had been removed in 1997. Also, he had been treated for multiple actinic keratosis, two prior BCC's on his cheek and forehead, and a large, deep infiltrating squamous cell carcinoma (SCC) in the left medial canthal region, for which an excenteratio bulbae and a lymph node dissection had taken place in 2000.

We treated the BCC on his glabella with MMS. After two stages and eight frozen sections, there remained superficial BCC in one of the slides, corresponding with the right side of the nose. The Mohs procedure was then terminated, because he had little healthy skin left for reconstruction due to extensive actinic damage in the face. The defect of $15 \times 10 \mathrm{~mm}$ was closed by primary approximation. The residual superficial BCC was treated after 5 weeks with PDT (Waldmann PDT 1200, $100 \mathrm{~mW} / \mathrm{cm}^{2}, 100$ $\mathrm{J} / \mathrm{cm}^{2}$ ). Sixteen months post treatment there was clinically no sign of residual tumour.

\section{Patient 2}

An otherwise healthy male of 55 years was seen with a recurrent tumour in the right temporal zone 6 months after MMS for a mixed nodular, superficial and infiltrative type BCC. Histopathologic examination showed a superficial BCC. He had been treated before for multiple BCCs of different subtypes in his face with MMS and surgical excision. Because of the recurrent character of this tumour, it was again treated by MMS, and after 1 stage and 4 frozen sections there was superficial growing BCC in 2 of 4 Mohs slides. Three punch-biopsies taken within the surrounding area of a few centimetres, in which tumour tissue was difficult to delineate, also showed superficial $B C C$. Because of the superficial aspect of the tumour and the wide area in which the superficial BCC extended, the Mohs procedure was terminated. The size of the defect that had occurred so far was $23 \times 18 \mathrm{~mm}$ and was closed by primary approximation. A 5 centimetres surrounding area was treated with PDT after 10 weeks as described before (this time, the following settings were used: $90 \mathrm{~mW} / \mathrm{cm}^{2}, 100 \mathrm{~J} / \mathrm{cm}^{2}$ ). After 26 months there was clinically no sign of a recurrence. 


\section{Patient 3}

An 80 years-old, pulmonary and cardiac-compromised male patient with a clear sun exposure in history, was sent to our clinic with a recurrent BCC on the right side of his forehead. The primary tumour had been treated with surgical excision several years before. He had been treated for multiple BCCs in the head and neck region in the previous years by surgical excision and cryosurgery. Histopathologic examination of a punch biopsy showed a solid type BCC.

He was treated with MMS because of the recurrent character of the BCC. Two stages and 10 frozen sections later, there was superficial $B C C$ remaining in 1 slide. At this time, the defect measured 40 by $50 \mathrm{~mm}$. The procedure was terminated because of severe dyspnoe of the patient and the defect was partially closed by a purr string. The remaining defect was left open for secondary intention healing. Eight weeks later, when the wound was healed, PDT was performed as described before $\left(100 \mathrm{~mW} / \mathrm{cm}^{2}\right.$, $\left.60 \mathrm{~J} / \mathrm{cm}^{2}\right)$. During the follow-up time, 5 new BCCs have been treated, of which one was located on his forehead, but outside the area treated by PDT. No recurrences appeared within the follow-up period of 27 months.

\section{Patient 4}

A man of 82 years has been treated at our clinic for 5 SCCs and 11 BCCs of different types in the head and neck region, with surgical excision, Mohs surgery and cryosurgery. At a regular oncology check-up two new primary tumours of $21 \times 18 \mathrm{~mm}$ and $8 \mathrm{~mm}$ were noticed in the pre-auricular zone on the left side. (Figure 7.1a) Histopathologic examination after biopsy of the largest tumour showed a solid growing $B C C$. Because of the localization and size of the tumour, the patient was treated with MMS. After 5 stages and 14 frozen sections there was superficial growing BCC remaining in three slides. (Figure $7.2 \mathrm{a}, 7.2 \mathrm{~b}$ ) The procedure was terminated when a defect of $66 \times 39 \mathrm{~mm}$ remained. (Figure $7.1 \mathrm{~b}$ ) The defect was partially closed by primary approximation and the remaining with a full thickness skin graft from the supra-clavicular area. Again, PDT was performed as described before and 13 months later there were still no signs of recurrence of the tumour. (Figure 7.1c) Several months after this last physical examination, the patient died of an unrelated cause.

\section{Discussion}

There are many different treatment modalities for BCCs like surgical excision, cryosurgery, radiotherapy, MMS and PDT (Kuijpers et al., 2002). MMS has the lowest recurrence rates $(1,7-6,5 \%$ for primary $\mathrm{BCC}$ and $4,8-10 \%$ for recurrent $\mathrm{BCC})$ (Julian and Bowers, 1997; Wennberg et al., 1999). and is well suited for large, aggressive primary and recurrent BCCs in the face (Rowe et al., 1989a; Rowe et al., 1989b). An important aim of MMS besides a low recurrence rate, is maximal preservation of healthy skin so reconstruction of the surgical defect is easier and good cosmetic results can be achieved. 


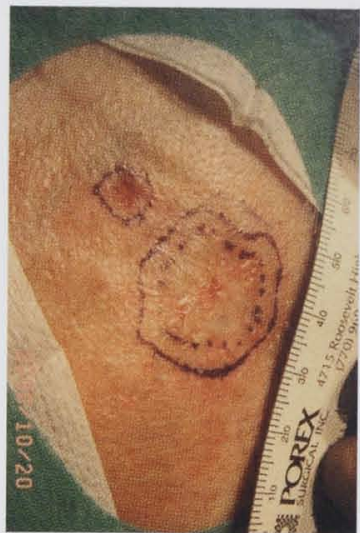

Figure 7.1a.

Patient 4; tumour before treatment.

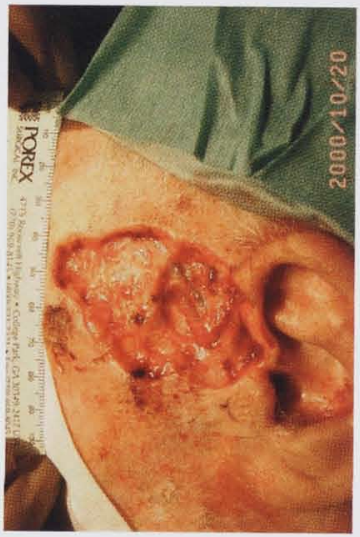

Figure $7.1 \mathrm{~b}$.

Patient 4; final defect after surgery.

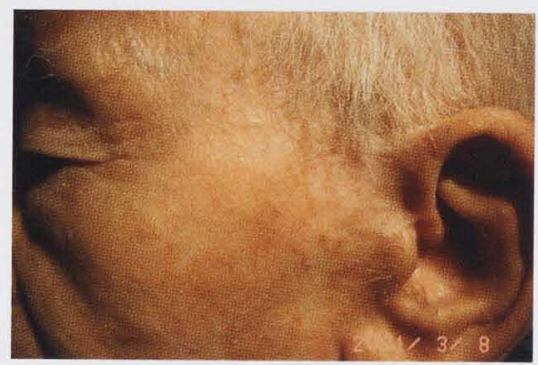

Figure 7.1c.

Patient 4; treated area 13 months after PDT.

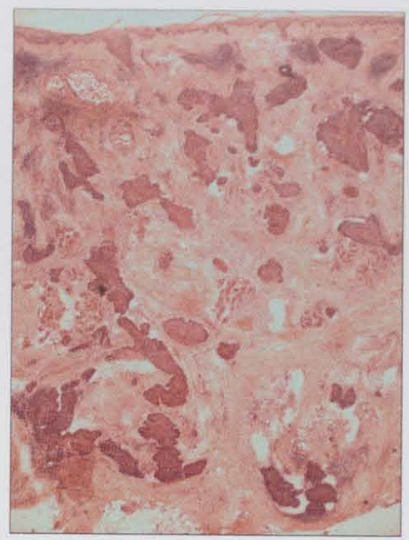

Figure 7.2a.

Histological aspect of the tumour of patient 4; solid BCC in early Mohs stage.

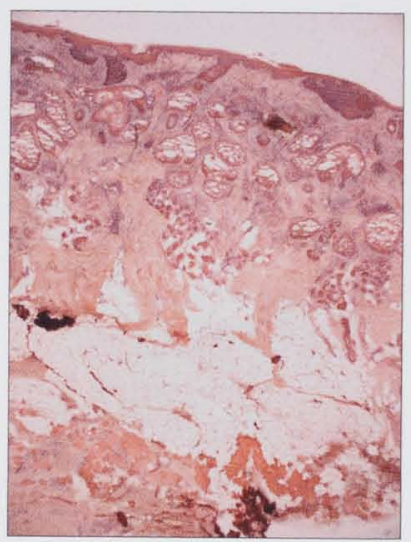

Figure 7.2b.

Histological aspect of the tumour of patient 4; superficial BCC in latter Mohs stage. 
Preservation of healthy tissue is especially important in patients with multiple skin cancers who are at risk for developing new non-melanoma skin cancer (NMSC) in the future, for instance patients with nevoid basal cell carcinoma syndrome, patients with immunosuppressive therapy and patients with extensive sun exposure in history. While treating patients, especially those who have multiple skin cancers, with MMS: we experienced that after clearing the area of the aggressive type $\mathrm{BCC}$, we often needed extra stages to clear the area of fields of remaining, superficial growing BCC. This way we created larger defects than expected, which led to our search for a way to prevent this, perhaps unnecessary, loss of tissue. PDT is a rather young treatment modality that is still under investigation. Although there is no uniformity yet about the fluence rates and doses of light that are best suited for treatment of BCCs, good results are reported in treating superficial BCCs. In our setting, we also have good experience in treating patients with superficial BCC and treatment of nodular BCC with prior curettage (Thissen et al., 2000b).

These results led to the idea to treat patients, who are cleared of the aggressive and deeper component of the BCC during MMS, additionally with PDT to clear remaining superficial parts of the tumour. This will lead to preservation of tissue while clearing adequately all tumour cells. With this case series, we show that the combination of MMS to clear all nonsuperficial BCC, and PDT to clear the remaining superficial BCC may lead to cure of the tumour with maximal conservation of skin and excellent cosmetic results. Although the follow-up period is short, varying at this time from 13 to 27 months, and this case serie is small, first result are promising.

These patients presented here, are good examples of those encountered by dermatologists and Mohs surgeons and illustrate the dilemmas that can occur during Mohs procedure whether to continue or not in case of tumour-positivity of the frozen sections with superficial tumour tissue which sometimes extends far in the surroundings.

We believe that PDT can have a role as adjuvant therapy in cases where Mohs surgery tends to develop undesirable large defects in the face, due to superficial spreading BCC. Especially patients with a history of multiple BCCs, who have little healthy skin left for reconstruction due to previous operations, are suitable. More patients treated with this combination of techniques, with a longer follow up period are needed to assess recurrence rates and to assess the treatment indications. 


\section{Chapter 8}

Summary, general discussion and recommendations for treatment and research 
Basal cell carcinoma ( $\mathrm{BCC}$ ) is the most common malignancy among Caucasians worldwide. It is a subtype of non-melanoma skin cancer (NMSC) linked to overexposure to the sun, especially during childhood. Mortality rates due to BCC are low, but its increasing incidence and prolonged morbidity lead to a large impact on our health services. Since recurrent BCCs in particular are able to locally invade and destroy tissue, the prevention of recurrence and new primary tumours is the most important goal of treatment. Early recognition and effective treatment are important to reduce the incidence of recurrent $\mathrm{BCC}$ and relieve the economic burden of its management.

\section{Conclusions based on our findings}

Results of the literature review and retrospective study

Chapters 2 and 3 describe MMS as a treatment of BCC and review the literature. Cure rates reported in the literature for both primary and recurrent BCC are consistently higher for MMS than for all other treatment modalities. Reported recurrence rates for MMS for primary BCC range from 0.0 to $6.5 \%$, while those for surgical excision (SE) vary from 5.3 to $10.1 \%$. We found that although MMS is often mentioned, comparative, prospective studies are lacking for MMS as well as for other BCC treatment modalities. We conclude that the literature provides insufficient information to predict treatment results.

Another problem in comparing reported results of treatment is the diversity of study designs and follow-up periods. Chapter 3 presents the results of a retrospective evaluation of MMS for primary and recurrent facial BCC in a secondary referral centre for NMSC (the University Hospital Maastricht). We report recurrence rates for primary $\mathrm{BCC}$ of $3.2 \%$ and for recurrent $\mathrm{BCC}$ of $6.7 \%$ after treatment with MMS. We noted a higher recurrence rate in recurrent $B C C$, in histopathologically aggressive type $B C C$, in BCCs treated by MMS with more than 3 Mohs stages and in those with a large defect.

\section{Results of our prospective study}

\section{- Recurrence rates}

Chapter 4 reports the results of our prospective randomised trial, comparing SE with MMS for both primary and recurrent BCC. This study started in 1999 and is still continuing. After a mean follow-up of 2.66 years, we have found 3 recurrences $(1.5 \%)$ following MMS and 6 recurrences $(3 \%)$ following SE in the primary group. In the recurrent group, there have been 2 recurrences $(2 \%)$ following MMS and $8(8 \%)$ following SE after a mean follow-up of 2.08 years.

The cut-off point for statistical analysis in the evaluation of recurrence in the primary group is 30 months and that in the recurrent group 18 months. At that time, 3 recurrences (1.9\%) following MMS and 5 recurrences (2.9\%) following SE had occurred. This difference is not statistically significant based on intention-to-treat analysis. The recurrent group had 3 recurrences $(3.2 \%)$ following SE and 0 
recurrences $(0 \%)$ following MMS, a difference which is not statistically significant either.

- Incomplete excisions

Of all BCCs treated with SE (with a $3 \mathrm{~mm}$ margin), $18 \%$ of the primary and $32 \%$ of the recurrent BCCs were incompletely excised. Subdivision of primary BCCs showed that $24 \%$ of all histopathologically aggressive BCCs were incompletely excised. We also noted more incomplete excisions at peri-ocular sites and on the ears, but this difference was not statistically significant.

Furthermore we found a significantly larger defect size with incomplete SE than with a Mohs procedure with more than one stage.

\section{- Cosmetic outcome}

It has been shown in the past that SE yields superior cosmetic outcome compared to both radiotherapy (RT) and cryosurgery (CS). We found no overall difference in cosmetic outcome after treatment of facial BCC by SE or MMS. There was a large and statistically significant improvement of the cosmetic aspect of the scar from 6 to 18 months after both treatments.

We did find some other interesting facts that indicated a subgroup of BCC for whom MMS has an advantage over SE. Cosmetic results after treatment of primary BCC were much better than after treatment of recurrent BCC. Once again, it is established that prevention of recurrent $\mathrm{BCC}$ is the most important goal in the treatment of BCC. We noticed a significantly worse cosmetic outcome with increasing defect size. When comparing the results of incomplete excision with those of a Mohs procedure with more than one stage, defects were much larger after incomplete excision. Translating this to the cosmetic result means, that only defect size had a significant effect on the cosmetic outcome. Hence, MMS is preferable for BCCs that carry a high risk of incomplete excision, since it leads to as small a defect as possible and thereby increases the chances of a good cosmetic result. Earlier studies have shown that histopathologically aggressive BCC and recurrent BCC carry a significantly higher risk of incomplete excision, so it is in these cases that treatment with MMS is preferable.

Cost analysis

Costs of MMS and SE were prospectively compared, including all aspects of the treatment of a BCC (pre-operative visits/ examination, personal and material costs of the surgery, post-operative visits). MMS was found to be significantly more expensive than SE for both primary and recurrent BCC. Both the primary and the recurrent group showed a difference in costs of 250 euros between SE (around 750 euros) and MMS (around 1000 euros). Treatment of a recurrence was more expensive than of a primary $\mathrm{BCC}$, regardless of treatment modality. 


\section{Results of our histopathologic study}

Because recurrences still occur after treatment by MMS, even though this theoretically involves examining of $100 \%$ of the resection margins, we analysed the sensitivity of haematoxylin and eosin ( $H \& E$ ) stained slides. In only $2 \%$ of keratin-stained MMS slides did cells suspected of being BCC cells show positive staining, whereas the H\&E stained slides were negative. This was found in a recurrent, morphea growing BCC.

This means that adjuvant keratin slides may be useful in Mohs surgery only in selected cases (like a morphea type or perineural invasion).

Results of a combination of treatments (Mohs micrographic surgery and Photodynamic therapy)

In the past we have noticed that some Mohs procedures, especially in patients with multiple BCCs, could take a long time. In many cases, the centre of the tumour is of an aggressive histopathologic subtype, whereas the peripheral parts of the tumour are of the superficial subtype. Because the results of PDT for the treatment of superficial $\mathrm{BCC}$ are good, we treated patients in such cases with a combination of MMS and PDT.

\section{Recommendations for treatment}

We conclude from our studies that MMS is the therapeutic gold standard for BCC in terms of cure rates, margin control, and tissue conservation. Because of its higher cost and specialised technique, MMS is best reserved for specific indications in specialised centres. Based on the results reported in the literature and our retrospective and prospective studies we recommend MMS for (figure 8.1);

recurrent $\mathrm{BCC}$ of the face;

primary $\mathrm{BCC}$ s of the face $1 \mathrm{~cm}$ or more in size with aggressive histopathology; (primary peri-ocular BCCs and BCCs on the ear with sizes of $1 \mathrm{~cm}$ or more).

We chose for a margin of $1 \mathrm{~cm}$ because we believe that tumours smaller than $1 \mathrm{~cm}$ can be treated by SE with a margin of $3 \mathrm{~mm}$. However, this has to be confirmed by further research. 


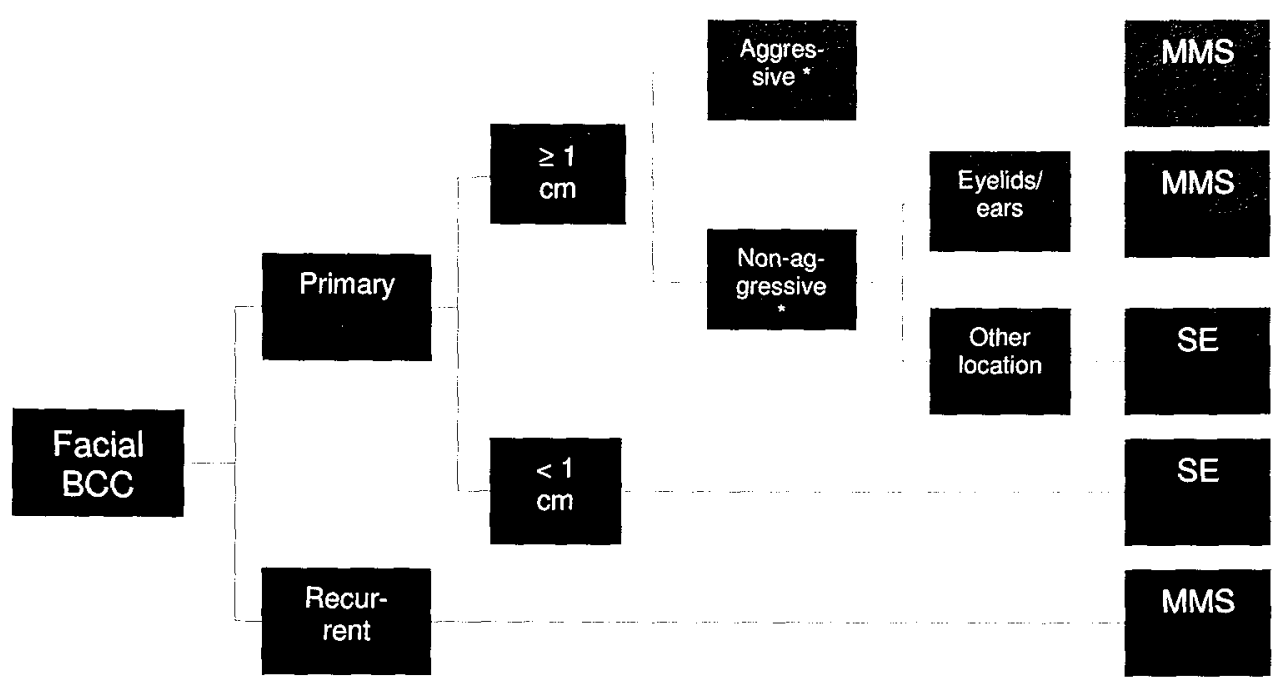

Figure 8.1 Flow-chart for treatment of facial basal cell carcinoma

* histopathologically

\section{Prevention}

Although we have shown that $\mathrm{BCC}$ can be effectively treated with good tissue conservation and good cosmetic outcome, prevention remains the most important aspect. Primary prevention, including avoidance of the sun in the middle of the day and wearing protective clothing and hats, especially during childhood, can prevent development of a BCC. The use of sunscreens with a high SPF $(\geq 30)$ can assist in this prevention if the sun cannot be avoided. These measures are also recommended for patients who have already had one BCC (secondary prevention).

\section{Recommendations for further research}

\section{- study in specific locations; ear, eyelids and nose.}

Because in this study tumours were not equally divided among different locations, there is no significant difference in incomplete excision between tumours located in the $\mathrm{H}$-zone and tumours located outside the $\mathrm{H}$-zone. However, because we did notice more incomplete excisions in tumours located peri-ocular and on the ears, this needs further study.

study in excision margins.

What is an optimal excision margin in treatment of facial BCC? Perhaps when excising tumours of an aggressive histopathologic subtype with a margin of 4 or $5 \mathrm{~mm}$, this can lead to more completely excised BCCs and lower recurrence rates so indications for MMS can be narrowed. 
- study MMS versus other frozen section techniques in terms of recurrence, timeand cost-effectiveness.

Results in the literature obtained by conventional frozen section technique are sometimes comparable to these obtained by MMS. It is often suggested that these take less time to process and are therefore less expensive. To actually compare these results with the results obtained by MMS a prospective randomised study is needed. - $\quad$ study MMS versus SE without standard margin of 3-mm.

In many cases the Mohs procedure is started with a smaller margin than 3-mm. A study to compare MMS with smaller margins and SE with "free" margins might result in different recurrence rates and cosmetic outcome. 
Bibliography 
Abdelsayed RA, Guijarro-Rojas M, Ibrahim NA, Sangueza OP. Immunohistochemical evaluation of basal cell carcinoma and trichepithelioma using Bcl-2, Ki67, PCNA and P53. J Cutan Pathol 2000; 27: 169-75.

Abide JM, Nahai F, Bennett RG. The meaning of surgical margins. Plast Reconstr Surg 1984; 73: 492-7.

Avril MF, Auperin A, Margulis A, Gerbaulet A, Duvillard P, Benhamou E, et al. Basal cell carcinoma of the face: surgery or radiotherapy? Results of a randomized study. Br J Cancer 1997; 76: 100-6.

Bandieramonte G, Lepera P, Moglia D, Bono A, De Vecchi C, Milani F. Laser microsurgery for superficial T1-T2 basal cell carcinoma of the eyelid margins. Ophthalmology 1997; 104: 1179-84.

Bastiaens MT, Hoefnagel JJ, Bruijn JA, Westendorp RG, Vermeer BJ, Bouwes Bavinck JN. Differences in age, site distribution, and sex between nodular and superficial basal cell carcinoma indicate different types of tumors. J Invest Dermatol 1998; 110: 880-4.

Batra RS, Kelley LC. Predictors of extensive subclinical spread in nonmelanoma skin cancer treated with Mohs micrographic surgery. Arch Dermato/ 2002; 138: 1043-51.

Beer TW, Shepherd P, Theaker JM. Ber EP4 and epithelial membrane antigen aid distinction of basal cell, squamous cell and basosquamous carcinomas of the skin. Histopathology 2000; 37: 21823.

Bentkover SH, Grande DM, Soto H, Kozlicak BA, Guillaume D, Girouard S. Excision of head and neck basal cell carcinoma with a rapid, crosssectional, frozen-section technique. Arch Facial Plast Surg 2002; 4: 114-9.

Berlin J, Katz KH, Helm KF, Maloney ME. The significance of tumor persistence after incomplete excision of basal cell carcinoma. J Am Acad Dermato/ 2002; 46: 549-53.

Bernstein PE. Mohs '98: single-procedure Mohs surgery with immediate reconstruction. Otolaryngol Head Neck Surg 1999; 120: 184-9.

Bernstein SC, Roenigk RK. Leiomyosarcoma of the skin. Treatment of 34 cases. Dermatol Surg 1996; 22: 631-5.

Bialy TL, Whalen J, Veledar E, Lafreniere D, Spiro J, Chartier T, et al. Mohs micrographic surgery vs traditional surgical excision: a cost comparison analysis. Arch Dermato/ 2004; 140: 736-42.

Bieley HC, Kirsner RS, Reyes BA, Garland LD. The use of Mohs micrographic surgery for determination of residual tumor in incompletely excised basal cell carcinoma. J Am Acad Dermatol 1992; 26 : 754-6.

Bisson MA, Dunkin CS, Suvarna SK, Griffiths RW. Do plastic surgeons resect basal cell carcinomas too widely? A prospective study comparing surgical and histological margins. Br J Plast Surg 2002; 55: 293-7. 
Bogdanov-Berezovsky A, Cohen A, Glesinger R, Cagnano E, Krieger Y, Rosenberg L. Clinical and pathological findings in reexcision of incompletely excised basal cell carcinomas. Ann Plast Surg 2001; 47: 299-302.

Bogdanov-Berezovsky A, Cohen AD, Glesinger R, Cagnano E, Krieger $Y$, Rosenberg L. Risk factors for incomplete excision of basal cell carcinomas. Acta Derm Venereo/ 2004; 84: 44-7.

Bower CP, Lear JT, de Berker DA. Basal cell carcinoma follow-up practices by dermatologists: a national survey. Br J Dermato/ 2001; 145: 94956.

Bowman PH, Ratz JL, Knoepp TG, Barnes CJ, Finley EM. Basosquamous Carcinoma. Dermatol Surg 2003; 29: 830-833.

Boyd AS, Shyr Y, King LE, Jr. Basal cell carcinoma in young women: an evaluation of the association of tanning bed use and smoking. J Am Acad Dermatol 2002; 46: 706-9.

Braun M, 3rd. The case for Mohs' surgery by the fixed-tissue technique. $J$ Dermatol Surg Oncol 1981; 7: 634-40.

Breuninger $\mathbf{H}$, Dietz $\mathrm{K}$. Prediction of subclinical tumor infiltration in basal cell carcinoma. J Dermatol Surg Oncol 1991; 17: 574-8.

Breuninger $\mathrm{H}$, Holzschuh. Die luckenlose histologische darstellung der schnittrander eines hauttumorexzisates (3D-histologie) in einer schnittebene mittels der "Flundertechnik". Akt Dermatol 1994; 20: 710.

Breuninger $\mathbf{H}$, Rassner $\mathbf{G}$, Schaumburg-Lever $\mathbf{G}$, Steitz A. [Long-term experiences with histologic control of the incision margin (3-D histology)]. Hautarzt 1989; 40: 14-8.

Brodland DG, Amonette R, Hanke CW, Robins P. The history and evolution of Mohs micrographic surgery. Dermatol Surg 2000; 26: 303-7.

Bumpous JM, Padhya TA, Barnett SN. Basal cell carcinoma of the head and neck: identification of predictors of recurrence. Ear Nose Throat $J$ 2000; 79: 200-2, 204.

Burg G, Hirsch RD, Konz B, Braun Falco O. Histographic surgery: accuracy of visual assessment of the margins of basal-cell epithelioma. $J$ Dermatol Surg 1975; 1: 21-4.

Cattoretti G, Berti E, Schiro R, D'Amato L, Valeggio C, Rilke F. Improved avidin-biotin-peroxidase com.plex $i \mathrm{BC}$ ) sining. Histochem J 1988; 20: $75-80$.

Chen TM, Rosen T, Orengo I. Treatmen of a la ce superficial basal cell carcinoma with $5 \%$ imiquimod: a case report and review of the literature. Dermatol Surg 2002; 28: 344-6.

Coebergh JW, Neumann HA, Vrints LW, van der Heijden L, Meijer WJ, Verhagen Teulings MT. Trends in the incidence of non-melanoma skin cancer in the SE Netherlands 1975-1988: a registry-based study. Br J Dermatol 1991; 125: 353-9.

Cook J, Zitelli JA. Mohs micrographic surgery: a cost analysis. J Am Acad Dermatol 1998; 39: 698-703.

Corona R, Dogliotti E, D'Errico M, Sera F, lavarone I, Baliva G, et al. Risk factors for basal cell carcinoma in a Mediterranean population: role of 
recreational sun exposure early in life. Arch Dermato/ 2001; 137 : 1162-8.

Cottel WI. Perineural invasion by squamous-cell carcinoma. J Dermatol Surg Oncol 1982; 8: 589-600.

Cox NH. Basal cell carcinoma in young adults. Br J Dermato/ 1992; 127: 26-9.

Czarnecki D, Mar A, Staples M, Giles G, Meehan C. The development of non-melanocytic skin cancers in people with a history of skin cancer. Dermatology 1994; 189: 364-7.

Czarnecki D, Staples M, Mar A, Giles G, Meehan C. Recurrent nonmelanoma skin cancer in southern Australia. Int J Dermato/ 1996; 35: 410-2.

Dahl E, Aberg M, Rausing A, Rausing EL. Basal cell carcinoma. An epidemiologic study in a defined population. Cancer 1992; 70: 104-8.

David DB, Gimblett ML, Potts MJ, Harrad RA. Small margin (2 mm) excision of peri-ocular basal cell carcinoma with delayed repair. Orbit 1999; 18: 11-15.

Davis JL, Randle HW, Zalla MJ, Roenigk RK, Brodland DG. A comparison of Mohs micrographic surgery and wide excision for the treatment of atypical fibroxanthoma. Dermatol Surg 1997; 23: 105-10.

Dawes KW, Hanke CW. Dermatofibrosarcoma protuberans treated with Mohs micrographic surgery: cure rates and surgical margins. Dermato/ Surg $1996 ; 22: 530-4$.

De Hertog SA, Wensveen CA, Bastiaens MT, Kielich CJ, Berkhout MJ, Westendorp RG, et al. Relation between smoking and skin cancer. $J$ Clin Oncol 2001; 19: 231-8.

De Silva SP, Dellon AL. Recurrence rate of positive margin basal cell carcinoma: results of a five-year prospective study. J Surg Oncol 1985; $28: 72-4$.

DiGiovanna JJ. Retinoid chemoprevention in the high-risk patient. J Am Acad Dermatol 1998; 39: S82-5.

Dixon AY, Lee SH, McGregor DH. Factors predictive of recurrence of basal cell carcinoma. Am J Dermatopathol 1989; 11: 222-32.

Dixon RS, Mikhail GR. Erythroplasia (Queyrat) of conjunctiva. J Am Acad Dermatol 1981; 4: 160-5.

Drake LA, Dinehart SM, Goltz RW, Graham GF, Hordinsky MK, Lewis CW, et al. Guidelines of care for Mohs micrographic surgery. American Academy of Dermatology. J Am Acad Dermatol 1995; 33: 271-8.

Dubin N, Kopf AW. Multivariate risk score for recurrence of cutaneous basal cell carcinomas. Arch Dermatol 1983; 119: 373-7.

Dzubow LM. False-negative tumor-free margins following Mohs surgery. J Dermatol Surg Oncol 1988; 14: 600-2.

Eliezri YD, Cohen PR. Cancer recurrence following Mohs micrographic surgery: a mechanism of tumor persistence. Plast Reconstr Surg 1992; 90: 121-5.

Epstein E. How accurate is the visual assessment of basal carcinoma margins? Br J Dermatol 1973; 89: 37-43. 
Eroglu A, Berberoglu U, Berreroglu S. Risk factors related to locoregional recurrence in squamous cell carcinoma of the skin. J Surg Oncol 1996; 61: 124-30.

Fink-Puches R, Soyer HP, Hofer A, Kerl H, Wolf P. Long-term follow-up and histological changes of superficial nonmelanoma skin cancers treated with topical delta-aminolevulinic acid photodynamic therapy. Arch Dermatol 1998; 134: 821-6.

Friedman HI, Williams T, Zamora S, al-Assaad ZA. Recurrent basal cell carcinoma in margin-positive tumors. Ann Plast Surg 1997; 38: 232-5.

Friedman PM, Friedman RH, Jiang SB, Nouri K, Amonette R, Robins P. Microcystic adnexal carcinoma: collaborative series review and update. J Am Acad Dermatol 1999; 41: 225-31.

Frieling UM, Schaumberg DA, Kupper TS, Muntwyler J, Hennekens CH. A randomized, 12-year primary-prevention trial of beta carotene supplementation for nonmelanoma skin cancer in the physician's health study. Arch Dermato/ 2000; 136: 179-84.

Fung TT, Hunter DJ, Spiegelman D, Colditz GA, Speizer FE, Willett WC. Vitamins and carotenoids intake and the risk of basal cell carcinoma of the skin in women (United States). Cancer Causes Control 2002; 13: 221-30.

Gallagher RP, Hill GB, Bajdik CD, Fincham S, Coldman AJ, McLean DI, et al. Sunlight exposure, pigmentary factors, and risk of nonmelanocytic skin cancer. I. Basal cell carcinoma. Arch Dermatol 1995; 131: 15763.

Gallagher RP, Ma B, McLean DI, Yang CP, Ho V, Carruthers JA, et al. Trends in basal cell carcinoma, squamous cell carcinoma, and melanoma of the skin from 1973 through 1987. J Am Acad Dermatol 1990; 23: 413-21.

Gaston DA, Naugle C, Clark DP. Mohs micrographic surgery referral patterns: the University of Missouri experience. Dermatol Surg 1999; 25: 862-6.

Ghauri RR, Gunter AA, Weber RA. Frozen section analysis in the management of skin cancers. Ann Plast Surg 1999; 43: 156-60.

Goepfert H, Dichtel WJ, Medina JE, Lindberg RD, Luna MD. Perineural invasion in squamous cell skin carcinoma of the head and neck. Am J Surg 1984; 148: 542-7.

Goldberg LH. Basal cell carcinoma. Lancet 1996; 347: 663-7.

Goldschmidt $\mathrm{H}$, Breneman JC, Breneman DL. lonizing radiation therapy in dermatology. J Am Acad Dermatol 1994; 30: 157-82; quiz 183-6.

Gonzalez S, Tannous $\mathbf{Z}$. Real-time, in vivo confocal reflectance microscopy of basal cell carcinoma. J Am Acad Dermatol 2002; 47: 869-74.

Grabski WJ, Salasche SJ. Positive surgical excision margins of a basal cell carcinoma. Dermatol Surg 1998; 24: 921-4.

Griffith BH, McKinney P. An appraisal of the treatment of basal cell carcinoma of the skin. Plast Reconstr Surg 1973; 51: 565-71.

Guthrie TH, Jr., McElveen LJ, Porubsky ES, Harmon JD. Cisplatin and doxorubicin. An effective chemotherapy combination in the treatment 
of advanced basal cell and squamous carcinoma of the skin. Cancer 1985; 55: 1629-32.

Hall VL, Leppard BJ, McGill J, Kesseler ME, White JE, Goodwin P. Treatment of basal-cell carcinoma: comparison of radiotherapy and cryotherapy. Clin Radiol 1986; 37: 33-4.

Hallock GG, Lutz DA. A prospective study of the accuracy of the surgeon's diagnosis and significance of positive margins in nonmelanoma skin cancers. Plast Reconstr Surg 2001; 107: 942-7.

Hannuksela-Svahn A, Pukkala E, Karvonen J. Basal cell skin carcinoma and other nonmelanoma skin cancers in Finland from 1956 through 1995. Arch Dermatol 1999; 135: 781-6.

Hartevelt MM, Bavinck JN, Kootte AM, Vermeer BJ, Vandenbroucke JP. Incidence of skin cancer after renal transplantation in The Netherlands. Transplantation 1990; 49: 506-9.

Hauben DJ, Zirkin H, Mahler D, Sacks M. The biologic behavior of basal cell carcinoma: analysis of recurrence in excised basal cell carcinoma: Part II. Plast Reconstr Surg 1982; 69: 110-6.

Heckmann M, Zogelmeier F, Konz B. Frequency of facial basal cell carcinoma does not correlate with site-specific UV exposure. Arch Dermatol 2002; 138: 1494-7.

Helfand M, Mahon SM, Eden KB, Frame PS, Orleans CT. Screening for skin cancer. Am J Prev Med 2001; 20: 47-58.

Heyderman E, Graham RM, Chapman DV, Richardson TC, McKee PH. Epithelial markers in primary skin cancer: an immunoperoxidase study of the distribution of epithelial membrane antigen (EMA) and carcinoembryonic antigen (CEA) in 65 primary skin carcinomas. Histopathology 1984; 8: 423-34.

Holme SA, Malinovszky K, Roberts DL. Changing trends in non-melanoma skin cancer in South Wales, 1988-98. Br J Dermatol 2000; 143: 12249.

Holmkvist KA, Roenigk RK. Squamous cell carcinoma of the lip treated with Mohs micrographic surgery: outcome at 5 years. J Am Acad Dermatol 1998; 38: 960-6.

Housman TS, Feldman SR, Williford PM, Fleischer AB, Jr., Goldman ND, Acostamadiedo JM, et al. Skin cancer is among the most costly of all cancers to treat for the Medicare population. J Am Acad Dermatol 2003; 48: 425-9.

Hruza GJ. Mohs micrographic surgery local recurrences. J Dermatol Surg Oncol 1994; 20: 573-7.

Huether MJ, Zitelli JA, Brodland DG. Mohs micrographic surgery for the treatment of spindle cell tumors of the skin. J Am Acad Dermatol 2001; 44: 656-9.

Humphreys TR, Malhotra R, Scharf MJ, Marcus SM, Starkus L, Calegari $\mathrm{K}$. Treatment of superficial basal cell carcinoma and squamous cell carcinoma in situ with a high-energy pulsed carbon dioxide laser. Arch Dermato/ 1998; 134: 1247-52.

Jacobs GH, Rippey JJ, Altini M. Prediction of aggressive behavior in basal cell carcinoma. Cancer 1982; 49: 533-7. 
Jemec GB, Holm EA. Nonmelanoma skin cancer in organ transplant patients. Transplantation 2003; 75: 253-7.

Jimenez FJ, Grichnik JM, Buchanan MD, Clark RE. Immunohistochemical techniques in Mohs micrographic surgery: their potential use in the detection of neoplastic cells masked by inflammation. J Am Acad Dermatol 1995; 32: 89-94.

Julian CG, Bowers PW. A prospective study of Mohs' micrographic surgery in two English centres. Br J Dermatol 1997; 136: 515-8.

Karagas MR, Greenberg ER, Spencer SK, Stukel TA, Mott LA. Increase in incidence rates of basal cell and squamous cell skin cancer in New Hampshire, USA. New Hampshire Skin Cancer Study Group. Int J Cancer 1999; 81: 555-9.

Katz KH, Helm KF, Billingsley EM, Maloney ME. Dense inflammation does not mask residual primary basal cell carcinoma during Mohs micrographic surgery. J Am Acad Dermatol 2001; 45: 231-8.

Kennedy C, Bajdik CD, Willemze R, De Gruijl FR, Bouwes Bavinck JN. The influence of painful sunburns and lifetime sun exposure on the risk of actinic keratoses, seborrheic warts, melanocytic nevi, atypical nevi, and skin cancer. J Invest Dermatol 2003; 120: 1087-93.

Kirk RE. Experimental design: procedures for the behavioral sciences. Pacific Grove, California: Brooks/ Cole Publishing Company, 1982: 394-395.

Ko CB, Walton S, Keczkes K, Bury HP, Nicholson C. The emerging epidemic of skin cancer. Br J Dermatol 1994; 130: 269-72.

Kokoszka A, Scheinfeld N. Evidence-based review of the use of cryosurgery in treatment of basal cell carcinoma. Dermatol Surg 2003; 29: 566-71.

Kopf AW. Computer analysis of 3531 basal-cell carcinomas of the skin. $J$ Dermatol 1979; 6: 267-81.

Kopke LFF, Konz B. [Micrographic surgery. Taking stock of the techniques available] Mikrographische chirurgie. Eine methodische bestandsaufnahme. Hautarzt 1995; 46: 607-14.

Koplin L, Zarem HA. Recurrent basal cell carcinoma. A review concerning the incidence, behavior, and management of recurrent basal cell carcinoma, with emphasis on the incompletely excised lesion. Plast Reconstr Surg 1980; 65: 656-64.

Krekels GA, Voorter C, Kuik F, Verhaegh ME, Ramaekers F, Neumann HAM. DNA-protection by sunscreens: Using p53-immunostaining. Eur J Dermatol 1997; 7: 259-62.

Kuijpers DI, Thissen MR, Neumann MH. Basal cell carcinoma: treatment options and prognosis, a scientific approach to a common malignancy. Am J Clin Dermatol 2002; 3: 247-59.

Kumar P, Watson S, Brain AN, Davenport PJ, McWilliam LJ, Banerjee SS, et al. Incomplete excision of basal cell carcinoma: a prospective multicentre audit. Br J Plast Surg 2002; 55: 616-22.

Kurzen H, Esposito L, Langbein L, Hartschuh W. Cytokeratins as markers of follicular differentiation: an immunohistochemical study of trichoblastoma and basal cell carcinoma. Am J Dermatopatho/ 2001; 23: 501-9. 
Lalloo MT, Sood S. Head and neck basal cell carcinoma: treatment using a 2-mm clinical excision margin. Clin Otolaryngo/ 2000; 25: 370-3.

Lang PG, Jr., McKelvey AC, Nicholson JH. Three-dimensional reconstruction of the superficial multicentric basal cell carcinoma using serial sections and a computer. Am J Dermatopatho/ 1987; 9: 198-203.

Larson PO. Keratoacanthomas treated with Mohs' micrographic surgery (chemosurgery). A review of forty-three cases. J Am Acad Dermatol 1987; 16: 1040-4.

Lawrence CM. Mohs surgery of basal cell carcinoma--a critical review. $\mathrm{Br} J$ Plast Surg 1993; 46: 599-606.

Lawrence CM. Mohs' micrographic surgery for basal cell carcinoma. Clin Exp Dermatol 1999; 24: 130-3.

Levi F, Te VC, Randimbison L, Erler G, La Vecchia C. Trends in skin cancer incidence in Vaud: an update, 1976-1998. Eur J Cancer Prev 2001; 10: 371-3.

Levine HL, Bailin PL. Basal cell carcinoma of the head and neck: identification of the high risk patient. Laryngoscope 1980; 90: 955-61.

Lo JS, Snow SN, Reizner GT, Mohs FE, Larson PO, Hruza GJ. Metastatic basal cell carcinoma: report of twelve cases with a review of the literature. J Am Acad Dermatol 1991; 24: 715-9.

Malhotra R, Huilgol SC, Huynh NT, Selva D. The Australian Mohs database, part II: periocular basal cell carcinoma outcome at 5-year follow-up. Ophthalmology 2004; 111: 631-6.

Maloney ME. Histology of basal cell carcinoma. Clin Dermatol 1995; 13: 5459.

Marchac D. Analysis of a series of 225 cases. In: Marchac D, editor. Surgery of basal cell carcinoma of the face: Springer-Verlag, 1988: 85-96.

Marcil I, Stern RS. Risk of developing a subsequent nonmelanoma skin cancer in patients with a history of nonmelanoma skin cancer: a critical review of the literature and meta-analysis. Arch Dermatol 2000; 136: 1524-30.

Marghoob A, Kopf AW, Bart RS, Sanfilippo L, Silverman MK, Lee P, et al. Risk of another basal cell carcinoma developing after treatment of a basal cell carcinoma. J Am Acad Dermatol 1993; 28: 22-8.

Marghoob AA. Basal and squamous cell carcinomas. What every primary care physician should know. Postgrad Med 1997; 102: 139-42, 146, 152-4 passim.

Marini M. Imiquimod 5\% cream: a topical immune response modifier. Int $\mathrm{J}$ Dermatol 2002; 41 Suppl 1: 1-2.

Marks R. An overview of skin cancers. Incidence and causation. Cancer 1995; 75: 607-12.

Martin RC, 2nd, Edwards MJ, Cawte TG, Sewell CL, McMasters KM. Basosquamous carcinoma: analysis of prognostic factors influencing recurrence. Cancer 2000; 88: 1365-9.

Martinez JC, Otley CC, Stasko T, Euvrard S, Brown C, Schanbacher CF, et al. Defining the clinical course of metastatic skin cancer in organ 
transplant recipients: a multicenter collaborative study. Arch Dermatol 2003; 139: 301-6.

McCormack CJ, Kelly JW, Dorevitch AP. Differences in age and body site distribution of the histological subtypes of basal cell carcinoma. A possible indicator of differing causes. Arch Dermato/ 1997; 133: 5936.

Menn H, Robins P, Kopf AW, Bart RS. The recurrent basal cell epithelioma. A study of 100 cases of recurrent, re-treated basal cell epitheliomas. Arch Dermatol 1971; 103: 628-31.

Mikhail GR, Boulos RS, Knighton RS, Rogers JS, Malik G, Ditmars DM, Jr., et al. Cranial invasion by basal cell carcinoma. J Dermatol Surg Oncol 1986; 12: 459-64.

Milan T, Verkasalo PK, Kaprio J, Koskenvuo M. Lifestyle differences in twin pairs discordant for basal cell carcinoma of the skin. Br J Dermatol 2003; 149: 115-23.

Miller SJ. Biology of basal cell carcinoma (Part I). J Am Acad Dermatol 1991; 24: 1-13.

Milroy CJ, Horlock N, Wilson GD, Sanders R. Aggressive basal cell carcinoma in young patients: fact or fiction? Br J Plast Surg 2000; 53 : 393-6.

Mohs F. Chemosurgery: a microscopically controlled method of cancer excision. Archives of surgery 1941a; 42: 279-95.

Mohs F. Chemosurgery: a microscopically controlled method of cancer excision. Archives of surgery 1941b; $42: 279$.

Mohs F. Chemosurgical treatment of cancer of the face: a microscopically controlled method of excision. Archives of dermatology and syphilolgy 1947; 56: 143.

Mohs F, Larson P, Iriondo M. Micrographic surgery for the microscopically controlled excision of carcinoma of the external ear. J Am Acad Dermatol 1988; 19: 729-37.

Mohs FE. Micrographic surgery for the microscopically controlled excision of eyelid cancers. Arch Ophthalmol 1986; 104: 901-9.

Mohs FE, Snow SN. Microscopically controlled surgical treatment for squamous cell carcinoma of the lower lip. Surg Gynecol Obstet 1985; 160: $37-41$.

Mohs FE, Zitelli JA. Microscopically controlled surgery in the treatment of carcinoma of the scalp. Arch Dermatol 1981; 117: 764-9.

Mondragon RM, Barrett TL. Current concepts: the use of immunoperoxidase techniques in mohs micrographic surgery. J Am Acad Dermato/ 2000; 43: $66-71$.

Mora RG, Robins P. Basal-cell carcinomas in the center of the face: special diagnostic, prognostic, and therapeutic considerations. J Dermatol Surg Oncol 1978; 4: 315-21.

Morton CA, Brown SB, Collins S, Ibbotson S, Jenkinson H, Kurwa H, et al. Guidelines for topical photodynamic therapy: report of a workshop of the British Photodermatology Group. Br J Dermatol 2002; 146: 55267. 
Morton CA, MacKie RM, Whitehurst C, Moore JV, McColl JH. Photodynamic therapy for basal cell carcinoma: effect of tumor thickness and duration of photosensitizer application on response. Arch Dermatol 1998; 134: 248-9.

Morton CA, Whitehurst C, McColl JH, Moore JV, MacKie RM. Photodynamic therapy for large or multiple patches of Bowen disease and basal cell carcinoma. Arch Dermatol 2001; 137: 319-24.

Motley RJ, Gould DJ, Douglas WS, Simpson NB. Treatment of basal cell carcinoma by dermatologists in the United Kingdom. British Association of Dermatologists Audit Subcommittee and the British Society for Dermatological Surgery. Br J Dermatol 1995; 132: 437-40.

Nagore E, Grau C, Molinero J, Fortea JM. Positive margins in basal cell carcinoma: relationship to clinical features and recurrence risk. A retrospective study of 248 patients. J Eur Acad Dermatol Venereol 2003; 17: 167-70.

Neering $\mathrm{H}$, Cramer MJ. [Skin cancer in The Netherlands] Huidkanker in Nederland. Ned Tijdschr Geneeskd 1988; 132: 1330-3.

Netscher DT, Spira M. Basal cell carcinoma: an overview of tumor biology and treatment. Plast Reconstr Surg 2004; 113: 74E-94E.

Neumann HAM, Krekels GAM, Verheagh MEJM. Treatment of 208 extensive basal cell carcinomas with Mohs micrographic surgery. $J$ Eur Acad Dermatol Venereol 1996; 6: 217-225.

Niazi ZB, Lamberty BG. Perineural infiltration in basal cell carcinomas. Br J Plast Surg 1993; 46: 156-7.

Nijssen A, Bakker Schut TC, Heule F, Caspers PJ, Hayes DP, Neumann $\mathrm{MH}$, et al. Discriminating basal cell carcinoma from its surrounding tissue by Raman spectroscopy. J Invest Dermato/ 2002; 119: 64-9.

Nordin P. Curettage-cryosurgery for non-melanoma skin cancer of the external ear: excellent 5-year results. Br J Dermatol 1999; 140: 291-3.

Nordin P, Larko O, Stenquist B. Five-year results of curettage-cryosurgery of selected large primary basal cell carcinomas on the nose: an alternative treatment in a geographical area underserved by Mohs' surgery. Br J Dermatol 1997; 136: 180-3.

Novick M, Gard DA, Hardy SB, Spira M. Burn scar carcinoma: a review and analysis of 46 cases. J Trauma 1977; 17: 809-17.

NVDV. Richtlijn behandeling van patienten met basaalcelcarcinomen: Nederlandse vereniging voor Dermatologie en Venereologie, 2003.

O'Connor WJ, Roenigk RK, Brodland DG. Merkel cell carcinoma. Comparison of Mohs micrographic surgery and wide excision in eighty-six patients. Dermatol Surg 1997; 23: 929-33.

Orengo IF, Salasche SJ, Fewkes J, Khan J, Thornby J, Rubin F.

Correlation of histologic subtypes of primary basal cell carcinoma and number of Mohs stages required to achieve a tumor-free plane. J Am Acad Dermatol 1997; 37: 395-7.

Panje WR, Ceilley RI. The influence of embryology of the mid-face on the spread of epithelial malignancies. Laryngoscope 1979; 89: 1914-20.

Pariser DM, Lowe JL, Stewart DM, Jarrat MT, Lucky AW, Pariser RJ, et al. Photodynamic therapy with topical methyl aminolevulinate for actinic 
keratosis:results of a prospective randomized multicenter trial. J Am Acad Dermatol 2003; 48: 227-232.

Peng Q, Warloe T, Berg K, Moan J, Kongshaug M, Giercksky KE, et al. 5Aminolevulinic acid-based photodynamic therapy. Clinical research and future challenges. Cancer 1997; 79: 2282-308.

Petit JY, Avril MF, Margulis A, Chassagne D, Gerbaulet A, Duvillard P, et al. Evaluation of cosmetic results of a randomized trial comparing surgery and radiotherapy in the treatment of basal cell carcinoma of the face. Plast Reconstr Surg 2000; 105: 2544-51.

Petter G, Haustein UF. Squamous cell carcinoma of the skin-histopathological features and their significance for the clinical outcome. J Eur Acad Dermatol Venereo/ 1998; 11: 37-44.

Poniecka AW, Alexis JB. An immunohistochemical study of basal cell carcinoma and trichoepithelioma. Am J Dermatopatho/ 1999; 21: 3326.

Prieto VG, Lugo J, McNutt NS. Intermediate- and low-molecular-weight keratin detection with the monoclonal antibody MNF116. An immunohistochemical study on 232 paraffin-embedded cutaneous lesions. J Cutan Pathol 1996; 23: 234-41.

Ramnarain ND, Walker NP, Markey AC. Basal cell carcinoma: rapid techniques using cytokeratin markers to assist treatment by micrographic (Mohs') surgery. Br J Biomed Sci 1995; 52: 184-7.

Randle HW. Basal cell carcinoma. Identification and treatment of the high-risk patient. Dermato/ Surg 1996; 22: 255-61.

Rapini RP. Comparison of methods for checking surgical margins. J Am Acad Dermato/ 1990; 23: 288-94.

Ratner D, Bagiella $\mathbf{E}$. The efficacy of curettage in delineating margins of basal cell carcinoma before Mohs micrographic surgery. Dermatol Surg 2003; 29: 899-903.

Ratner D, Lowe L, Johnson TM, Fader DJ. Perineural spread of basal cell carcinomas treated with Mohs micrographic surgery. Cancer 2000; 88: 1605-13.

Reymann F. Treatment of basal cell carcinoma of the skin with 5-fluorouracil ointment. A 10-year follow-up study. Dermatologica 1979; 158: 36872.

Rhodes LE, de Rie M, Enstrom Y, Groves R, Morken T, Goulden V, et al. Photodynamic therapy using topical methyl aminolevulinate vs surgery for nodular basal cell carcinoma: results of a multicenter randomized prospective trial. Arch Dermatol 2004; 140: 17-23.

Rigel DS, Friedman RJ, Kopf AW. Lifetime risk for development of skin cancer in the U.S. population: current estimate is now 1 in $5 . J \mathrm{Am}$ Acad Dermatol 1996; 35: 1012-3.

Rigel DS, Robins P, Friedman RJ. Predicting recurrence of basal-cell carcinomas treated by microscopically controlled excision: a recurrence index score. J Dermatol Surg Oncol 1981; 7: 807-10.

Rippey JJ. Why classify basal cell carcinomas? Histopathology 1998; 32 : 393-8. 
Robins P, Rodriguez-Sains R, Rabinovitz H, Rigel D. Mohs surgery for periocular basal cell carcinomas. J Dermatol Surg Oncol 1985; 11: 1203-7.

Robinson JK. Risk of developing another basal cell carcinoma. A 5-year prospective study. Cancer 1987; 60: 118-20.

Robinson JK, Dahiya M. Basal cell carcinoma with pulmonary and lymph node metastasis causing death. Arch Dermatol 2003; 139: 643-8.

Robinson JK, Fisher SG. Recurrent basal cell carcinoma after incomplete resection. Arch Dermato/ 2000; 136: 1318-24.

Rodriguez-Sains RS, Robins P, Smith B, Bosniak SL. Radiotherapy of periocular basal cell carcinomas: recurrence rates and treatment with special attention to the medical canthus. Br J Ophthalmol 1988; 72 : 134-8.

Rowe DE, Carroll RJ, Day CL. Long-term recurrence rates in previously untreated (primary) basal cell carcinoma: implications for patient follow-up. J Dermatol Surg Oncol 1989a; 15: 315-28.

Rowe DE, Carroll RJ, Day CL. Mohs surgery is the treatment of choice for recurrent (previously treated) basal cell carcinoma. J Dermatol Surg Oncol 1989b; 15: 424-31.

Rowe DE, Carroll RJ, Day CL. Prognostic factors for local recurrence, metastasis, and survival rates in squamous cell carcinoma of the skin, ear, and lip. Implications for treatment modality selection. $J$ Am Acad Dermatol 1992; 26: 976-90.

Sahl WJ, Jr., Snow SN, Levine NS. Giant basal cell carcinoma. Report of two cases and review of the literature. J Am Acad Dermatol 1994; 30: 856-9.

Sakura CY, Calamel PM. Comparison of treatment modalities for recurrent basal cell carcinoma. Plast Reconstr Surg 1979; 63: 492-6.

Salasche S. Imiquimod 5\% cream: a new treatment option for basal cell carcinoma. Int J Dermato/ 2002; 41 Suppl 1: 16-20.

Salasche SJ, Amonette RA. Morpheaform basal-cell epitheliomas. A study of subclinical extensions in a series of 51 cases. J Dermatol Surg Oncol 1981; 7: 387-94.

Saldanha G, Fletcher A, Slater DN. Basal cell carcinoma: a dermatopathological and molecular biological update. Br J Dermatol 2003; 148: 195-202.

Schinstine M, Goldman GD. Risk of synchronous and metachronous second nonmelanoma skin cancer when referred for Mohs micrographic surgery. J Am Acad Dermatol 2001; 44: 497-9.

Sexton M, Jones DB, Maloney ME. Histologic pattern analysis of basal cell carcinoma. Study of a series of 1039 consecutive neoplasms. J Am Acad Dermatol 1990; 23: 1118-26.

Shelley WB, Wood MG. Nodular superficial pigmented basal cell epitheliomas. Arch Dermatol 1982; 118: 928-30.

Shriner DL, McCoy DK, Goldberg DJ, Wagner RF. Mohs micrographic surgery. J Am Acad Dermatol 1998; 39: 79-97.

Shuster $\mathbf{S}$. The case against micrographically controlled skin surgery. Acta Derm Venereol 1999; 79: 2-3. 
Silverman MK, Kopf AW, Bart RS, Grin CM, Levenstein MS. Recurrence rates of treated basal cell carcinomas. Part 3: Surgical excision. J Dermatol Surg Oncol 1992; 18: 471-6.

Silverman MK, Kopf AW, Grin CM, Bart RS, Levenstein MJ. Recurrence rates of treated basal cell carcinomas. Part 1: Overview. J Dermatol Surg Oncol 1991a; 17: 713-8.

Silverman MK, Kopf AW, Grin CM, Bart RS, Levenstein MJ. Recurrence rates of treated basal cell carcinomas. Part 2: Curettageelectrodesiccation. J Dermato/ Surg Oncol 1991b; 17: 720-6.

Sloane JP. The value of typing basal cell carcinomas in predicting recurrence after surgical excision. Br J Dermatol 1977; 96: 127-32.

Smeets NW, Stavast-Kooy AJ, Krekels GA, Daemen MJ, Neumann HA. Adjuvant cytokeratin staining in Mohs micrographic surgery for basal cell carcinoma. Dermato/ Surg 2003; 29: 375-7.

Smith SP, Foley EH, Grande DJ. Use of Mohs micrographic surgery to establish quantitative proof of heightened tumor spread in basal cell carcinoma recurrent following radiotherapy. J Dermatol Surg Oncol 1990; 16: 1012-6.

Smith SP, Grande DJ. Basal cell carcinoma recurring after radiotherapy: a unique, difficult treatment subclass of recurrent basal cell carcinoma. J Dermatol Surg Oncol 1991; 17: 26-30.

Snow SN, SahI W, Lo JS, Mohs FE, Warner T, Dekkinga JA, et al. Metastatic basal cell carcinoma. Report of five cases. Cancer 1994; 73: 328-35.

Spates ST, Mellette JR, Jr., Fitzpatrick J. Metastatic basal cell carcinoma. Dermatol Surg 2003; 29: 650-2.

Spencer JM, Nossa R, Tse DT, Sequeira M. Sebaceous carcinoma of the eyelid treated with Mohs micrographic surgery. J Am Acad Dermatol 2001; 44: 1004-9.

Suhge d'Aubermont PC, Bennett RG. Failure of curettage and electrodesiccation for removal of basal cell carcinoma. Arch Dermatol 1984; 120: 1456-60.

Sussman LA, Liggins DF. Incompletely excised basal cell carcinoma: a management dilemma? Aust NZ J Surg 1996; 66: 276-8.

Svanberg K, Andersson T, Killander D, Wang I, Stenram U, AnderssonEngels $\mathbf{S}$, et al. Photodynamic therapy of non-melanoma malignant tumours of the skin using topical delta-amino levulinic acid sensitization and laser irradiation. Br J Dermato/ 1994; 130: 743-51.

Swanson NA. Mohs surgery. Technique, indications, applications, and the future. Arch Dermatol 1983; 119: 761-73.

Swanson NA, Taylor WB. Plantar verrucous carcinoma. Literature review and treatment by the Mohs' chemosurgery technique. Arch Dermatol 1980; 116: 794-7.

Telfer NR, Colver GB, Bowers PW. Guidelines for the management of basal cell carcinoma. British Association of Dermatologists. Br J Dermatol 1999; 141: 415-23. 
Thissen MR, Neumann HA, Berretty PJ, Ideler AH. [The treatment of basal cell carcinoma patients by dermatologists in Netherland]. Ned Tijdschr Geneeskd 1998; 142: 1563-7.

Thissen MR, Neumann MH, Schouten LJ. A systematic review of treatment modalities for primary basal cell carcinomas. Arch Dermato/ 1999; 135: 1177-83.

Thissen MR, Nieman FH, Ideler AH, Berretty PJ, Neumann HA. Cosmetic results of cryosurgery versus surgical excision for primary uncomplicated basal cell carcinomas of the head and neck. Dermatol Surg 2000a; 26: 759-64.

Thissen MR, Schroeter CA, Neumann HA. Photodynamic therapy with delta-aminolaevulinic acid for nodular basal cell carcinomas using a prior debulking technique. Br J Dermato/ 2000b; 142: 338-9.

Thomas DJ, King AR, Peat BG. Excision margins for nonmelanotic skin cancer. Plast Reconstr Surg 2003; 112: 57-63.

Tromovitch TA, Beirne G, Beirne C. Mohs' technique (cancer chemosurgery). Treatment of recurrent cutaneous carcinomas. Cancer 1966; 19: 867-8.

Tromovitch TA, Stegeman SJ. Microscopically controlled excision of skin tumors. Arch Dermatol 1974; 110: 231-2.

Turner RJ, Leonard N, Malcolm AJ, Lawrence CM, DahI MG. A retrospective study of outcome of Mohs' micrographic surgery for cutaneous squamous cell carcinoma using formalin fixed sections. $\mathrm{Br}$ J Dermato/ 2000; 142: 752-7.

US-Preventive-Services-Task-Force. Screening for skin cancer: recommendations and rationale. Am J Prev Med 2001; 20: 44-6.

Vainio $\mathbf{H}$, Miller AB, Bianchini F. An international evaluation of the cancerpreventive potential of sunscreens. Int J Cancer 2000; 88: 838-42.

van Bockel LW, van den Broecke DG, Spliet W, Canninga-van Dijk MR, Kon M. [Five patients with metastasized basal-cell carcinoma]. Ned Tijdschr Geneeskd 2003; 147: 2231-6.

van der Rhee HJ, van der Spek-Keijser LM, van Westering R, Coebergh JW. Increase in and stabilization of incidence and mortality of primary cutaneous malignant melanoma in Western Netherlands, 1980-95. Br J Dermatol 1999; 140: 463-7.

van Praag MC, Pavel S, Menke HE, Oranje AP. [Protection from sunlight, particularly for children]. Ned Tijdschr Geneeskd 2000; 144: 830-4.

Verhaegh ME, Arends JW, Majoie IM, Hoekzema R, Neumann HA.

Transforming growth factor-beta and bcl-2 distribution patterns distinguish trichoepithelioma from basal cell carcinoma. Dermatol Surg 1997; 23: 695-700.

Verhaegh ME, Sanders CJ, Arends JW, Neumann HA. Expression of the apoptosis-suppressing protein $\mathrm{Bcl}-2$ in non-melanoma skin cancer. $\mathrm{Br}$ J Dermatol 1995; 132: 740-4.

Vuyk HD, Lohuis PJ. Mohs micrographic surgery for facial skin cancer. Clin Otolaryngol 2001; 26: 265-73.

Wade TR, Ackerman AB. The many faces of basal-cell carcinoma. $J$ Dermatol Surg Oncol 1978; 4: 23-8. 
Wang I, Bendsoe N, Klinteberg CA, Enejder AM, Andersson-Engels S, Svanberg $S$, et al. Photodynamic therapy vs. cryosurgery of basal cell carcinomas: results of a phase III clinical trial. $\mathrm{Br} J$ Dermatol 2001; 144: 832-40.

Welch ML, Anderson LL, Grabski WJ. Evaluation and management of nonmelanoma skin cancer. The military perspective. Dermatol Clin 1999; 17: 19-28, vii.

Wennberg AM, Larko O, Stenquist B. Five-year results of Mohs' micrographic surgery for aggressive facial basal cell carcinoma in Sweden. Acta Derm Venereol 1999; 79: 370-2.

Wennberg AM, Lindholm LE, Alpsten M, Larko O. Treatment of superficial basal cell carcinomas using topically applied delta-aminolaevulinic acid and a filtered xenon lamp. Arch Dermatol Res 1996; 288: 561-4.

Wentzell JM, Robinson JK. Embryologic fusion planes and the spread of cutaneous carcinoma: a review and reassessment. J Dermatol Surg Oncol 1990; 16: 1000-6.

Werlinger KD, Upton G, Moore AY. Recurrence rates of primary nonmelanoma skin cancers treated by surgical excision compared to electrodesiccation-curettage in a private dermatological practice. Dermatol Surg 2002; 28: 1138-42; discussion 1142.

Wittenberg GP, Robertson DB, Solomon AR, Washington CV. Eccrine porocarcinoma treated with Mohs micrographic surgery: A report of five cases. Dermatol Surg 1999; 25: 911-3.

Wolf DJ, Zitelli JA. Surgical margins for basal cell carcinoma. Arch Dermatol 1987; 123: 340-4.

Zachary CB, Perkins W. Rapid immunoenzyme Mohs technique for skin cancer removal. Advances in Mohs surgery. Facial Plast Surg Clin of North Am 1998; 6: 337-45.

Zachary CB, Rest EB, Furlong SM, Arcedo PN, McGeorge BC, Kist DA. Rapid cytokeratin stains enhance the sensitivity of Mohs micrographic surgery for squamous cell carcinoma. J Dermatol Surg Oncol 1994; 20: $530-5$.

Zollo JD, Zeitouni NC. The Roswell Park Cancer Institute experience with extramammary Paget's disease. Br J Dermato/ 2000; 142: 59-65. 
Bibliography 
Samenvatting 
Het basaalcelcarcinoom (BCC) is de meest voorkomende vorm van (huid-)kanker in blanken. Jaarlijks krijgen zo'n 40.000 patiënten een BCC in Nederland. Omdat het slechts zelden uitzaait is het wat betreft overleving een relatief onbelangrijke tumor. Echter omdat het zo vaak voorkomt en het door vele specialisten wordt behandeld, heeft het een belangrijke (financiële) impact op onze gehele gezondheidszorg. De meeste BCCs kunnen goed behandeld worden met relatief eenvoudige methoden zoals standaard excisie (SE) en cryochirurgie. Een aantal BCCs gedraagt zich agressiever en heeft een meer gecompliceerde behandeling nodig zoals Mohs' micrografische chirurgie (MMC).

Dit proefschrift behandeld de vraag welke BCCs behandeld moeten worden met MMC voor wat betreft recidiefkans (= de kans op een BCC op dezelfde plek als voor de behandeling), de kans op een niet radicale excisie, het cosmetisch resultaat en de kosteneffectiviteit.

In hoofdstuk een worden de epidemiologie, de klinische en histologische kenmerken, behandelingsmogelijkheden en hoogrisico factoren voor een recidief $\mathrm{BCC}$ besproken. Het BCC komt het meest voor in het hoofdhals gebied. Dit heeft te maken met de belangrijkste oorzaak voor het ontstaan namelijk blootstelling aan zonlicht (UVstraling). Mensen met een blanke huid, die als gevolg van werk of hobby's veel aan de zon blootgesteld zijn hebben een verhoogd risico op het krijgen van een BCC. De tumor wordt in de meeste gevallen gekenmerkt door een glanzend papeltje met teleangiëctasiën. Histopathologisch wordt het dan gekenmerkt door tumorvelden van basaloïde cellen met perifere palisadering en omgeven door een myxoid stroma. Een $\mathrm{BCC}$ met kleinere velden van nodulair BCC is het micronodulair BCC. Dit heeft een agressievere groeiwijze dan het nodulair BCC. Na het nodulaire BCC komt het superficieel BCC wat betreft frequentie op de tweede plaats. Het wordt klinisch gekenmerkt door een erythematosquameuze plaque en is het frequentst op de romp gelokaliseerd. Minder vaak komen het sprieterig of morphea BCC en het BCC met squameuze differentiatie voor. Deze komen meestal voor in het gelaat en lijken op een litteken, glanzend met teleangiëctasiën, soms iets verheven. Daarnaast is er nog een groep tumoren die niet onder een van deze 5 types kan worden geclassificeerd omdat ze meer dan 1 histologisch type bevatten (de gemengde types). Deze gedragen zich als het meest agressieve type. Het nodulair en superficieel groeiend BCC worden gerekend tot de niet-agressief groeiende BCCs; het sprieterig/ morphea BCC, het micronodulair BCC of het BCC met squameuze differentiatie tot de agressief groeiende BCCs.

Voor de behandeling van het BCC beschikt de arts over verschillende therapie modaliteiten. De keuze is afhankelijk van de tumor (grote, locatie, histologisch type) en de patiënt. Daarnaast speelt ook de ervaring van de behandelaar en de beschikbaarheid van een behandeling een rol bij de keuze. Meest gebruikt wordt de SE, waarbij de tumor met een marge wordt verwijderd, de wond gesloten en het weefsel opgestuurd voor histopathologische controle van de snijranden. Indien er nog 
$\mathrm{BCC}$ in de snijranden wordt gezien vindt er een re-excisie plaats. Bij het histopathologisch onderzoek wordt, middels verticale coupes, (een deel van) de snijranden beoordeeld.

Andere behandelingen voor het BCC zijn cryochirurgie, radiotherapie en curettage \& electrodessicatie. Nieuwe, experimentele, behandelingsmogelijkheden zijn imiquimod en photodynamische therapie (PDT).

Voor de behandeling van het BCC is het belangrijk een onderscheid te maken tussen hoog- en laagrisico tumoren. Hoogrisico tumoren zijn tumoren die groeien met subklinische extensies en/ of een verhoogd risico hebben op een recidief. Dit zijn histopathologisch agressieve BCCs, BCCs gelokaliseerd in de $\mathrm{H}$-zone van het gelaat, BCCs groter of gelijk aan $2 \mathrm{~cm}$, recidief BCCs, BCCs met perineurale invasie, BCCs bij patiënten met multipele huidmaligniteiten. Hoogrisico tumoren hebben een agressievere behandeling nodig.

$\mathrm{Na}$ behandeling van een $\mathrm{BCC}$ is de kans op het krijgen van nog een $\mathrm{BCC}$ binnen 3 jaar ongeveer $44 \%$.

Omdat de belangrijkste oorzaak van het ontstaan van een BCC het zonlicht is, is de preventie daarop gericht. Het vermijden van de zon tijdens piekuren (11-16 uur), het dragen van beschermende kleding, een hoed of pet en het gebruik van zonnebrandcrèmes met een voldoende hoge beschermingsfactor (SPF 30+) met name bij kinderen en adolescenten, dragen bij aan die preventie.

In hoofdstuk twee wordt de ontwikkeling van Mohs' micrografische chirurgie (MMC) besproken. Deze techniek werd in de dertiger jaren door Dr. Frederic E Mohs ontwikkeld. Hij ontdekte dat na fixatie van de tumor met een zinkchloridepasta het weefsel geschikt was voor histopathologisch onderzoek. Hij excideerde de tumor en maakte horizontale vriescoupes waarmee $100 \%$ van de snijranden in beeld werd gebracht. Dit combineerde hij met het systematisch in kaart brengen van de tumor op een tekening op papier en bij de patiënt zelf. Indien er tumor in de snijranden aanwezig was werd de tumor opnieuw gefixeerd en na 24 uur opnieuw geëxcideerd. Op deze manier werd maximale curatie, histopathologisch gecontroleerd, bij behoud van zoveel mogelijk gezand weefsel bereikt. Het nadeel van deze techniek was de tijdrovendheid van de chemische fixatie en de ontsteking en pijn die deze fixatie bij de patiënt veroorzaakte. Voor een demonstratievideo en omdat de fixatie tot veel irritatie van de ogen leidde, paste Mohs in de vijftiger jaren voor het eerst de techniek toe zonder fixatie; de verse-weefsel-techniek. Dit werd overgenomen door anderen en het bleek dat het succes van de door Mohs ontwikkelde techniek niet ligt in de chemische fixatie maar in de horizontale vriescoupes en het systematisch in kaart brengen van de tumor. Deze combinatie leidde tot de naam Mohs' micrografische chirurgie. MMC wordt vooral toegepast voor hoogrisico BCCs (grote, agressieve en recidief BCCs in het gelaat), maar ook voor vele andere huidmaligniteiten. In de VS wordt ongeveer $30 \%$ van alle niet-melanoma huidmaligniteiten er mee behandeld terwijl in Europa alleen de hoogrisico tumoren worden behandeld met MMC. 
In hoofdstuk drie wordt een analyse gemaakt van alle BCCs die van 1992 tot 1999 in het Academisch Ziekenhuis Maastricht werden behandeld. In deze periode werden in totaal 720 BCCs bij 620 patiënten behandeld. Van deze 720 BCCs kregen 27 tumoren een recidief. Recidiefpercentages berekend middels een Kaplan-Meier survivalanalyse waren $3.2 \%$ voor primaire BCCs en $6.7 \%$ voor recidief BCCs. Prognostische factoren voor een recidief $\mathrm{BCC}$ zijn agressief groeiende $\mathrm{BCCs}$, meerdere ( $\geq 3$ ) Mohs' rondes, grote (> $4 \mathrm{~cm}$ diameter) defecten en een recidief $\mathrm{BCC}$.

De resultaten van onze studie werden vergeleken met de getallen uit de literatuur. Hiervoor werden de databases van de Medline, Pubmed en Embase geraadpleegd en werden alle Engelstalige studies die melding maakten van recidief percentages na behandeling van het BCC van het gelaat middels MMC geëvalueerd. Van het totaal aantal van 479 artikelen, bleken slechts 8 artikelen aan onze inclusiecriteria (recidiefpercentage na minimaal 5 jaar follow-up, gescheiden voor primair en recidief, gescheiden voor type huidmaligniteit) te voldoen. De grootste studies zijn die van Mohs zelf waarin hij de resultaten per regio (oren, ogen en scalp) beschrijft. Recidief percentages in deze 8 studies variëren van 0 tot $6.5 \%$ voor primair en $4.8-12.0 \%$ voor recidief BCCs. Deze getallen komen dus goed overeen met de getallen die wij hebben gevonden. Als deze weer werden vergeleken met 5-jaars recidiefpercentages na behandeling middels andere therapie modaliteiten, bleken na MMC de laagste 5-jaars recidief percentages. Helaas is er geen enkele vergelijkende studie van MMC en een andere therapie. Tot op heden aanwezige studies die 5-jaars recidiefpercentages beschrijven van behandeling van BCCs in het gelaat middels MMC.

In hoofdstuk vier worden de resultaten beschreven van de prospectief gerandomiseerde studie; MMC versus SE voor BCCs in het gelaat. Voor deze studie werden 604 tumoren, 408 primaire en 204 recidief BCCs geïncludeerd. $\mathrm{Na}$ randomisatie werden ze behandeld middels MMC of SE.

Inclusiecriteria voor een primair BCC waren: een BCC van $1 \mathrm{~cm}$ gelokaliseerd in de $\mathrm{H}$ zone of van een agressief histopathologisch type in het gelaat. Inclusiecriteria voor een recidief $\mathrm{BCC}$ waren; een $1^{\mathrm{e}}$ of $2^{\mathrm{e}}$ recidief $\mathrm{BCC}$ in het gelaat. Zowel het primair als het recidief BCC moest histopathologisch bevestigd zijn. De levensverwachting moest minimaal 3 jaar zijn.

Bij beide operaties werd de tumor met een marge van $3 \mathrm{~mm}$ geëxcideerd. Foto's werden genomen voor de ingreep (overzicht en close-up), van de tumor met marge afgetekend en liniaal, van het defect met liniaal en van de reconstructie. $\mathrm{Na}$ behandeling werden ze in de toen geldige oncologische follow-up opgenomen $\left(1^{\mathrm{e}}\right.$ jaar iedere 3 maanden, $2^{e}$ jaar iedere 6 maanden, $3^{e} \mathrm{t} / \mathrm{m} 5^{e}$ jaar ieder jaar) bij hun eigen dermatoloog. Na 6 en 18 maanden werden ze door de artsonderzoeker terug gezien ter beoordeling van het klinisch (optreden van een recidief) en het cosmetisch resultaat. Op deze momenten werden opnieuw foto's genomen. 
In de primaire groep werden na randomisatie 11 BCCs geëxcludeerd i.v.m. overiijden of verhuizing voor de ingreep (3), andere diagnose (5), amputatie oor waar BCC op zat (1) of omdat de patiënt geen operatie wilden (2). Er bleven 397 BCCs over; 199 werden behandeld middels SE en 198 middels MMC.

in de SE groep werden $18 \%$ van de tumoren irradicaal geëxcideerd. Na 2 excisies (marge $6 \mathrm{~mm}$ ) was nog $2 \%$ van de 199 BCCs tumor positief en volgde MMC.

In de MMC groep was meer dan $80 \%$ tumor vrij na 2 rondes. Wanneer de defecten van een irradicale excisie vergeleken werden met de defecten na een Mohs procedure van 2 of meer rondes, bleken defecten in de SE groep significant groter dan na MMC. Er waren significant meer irradicale excisies bij agressief groeiende tumoren (24\%) vergeleken bij niet-agressief groeiende (12\%) tumoren. Er kwamen ook meer irradicale excisies voor peri-oculair en op de oren maar dit verschil was niet significant.

Achttien maanden postoperatief waren er $3(1.5 \%)$ recidieven na SE en $2(1.0 \%)$ recidieven na MMC, na 30 maanden (2,5 jaar) waren er $5(2.5 \%)$ recidieven na SE en $3(1.5 \%)$ na MMC.

In de recidiefgroep werden na randomisatie 3 BCCs geëxcludeerd i.v.m. overlijden (2) en een derde recidief (1). Vier BCCs werden geïncludeerd en gerandomiseerd voor SE maar werden op verzoek van de dermatoloog of de patiënt toch behandeld middels MMC. Deze BCCs werden in de intention-to-treat analyse van het recidief meegenomen in de SE groep. In de analyse van de operatie kenmerken werden deze geëxcludeerd. Er werden 98 BCCs behandeld middels SE en 99 middels MMC. Van deze 98 BCCs behandeld met SE was $32 \%$ irradicaal geëxcideerd na de eerste excisie en na 2 excisies (totale marge $6 \mathrm{~mm}$ ) was nog $8 \%$ tumor positief. In de MMS groep was $78 \%$ na 2 rondes tumor vrij. Opnieuw bleken defecten na een irradicale SE veel groter dan na een Mohs' procedure van 2 of meer rondes.

Achttien maanden postoperatief waren er $3(3 \%)$ recidieven na SE en $0(0 \%)$ na MMC, na 24 maanden (2 jaar) waren er $4(4 \%)$ recidieven na SE en $0(0 \%)$ na MMC.

De kosteneffectiviteit analyse laat voor zowel het primaire als het recidief BCC een significant verschil van ongeveer 250 Euro's zien ( \pm 1000 Euro's voor MMC en \pm 750 Euro's voor SE).

Geconcludeerd kan worden dat op dit moment de recidiefpercentages na beide behandelingen laag zijn en dat na MMC de recidiefpercentages iets lager zijn. Dat deze recidiefpercentages zo laag zijn in de SE groep, vergeleken met literatuurgegevens, kan mogelijk verklaard worden door het consequent re-excideren van irradicaal geëxcideerde BCCs.

Op basis van de significant hogere aantallen irradicale excisies die leiden tot een significant groter defect wordt MMC geadviseerd voor primair agressieve BCCs van 1 $\mathrm{cm}$ of meer in het gelaat en voor recidief BCCs in het gelaat.

In hoofdstuk vijf worden de cosmetische resultaten na behandeling middels MMC en SE vergeleken. Hiervoor werd een selectie (139 primaire en 89 recidief BCCs) van de tumoren geïncludeerd uit de prospectieve studie. Het cosmetisch resultaat werd door 
de patiënt zelf 6 en 18 maanden postoperatief beoordeeld. Op deze momenten werden foto's genomen (een overzicht en een close-up) voor beoordeling door het panel. Het panel beoordeelde de foto's niet wetend welke ingreep en op welk moment de foto genomen was. De beoordeling gebeurde op een schaal van 'excellent' - 'goed' - 'matig' - 'slecht' en door middel van een cijfer op een schaal van 1-10. Gemiddeld over tijd en ingreep was de score 2.14 (op een schaal van 1 tot 4, 'excellent'- 'slecht'). In het algemeen is er geen verschil tussen MMC en SE. Er vindt na beide ingrepen een significante verbetering plaats tussen 6 en 18 maanden postoperatief. Met een stijgende tumor diameter daalt het cosmetisch resultaat. Ook in geval van een groter defect is het cosmetisch resultaat significant slechter. Een litteken na behandeling van een recidief BCC wordt significant slechter beoordeeld dan na een primair BCC.

Geconcludeerd kan worden dat beide chirurgische technieken goede cosmetische resultaten geven. Ook vanuit cosmetisch oogpunt is het vermijden van een recidief $B C C$ en het vermijden van grote defecten van essentieel belang. Bij BCCs waarbij een grote kans bestaat dat deze irradicaal geexcideerd worden, verdient MMC, ook vanuit cosmetisch oogpunt, de voorkeur.

In hoofdstuk zes wordt ingegaan op de vraag waarom na MMC, waarbij toch $100 \%$ van de snijranden in beeld wordt gebracht, een recidief kan optreden. Een verklaring wordt gezocht in de sensitiviteit van de middels haematoxyline en eosine (H\&E) gekleurde vriescoupes. Hiervoor werden na 51 Mohs' procedures (op het moment dat de vriescoupes negatief voor tumor waren) extra coupes gemaakt die gekleurd werden met een cytokeratinekleuring (MNF-116). Deze werden beoordeeld door twee Mohs' chirurgen en bij twijfel door een onafhankelijk patholoog.

Van alle 143 vriescoupes die als negatief voor BCC werden afgegeven, was 1 coupe positief in de cytokeratinekleuring. Dit is een fout van $0.7 \%$ van alle coupes, echter een fout van $2 \%$ ( 1 van 51 ) in BCCs. Deze fout werd gezien in een sprieterig groeiend recidief $\mathrm{BCC}$ en kan dus deels een verklaring zijn voor recidivering. In zeer sprieterig groeiende BCCs kan het een overweging zijn om na de gebruikelijke Mohs' procedure, een aanvullende cytokeratinekleuring te verrichten.

In hoofdstuk zeven presenteren we enkele casuistieken van grote BCCs of BCCs bij patiënten met multipele huidmaligniteiten. We bemerkten dat bij deze patiënten de Mohs' procedure vaak zeer langdurig was, mede doordat er uitgebreid superficieel $\mathrm{BCC}$ te vinden was in de randen. Omdat zeer goede resultaten zijn bereikt na behandeling middels PDT bij het superficieel groeiend BCC, combineerde we beide technieken. Indien tijdens de Mohs bleek dat er in de randen enkel nog superficieel groeiend BCC aanwezig was, werd het defect gesloten en na enkele weken aanvullend behandeld met PDT. Hoewel de follow-up relatief kort is, lijkt deze combinatie van behandelingen een goede balans te zijn tussen maximale curatie en het behoud van gezond weefsel. 
Dankwoord 
Een dankwoord schrijven is een van de leukste dingen van een proefschrift. Het manuscript is af en de meeste formaliteiten zijn rond. Maar ook een dankwoord moet natuurlijk weloverwogen tot stand komen. Toch zal ik niet iedereen bij naam kunnen noemen maar daarom niet minder bedankt.

Dit dankwoord wil ik beginnen met de vrouw die dit hele project mogelijk heeft gemaakt. Gertruud, bedankt voor het vertrouwen wat je in me had waardoor ik deze klus mocht beginnen. Met veel plezier heb ik het Mohsproject mogen uitvoeren. Jouw begeleiding hierbij was er altijd op het juiste moment. Als er vragen waren kon ik altijd (al was je pas een week eerder bevallen) bij je terecht. Hier is het boekje wat jij graag zelf had willen maken. Ook Roger, Menno en Tobias bedankt voor de gastvrijheid bij jullie thuis.

Professor Neumann, ik zal een van de weinige assistenten geweest zijn die niet door u persoonlijk is uitgekozen. Toch heeft $u$ er ook vertrouwen in gehad dat ik dit aankon. Naast het wetenschappelijke deel heb ik veel praktische vaardigheden van $u$ geleerd. Met $u$ opereren was altijd een verrassing: nooit eerder had ik de arterie temporalis geraakt (en dan tijdens een OK twee keer) en een kleine Mohs' ingreep bij uw garagist uit Asten bleek opeens ook een stuk groter dan verwacht. De laatste twee jaar was u er niet meer voor de dagelijkse begeleiding maar bleef $u$ altijd bereikbaar (Wil, mijn dank hiervoor ook aan jou).

Judith, we hadden elkaar niet uitgezocht maar moesten opeens drie jaar samen werken. We bleken een gouden team. Met heel veel plezier heb ik zowel het opereren als de nauwkeurigheid van omgaan met oncologische patiënten van je geleerd. We hebben ook vele reisjes samen gemaakt die nooit saai waren. We gingen op bezoek bij alle perifeer dermatologen in Limburg en een deel van Brabant met jouw auto (waar komt dat stuk bumper vandaan?). Bijna wekelijks naar Roermond met de trein en met de Mohsmobiel (Paul bedankt) weer terug. Een groot feest bleek de businessklasse naar Mexico waarbij de terugreis veel minder soepel verliep. Als eerste ga ik nu promoveren, volgend jaar jij? Bedankt dat je met veel enthousiasme mijn paranimf wilt zijn.

Dit hele project zou natuurlijk niets zijn geworden zijn zonder de patiënten die hieraan wilden deelnemen. Deze patiënten werden gemotiveerd om mee te doen door dermatologen uit de regio. Zonder de medewerking van deze dermatologen aan dit project was ik waarschijnlijk nu nog patiënten aan het includeren. Met name de dermatologen uit Heerlen, Roermond, Veldhoven en Venlo hebben samen meer dan de helft van de patiënten aangeleverd. Heel bijzonder was onze samenwerking met Roermond waar we zowel de excisies als de controles hebben gedaan. Daar werden we ontvangen door een enthousiast team van verpleegkundigen en natuurlijk Vivian die alles in goede banen leidde en waar nooit iets te veel voor was. 
$\mathrm{Na}$ het includeren volgde dan het opereren van alle patiënten. Om al die 600 tumoren binnen $1 \frac{1}{2}$ jaar te verwijderen was een heel team nodig. Essentieel bij de Mohs zijn Ishmene en IIse. Zonder jullie fraaie coupes waren er veel meer recidieven geweest. Alle pathologen en met name Ton bedankt dat jullie je medewerking aan dit project verleenden. Het kwam niet altijd gelegen om naar de polikliniek dermatologie te gaan om Mohscoupes te beoordelen maar jullie kwamen altijd.

Ook op onze eigen polikliniek gaf het Mohsproject extra hectiek. Drie keer per week "Mohsen", drie of vier patiënten per dag en het liefst 's middags ook nog een paar excisies. Germaine, Patricia, Frits, Paulette en Marlène bedankt voor jullie ondersteuning en flexibiliteit.

Het plannen van alle patiënten voor intake, operatie en controle bracht bij "de balie" ook extra werk te weeg. Daar kwam ik weer met briefjes met patiënten die ik zelf had opgeroepen of die van Marie-Paule een briefje moesten krijgen. Op het secretariaat kon ik een beroep doen op Els die alle patiënten registreerde en in de gaten hield wanneer, en of deze op controle waren geweest.

Al die Mohsen konden natuurlijk niet door twee mensen worden uitgevoerd. Monique, Kim en Anja mochten mee operen maar dan moest wel alles nauwkeurig worden geregistreerd en gefotografeerd. Niet altijd even gemakkelijk zo'n controlerend assistentje met haar camera. Anja bedankt voor je niet aflatende interesse in mijn proefschrift, de gezelligheid op onze "oude" AlO kamer en het regelen van deze dag. Ik ben blij dat jij (verrast) mijn paranimf wilt zijn.

Onze meeste excisies mochten we uitvoeren op het dagcentrum. Meiden, dankzij de gezelligheid van jullie team heb ik er altijd met veel plezier geopereerd. De preoperatieve functietesten waren vaak een bron van hilariteit. Bedankt voor de assistentie en het fotograferen tijdens de ingrepen.

Fred, Brigitte en Carmen. Het Mohsproject heeft niet alleen een klinische kant maar ook een sociaal-wetenschappelijke en economische kant. Ondanks dat tijdens onze vergaderingen bleek dat onze ideeën soms niet geheel hetzelfde waren, hebben we het project tot een goed einde gebracht, aan de gezondheidsraad een mooi verslag afgeleverd en een fraaie publicatie in de Lancet. Bedankt voor al jullie hulp en adviezen.

De studenten (Annemieke, Willem, Esther en Brigitte) wil ik bedanken voor hun hulp bij de retrospectieve studie en de literatuur review.

Patty, als studente mocht ik al bij je komen voor hulp bij de epidemiologische verwerking van mijn gegevens. Ook vorig jaar kon ik weer bij je terecht. Binnen twee uurtjes maakte je me weer wegwijs in SPSS waarna ik aan de slag kon. Het heeft geresulteerd in een fraaie publicatie. 
Professor Steijlen, op het moment dat $u$ leiding kwam geven aan onze vakgroep was de praktische kant van het onderzoek reeds afgerond waardoor u er niet direct bij betrokken bent geweest. Toch wil ik $u$ bedanken voor de ruimte die $u$ mij vorig jaar gaf om ongestoord aan dit proefschrift te werken en uw interesse in de vorderingen hiervan.

Werken bij de dermatologie in het AZM is mede dankzij de sfeer binnen de assistentenclub zeer plezierig. Dankzij mijn collega's in de "Research room" voelde ik me er 5 jaar geleden al snel thuis. Bedankt voor de flexibiliteit van iedereen waardoor ik vorig jaar enkele maanden ongestoord aan dit proefschrift kon werken.

En omdat ontspanning heel belangrijk is in stressvolle tijden wil ik ook mijn sportteam bedanken. Niet alleen het sporten maar vooral ook ons geklets maakten dat ik weer relaxter en met nieuwe energie naar huis kon gaan. Dat blijven we nog jaren doen!

Aan het einde van het proefschrift ben ik gekomen bij de belangrijkste mensen in mijn leven. Noud, je dacht je stoere vriendin te volgen naar Maastricht maar je brede schouders (en Word-helpdesk) bleken meer dan eens nodig. Het boekje is af, nu is er tijd voor "ons".

Pap en mam, zonder jullie was dit proefschrift er niet gekomen. Jullie hebben me al 31 jaar op alle mogelijke manieren gestimuleerd. Jullie hebben altijd in mij geloofd, mij gesteund en op de goede momenten een duwtje gegeven (want er was een tijd dat ik liever bij mijn vriendinnen bleef dan voor een wetenschappelijke opleiding koos). Dit is 'mijn boekje' voor juilie. 
Curriculum vitae

\section{List of publications}


Nicole Wilhelmina Johanna Smeets werd op 18 januari 1973 geboren in Tegelen. In 1991 werd het VWO diploma behaald aan het Collegium Marianum te Venlo. Hierop volgde de studie geneeskunde aan de Rijksuniversiteit Limburg/ Universiteit Maastricht. In 1998 behaalde ze het artsexamen.

Van september 1998 tot Juli 1999 werkte ze als AGNIO heelkundige specialismen in het Franciscus ziekenhuis te Roosendaal. In Juli 1999 werd begonnen met het promotieonderzoek als artsonderzoeker bij de vakgroep Dermatologie van het AZM. In maart 2002 begon ze aan de opleiding tot dermatoloog. Deze zal in februari 2006 worden voltooid. 


\section{Publications}

Smeets NWJ. Eccrien porocarcinoom. Nederlands Tijdschrift voor Dermatolologie en Venereologie $2002 ; 12: 157-8$

Smeets NWJ. Het basaalcelcarcinoom. Nederlands Tijdschrift voor Dermatolologie en Venereologie 2002; 12: 163-5

Field L, Krekels G, Ostertag J, Smeets N, Neumann H. The cervicomental "TurkeyGobbler Deformity". A new sourcefor full thickness grafts. Dermatologic Surgery $2002 ; 28$ : $352-5$

Smeets N, Stavast-Kooy A, Krekels G, Daemen M, Neumann H. Adjuvant cytokeratin staining in Mohs micrographic surgery for basal cell carcinoma. Dermatologic Surgery $2003 ; 29(4): 375-7$

Kuijpers D, Smeets N, Krekels G, Thissen M. Photodynamic therapy as adjuvant treatment of extensive basal cell carcinoma treated with Mohs micrographic surgery. Dermatologic Surgery 2004; 30(5): 794-8

Smeets N, Kuijpers D, Nelemans P, Ostertag J, Verhaegh M, Krekels G, Neumann M. Mohs micrographic surgery for treatment of basal cell carcinoma of the face- results of a retrospective study and review of the literature. British Journal of Dermatology 2004; 151: $141-47$

Smeets N, Krekels G, Ostertag J, Essers B, Dirksen C, Nieman F, Neumann M. Surgical excision versus Mohs micrographic surgery for basal cell carcinoma of the face; a prospective randomized trial. Accepted for publication by The Lancet

Raveh Tilleman T, Neumann M, Smeets $N$, Tilleman M. Skin waste in elliptical excision biopsies. Accepted for publication by the Scandinavian Journal of Plastic and Reconstructive Surgery and Hand Surgery.

Smeets N, Ostertag J, Nieman F, Krekeis G, Neumann M. Cosmetic results of treatment of facial basal cell carcinoma; a comparison between Mohs micrographic surgery and surgical excision. Submitted.

Essers B, Nieman F, Prins M, Krekels G, Smeets N, Neumann M. Determinants of satisfaction with the health state of the facial skin in patients undergoing surgery for facial basal cell carcinoma. Submitted. 
Essers B, Dirksen C, Nieman F, Smeets N, Krekels G, Prins M, Neumann M. Costeffectiveness of Surgical excision versus Mohs micrographic surgery for basal cell carcinoma of the face. Submitted.

Lapière K, Smeets $N$, Krekels G, Vermeulen A, Kremer B. Eccrine Porocarcinoma treated with Mohs micrographic surgery and post-operative radiotherapy. Submitted

\section{Presentations/ abstracts}

Prospective randomised study in effectiveness of the treatment of basal cell carcinoma in Caucasians by Mohs micrographic surgery versus surgical excision. XXII Congress of the ISDS, Guadalajara, 28-11/ 2-12-2001.

Mohs' micrografische chirurgie van non-melanoma huidkanker. IKL symposium "Dermato-oncologie". Born 11-12-2001.

Eccrien porocarcinoma. $297^{\mathrm{e}}$ jaarvergadering van de Nederlandse Vereniging voor Dermatologie en Venereologie, Maastricht, 7-6-2002.

Het basaalcelcarcinoom. $297^{\circ}$ jaarvergadering van de Nederlandse Vereniging voor Dermatologie en Venereologie, Maastricht, 7-6-2002.

Prospective randomised study in effectiveness of the treatment of basal cell carcinoma in Caucasians by Mohs micrographic surgery versus surgical excision. XXIII Congress of the ISDS, Porto 18-9/20-9-2002. 